\section{Universidade de São Paulo}

Faculdade de Medicina de Ribeirão Preto

\section{0}

Quantificação de fibras positivas para substância $\mathrm{P}$ em nervo Sural de ratos espontaneamente hipertensos

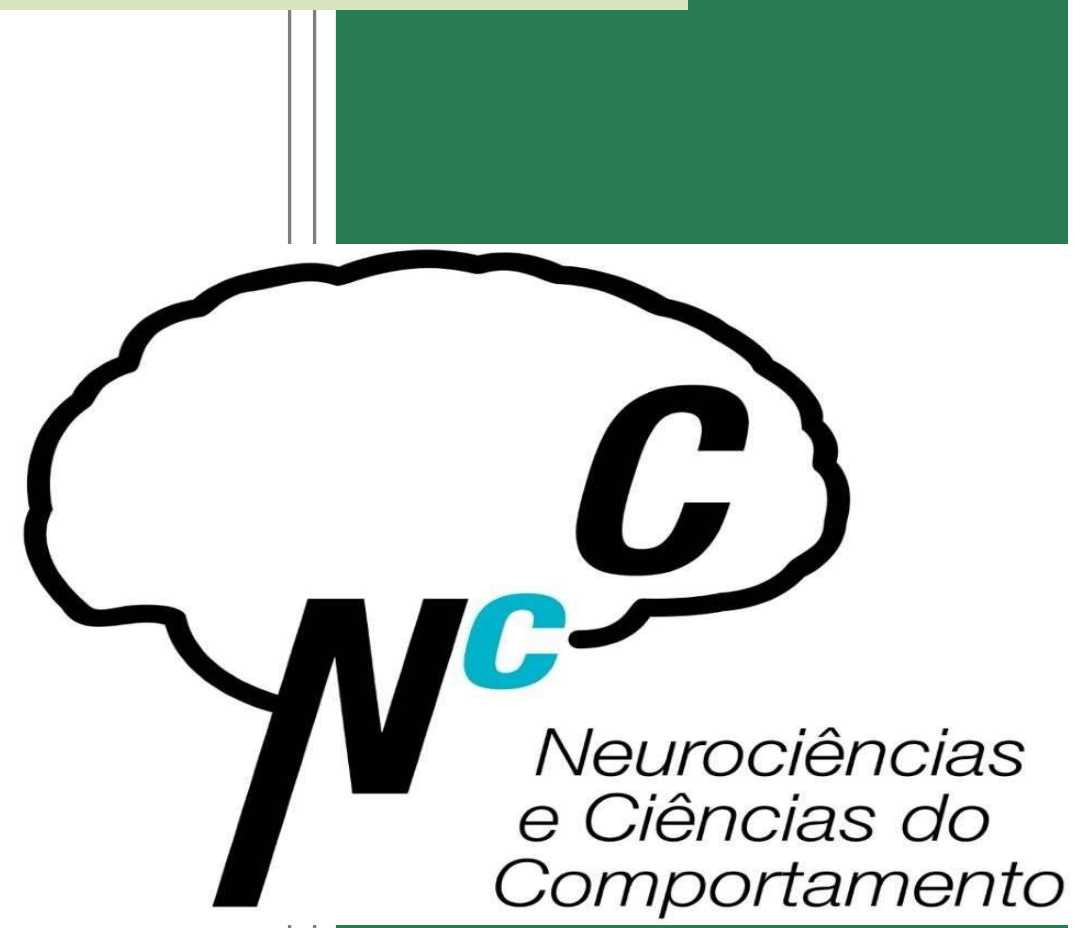

Carolina Giorgetto

Tese 


\title{
Quantificação de fibras positivas para substância P em nervo Sural de ratos espontaneamente hipertensos
}

\author{
"Versão corrigida. A versão original encontra-se disponível tanto na \\ Biblioteca da Unidade que aloja o Programa, quanto na Biblioteca Digital \\ de Teses e Dissertações da USP (BDTD)."
}

Tese apresentada ao Programa de Pós-Graduação em Medicina (Neurologia) do Departamento de Neurociências e Ciências do Comportamento da Faculdade de Medicina de Ribeirão Preto da Universidade-USP para obtenção do título de Doutora em Ciências.

Área de Concentração: Neurologia e Neurociências.

Orientadora: Profa. Dr ${ }^{a}$. Valéria Paula Sassoli Fazan

Ribeirão Preto 
Autorizo a reprodução e divulgação total ou parcial deste trabalho, por qualquer meio, convencional ou eletrônico, para fins de estudo e pesquisa, desde que citada a fonte.

Catalogação na Publicação

Serviço de Documentação

Faculdade de Medicina de Ribeirão Predo da Universidade de São Paulo

Giorgetto, Carolina

Quantificação de fibras positivas para substância $P$ em nervo Sural de ratos espontaneamente hipertensos/ Carolina Giorgetto; orientadora Profa. Dra. Valéria Paula Sassoli Fazan. - 2020.

$121 \mathrm{f} .:$ il.

Tese (Doutorado) - Programa de Pós-Graduação em Medicina (Neurologia), Faculdade de Medicina de Ribeirão Preto, Universidade de São Paulo, Ribeirão Preto, 2020.

Versão Original

1. Nervo Sural. 2. Fibras mielínicas finas. 3. Fibras amielínicas. 4Substância P. 5- Ratos espontaneamente hipertensos. 6- Gêneros. 
GIORGETTO, C. Quantificação de fibras positivas para substância P em nervo Sural de ratos espontaneamente hipertensos. 2020. 121 folhas. Tese (Doutorado)Faculdade de Medicina de Ribeirão Preto, Universidade de São Paulo,2020.

Aprovado em: 15/ 05 / 2020

\section{Banca Examinadora:}

Profa. Dr ${ }^{\mathrm{a}}$. Valéria Paula Sassoli Fazan

Instituição: Faculdade de Medicina de Ribeirão Preto (FMRP-USP)

Julgamento: Aprovado

Prof. Dr. Wilson Marque Júnior

Instituição: Faculdade de Medicina de Ribeirão Preto (FMRP-USP)

Julgamento: Aprovado

Prof. Dr. João Paulo Mardegan Issa

Instituição: Faculdade de Odontologia de Ribeirão Preto (FORP-USP)

Julgamento: Aprovado

Prof. Dr. Bruno César Schimming

Instituição: Universidade Estadual Paulista Júlio de Mesquita Filho (UNESP)

Julgamento: Aprovado 


\section{AGRADECIMENTOS}

Aos meus pais, minha tia Sandra, meu esposo Gustavo, que, com muito carinho e apoio, não mediram esforços para que eu chegasse até esta etapa de minha vida.

À Profa . Dra . Valéria Paula Sassoli Fazan, pela oportunidade, orientação e incentivo que tornaram possível a conclusão deste trabalho e a formação da profissional que me tornei. Obrigada por todo o aprendizado, por sua dedicação em busca de recursos para a manutenção do funcionamento do laboratório.

Aos meus amigos do laboratório de Morfologia e Morfometria, em especial ao amigo querido Jairo Pinheiro da Silva, quem me trouxe até esta turma. Obrigada a todos por tornarem meus dias mais alegres.

Aos queridos Sandra Balero Penharvel Martins e Jorge Forjaz pelos ensinamentos, apoio constante e pelas conversas descontraídas na hora do café.

Ao Jaci Airton Castania e também ao prof. Dr. Hélio César Salgado por ceder seu laboratório e equipe para a realização deste trabalho.

Ao querido Antônio Renato Meirelles e Silva por ceder sua paciência e apoio técnico especializado.

À CAPES e FAEPA pela concessão da bolsa e suporte financeiro para realização desta pesquisa. 


\section{RESUMO}

\section{GIORGETTO, C. Quantificação de fibras positivas para substância P em nervo}

Sural de ratos espontaneamente hipertensos. 2020. $121 \mathrm{f}$. Tese (Doutorado) Faculdade de Medicina, Universidade de São Paulo, Ribeirão Preto, 2020.

A hipertensão arterial sistêmica é uma doença altamente incidente e fator de risco, principalmente, para acidentes vasculares cerebrais. No entanto, é raramente explorada como possível causa de neuropatia para fibras mielínicas finas e amielínicas. A biópsia do nervo periférico é um recurso importante no diagnóstico de neuropatias, sendo inclusão em resina epóxi padrão-ouro de identificação e quantificação de fibras nervosas. No entanto, a imunomarcação vem sendo adicionada à investigação de neuropatias inflamatórias. Porém, anticorpos contra neurotransmissores para identificação de fibras específicas são muito pouco explorados. Assim, o objetivo deste estudo foi identificar substância P (SP), através de imunohistoquímica (IHQ), e quantificar a densidade de fibras mielínicas finas e amielínicas reativas a este neurotransmissor nos segmentos proximais e distais dos nervos surais de ratos espontaneamente hipertensos (SHR) e normotensos (WKY), machos e fêmeas ( $n=6$ por grupo) com 20 semanas de idade, comparando os diferentes segmentos e lados deste nervo. Após anestesia e medida direta da pressão arterial, os nervos foram dissecados e preparados tecnicamente para $\mathrm{IHQ}$, a qual seguiu protocolo padronizado. A quantificação da densidade de fibras reativas à SP presente nos nervos foi realizada através do programa computacional Image J. Para dados pareados com distribuição normal realizou-se teste t de Student pareado, em caso contrário foi executado o teste de Wilcoxon, e para dados não pareados com distribuição normal realizou-se teste t de Student, em caso contrário, o teste de Mann- 
Whitney. Os resultados foram considerados estatisticamente significativos quando $p<0,05$. Diferenças significativas foram observadas para o parâmetro proposto quando comparadas as fêmeas WKY com as SHR e quando comparados os machos WKY com os SHR. Os resultados indicaram que a hipertensão arterial sistêmica altera importantes componentes do nervo Sural de animais hipertensos. Além disso, as comparações entre machos e fêmeas WKY e SHR permitiram concluir também que a densidade das fibras imunomarcadas neste nervo não possui correlação com gênero, mas sim com linhagem.

Palavras-chave: Nervo Sural. Fibras mielínicas finas. Fibras amielínicas. Substância P. Ratos espontaneamente hipertensos. Gêneros.

O presente trabalho foi realizado com apoio da Coordenação de Aperfeiçoamento de Pessoal de Nível Superior - Brasil (CAPES) - Código de Financiamento 88882.328289/2019-01. 


\begin{abstract}
GIORGETTO, C. Substance $\mathbf{P}$ quantification in the Sural nerve of hypertensive

rats. 2020. $121 \mathrm{f}$. Thesis (Doctoral) - Faculdade de Medicina, Universidade de São Paulo, Ribeirão Preto, 2020.
\end{abstract}

Systemic arterial hypertension is a highly incident disease and a major risk factor for stroke. However, it is rarely explored as a possible cause of neuropathy for thin myelinic fibers and amyelinic fibers. Peripheral nerve biopsy is an important resource in the diagnosis of neuropathies, being embedding in epoxy resin the gold standard for identification and quantification of nerve fibers. However, immunostaining has been added to the investigation of inflammatory neuropathies. However, antibodies against neurotransmitters for identifying specific fibers are very little explored. Thus, the objective of this work was to identify substance $P(\mathrm{SP})$ by immunohistochemistry (IHC), and to quantify the density of SP-reactives thin myelin fibers and unmyelinated fibers in the proximal and distal segments of the nerves in the spontaneous hypertensive rat (SHR) and normotensive (WKY), males and females ( $n=6$ per group) at 20 weeks of age, comparing the different segments and sides of this nerve. After anesthesia and direct blood pressure measurement, the nerves were dissected and technically prepared for IHC, which followed a standardized protocol. The quantification of the density of SP-reactive fibers present in the nerves was performed using the computer program Image J. For paired data with normal distribution, Student's t-test was performed, otherwise the Wilcoxon test was performed, and for unpaired data with normal distribution, Student's t-test was performed, otherwise Mann-Whitney test was executed. Results were considered statistically significant when $p<0.05$. Significant differences were observed for the proposed parameter when comparing WKY females 
with SHR ones and when comparing WKY males with SHR ones. The results indicated that systemic arterial hypertension alters important sural nerve components in hypertensive animals. Moreover, the comparisons between males and females WKY and SHR also allowed to concluded that the density of the immuno-labeled fibers in this nerve is not correlated with gender, but with lineage.

Keywords: Sural nerve. Thin myelin fibers. Unmyelinated fibers. Substance P. Spontaneously hypertensive rats. Genders.

This study was financed in part by the Coordenação de Aperfeiçoamento de Pessoal de Nível Superior - Brasil (CAPES) - Finance Code 88882.328289/2019-01. 


\section{LISTA DE FIGURAS}

Figura 1- Representação da anatomia do nervo Sural do rato 26

Figura 2- Representação da anatomia do nervo Sural do ser humano 28

Figura 3- Fotomicrografia de corte semifino de nervo Sural de rato WKY 31

Figura 4- Ultramicrografia eletrônica do nervo Isquiático de rato Wistar 31

Figura 5- Representação do método direto 32

Figura 6- Representação do método indireto simples 33

Figura 7- Representação do método indireto LSAB .34

Figura 8- Representação esquemática da revelação por DAB 35

Figura 9- Representação da estrutura molecular da substância $P$ 36

Figura 10- Procedimento cirúrgico para dissecação de nervo Sural do animal. 45

Figura 11- Nervo Sural dissecado .46

Figura 12- Comparação dos pesos corporais entre os grupos experimentais. .52

Figura 13- Comparação da frequência cardíaca entre os grupos experimentais 53

Figura 14- Comparação da pressão arterial sistólica entre os grupos experimentais 54

Figura 15- Comparação da pressão arterial diastólica entre os grupos experimentais 
Figura 16- Comparação da média das pressões cardíacas entre os grupos experimentais .

Figura 17- Comparação da densidade de fibras imunomarcadas nos animais do grupo WKY-M 57

Figura 18- Fotomicrografias aleatoriamente selecionadas de cortes longitudinais de nervos surais de animais representativos do grupo WKY-M 58

Figura 19- Comparação da densidade de fibras imunomarcadas nos animais do grupo WKY-F 59

Figura 20- Fotomicrografias aleatoriamente selecionadas de cortes longitudinais de nervos surais de animais representativos do grupo WKY-F 60

Figura 21- Comparação da densidade de fibras imunomarcadas entre os grupos WKY-M e WKY-F 61

Figura 22- Comparação da densidade de fibras imunomarcadas no grupo SHR-M.62

Figura 23- Fotomicrografias aleatoriamente selecionadas de cortes longitudinais de nervos surais de animais representativos do grupo SHR-M. 63

Figura 24- Comparação da densidade de fibras imunomarcadas no grupo SHR-F .64

Figura 25- Fotomicrografias aleatoriamente selecionadas de cortes longitudinais de nervos surais de animais representativos do grupo SHR-F 65

Figura 26- Comparação da densidade de fibras imunomarcadas entre os grupos SHRM e SHR-F 66 
Figura 27- Comparação da densidade de fibras imunomarcadas entre os grupos WKY-M e SHR-M 67

Figura 28- Comparação da densidade de fibras imunomarcadas entre os grupos WKY-F e SHR-F. 69 


\section{LISTA DE SIGLAS E ABREVIATURAS}

$A B C$

AVE

CEUA

$\mathrm{cm}$

DAB

EPM

FC

Fig

FMRP

HA

HRP

IAM

IB

IBGE

IC

IHQ

LAB

LSAB

$\mathrm{Ni}-\mathrm{DAB}$

$\mathrm{NH}$

NHS-IB

$\mathrm{NK}-1$

NK-2

NK-3
Avidina-biotina-peroxidase

Acidente vascular encefálico

Comissão de Ética no Uso de Animais

Centímetros

3,3'-diaminobenzidina tetrahidrocloreto

Erro padrão da média

Frequência cardíaca

Figura

Faculdade de Medicina de Ribeirão Preto

Hipertensão arterial

Horseradish Peroxidase

Infarto agudo do miocárdio

Tris-PBS-Triton

Instituto Brasileiro de Geografia e Estatística

Insuficiência cardíaca

Imunohistoquímica

Labelled-avidin-biotin

Labelled-streptavidin-biotin

Solução de diaminobenzidina intensificada com níquel

Soro de cavalo

Soro de cavalo diluído em Tris-PBS-Triton

Neurocinina 1

Neurocinina 2

Neurocinina 3 


\begin{tabular}{ll} 
OCT & Optimal Cutting Temperature \\
PA & Pressão arterial \\
PAD & Pressão arterial diastólica \\
pH & Potencial hidrogeniônico \\
PAP & Peroxidade-antiperoxidase \\
PAM & Pressão arterial média \\
PAS & Pressão arterial sistólica \\
RNAm & Messenger Ribonucleic Acid \\
SBC & Sociedade Brasileira de Cardiologia \\
SHR & Spontaneously hypertensive rat \\
SHR-F & Spontaneously hypertensive rats fêmeas \\
SHR-M & Spontaneously hypertensive rat machos \\
SP & Substância P \\
SDD & Sural direito distal \\
SDP & Sural direito proximal \\
SED & Sural esquerdo distal \\
SEP & Sural esquerdo proximal \\
WHO & Organização Mundial da Saúde \\
WKY & Wistar Kyoto \\
WKY-F & Wistar Kyoto fêmeas \\
WKY-M & \\
& Wistar Kyoto machos \\
\hline
\end{tabular}




\section{LISTA DE SÍMBOLOS}

\begin{tabular}{|c|c|}
\hline $\mathrm{mmHg}$ & Milímetros de mercúrio \\
\hline$\geq$ & Maior ou igual \\
\hline$\%$ & Porcentagem \\
\hline U\$ & Dólar \\
\hline$x$ & Vezes \\
\hline$\mu \mathrm{m}$ & Micrômetro \\
\hline$\beta$ & Beta \\
\hline Y & Gama \\
\hline$\alpha$ & Alfa \\
\hline$\delta$ & Delta \\
\hline g & Gramas \\
\hline${ }^{\circ} \mathrm{C}$ & Graus Celsius \\
\hline \pm & Mais ou menos \\
\hline l & Por \\
\hline$\circledR$ & Marca registrada \\
\hline$n$ & Número de sujeitos \\
\hline $\mathrm{mg}$ & Miligrama \\
\hline $\mathrm{Kg}$ & Quilo \\
\hline M & Molar \\
\hline$\mu \mathrm{m}^{2}$ & Micrômetro quadrado \\
\hline$<$ & Menor \\
\hline$>$ & Maior \\
\hline
\end{tabular}




\section{SUMÁRIO}

1. INTRODUÇÃO

1.1. HIPERTENSÃO ARTERIAL

1.2. RATOS ESPONTANEAMENTE HIPERTENSOS

1.3. NERVO SURAL

1.4. IMUNOHISTOQUÍMICA NA ABORDAGEM HISTOLÓGICA DOS NERVOS PERIFÉRICOS

1.5. SUBSTÂNCIA P 35

2. OBJETIVOS

2.1. OBJETIVOS GERAIS

2.2. OBJETIVOS ESPECÍFICOS

3. MATERIAL E MÉTODOS

3.1. ANIMAIS

3.2. PROCEDIMENTO CIRÚRGICO

3.3. PROCEDIMENTO HISTOLÓGICO

3.4. IMUNOHISTOQUÍMICA PARA SUBSTÂNCIA P

3.5. ANÁLISE HISTOLÓGICA

3.6. ANÁLISE ESTATÍSTICA

4. RESULTADOS

4.1. PESO CORPORAL

4.2. FREQUÊNCIA CARDÍACA 
4.3. DADOS HEMODINÂMICOS

4.3.1. Pressão arterial sistólica $\quad 54$

4.3.2. Pressão arterial diastólica 55

4.3.3. Pressão arterial média $\quad 55$

4.4. DENSIDADE DE FIBRAS IMUNOMARCADAS PARA SUSBSTÂNCIA P 56

4.4.1. Análises intragrupo: ratos da linhagem WKY 56

4.4.2. Análises intragrupo: ratas da linhagem WKY 59

4.4.3. Análises intergrupos: ratos e ratas da linhagem WKY 61

4.4.4. Análises intragrupo: ratos da linhagem SHR 62

4.4.5. Análises intragrupo: ratas da linhagem SHR 64

4.4.6. Análises intergrupos: ratos e ratas da linhagem SHR 66

4.4.7. Análises intergrupos: ratos das linhagens WKY e SHR 67

4.4.8. Análises intergrupos: ratas das linhagens WKY e SHR 68

$\begin{array}{ll}\text { 5. DISCUSSÃO } & \mathbf{7 0}\end{array}$

$\begin{array}{ll}\text { 5.1. PESO CORPORAL } & 71\end{array}$

5.2. FREQUÊNCIA CARDÍACA $\quad 71$

5.3. DADOS HEMODINÂMICOS

5.4. DENSIDADE DE FIBRAS IMUNOMARCADAS PARA SUSBSTÂNCIA P

6. CONCLUSÕES

$\begin{array}{ll}\text { 7. REFERÊNCIAS } & 83\end{array}$

$\begin{array}{ll}\text { 8. ANEXOS } & 117\end{array}$ 
8.1. COMISSÃO DE ÉTICA NO USO DE ANIMAIS 118

8.2. ARTIGO SUBMETIDO PARA PERIÓDICO 119

8.3. TRABALHOS PUBLICADOS EM ANAIS DE CONGRESSOS 120 


\subsection{HIPERTENSÃO ARTERIAL}

As doenças crônicas são consideradas um grave problema de saúde em todo o mundo, que geram gastos importantes aos cofres públicos (WEBER et al., 2014; GOIT; ANSARI, 2016). Dentre estas doenças destaca-se a hipertensão arterial (HA), condição clínica caracterizada por elevação sustentada dos níveis pressóricos 1140x90 mmHg, segundo a Organização Mundial da Saúde (WHO, 2013).

A HA possui causa multifatorial para sua gênese e manutenção, uma vez que a regulação da pressão arterial (PA), uma das funções fisiológicas mais complexas do organismo, depende de ações integradas dos sistemas cardiovascular, renal, neural e endócrino (FOËX; SEAR, 2004).

Dados epidemiológicos demonstram que a HA afeta aproximadamente 1 bilhão de pessoas no mundo, com previsão de aumento até o ano de 2025, podendo chegar a 1,5 bilhões de hipertensos (CHOCKALINGAM, 2007; JARARI et al., 2016; WEYER, 2016).

No Brasil, esta doença atinge cerca de 36 milhões de pessoas, o que corresponde a $32,5 \%$ da população do país, sendo os idosos, com idade superior a 65 anos, a parcela da sociedade mais afetada (60\%) (SCALA; MAGALHÃES; MACHADO, 2015). Adicionalmente, estudos realizados pelo Instituto Brasileiro de Geografia e Estatística através da Pesquisa Nacional de Saúde (IBGE, 2013), revelaram maior proporção de mulheres com diagnóstico médico de HA $(24,2 \%)$ em relação aos homens $(18,3 \%)$.

A maioria dos casos de HA, cerca de $90 \%$, não apresenta causa aparente facilmente identificável, sendo conhecida como HA primária ou essencial. A outra pequena parcela deles, cerca de $5 \%$ a $10 \%$, possui causas muito bem estabelecidas, 
as quais precisam ser devidamente diagnosticadas, uma vez que, com a remoção do agente etiológico, é possível controlar ou curar o quadro hipertensivo. Esta é chamada HA secundária (CHIONG et al., 2008; RIMOLDI; SCHERRER; MESSERLI, 2014).

Dessa maneira, os valores da PA podem ser influenciados por fatores de risco para seu aumento, os quais são descritos como não modificáveis e modificáveis. Os primeiros estão ligados à fatores genéticos, à idade, e estão relacionadas com o envelhecimento populacional (PICON et al., 2013) e ao sexo e etnia, tendo as mulheres da raça negra valores pressóricos mais elevados (NASCIMENTO-NETO et al., 2013); e os últimos, estão vinculados a causas renais, vasculares, endócrinas, neurológicas e gestacionais, como também ao Diabetes Melito, ao estresse, ao consumo de álcool, ao uso excessivo de sal, ao uso de anticoncepcionais orais, de nicotina, de drogas imunossupressoras, (CHIONG et al., 2008; HE; MacGREGOR, 2010; ZHAO et al., 2011; RIMOLDI; SCHERRER; MESSERLI, 2014; ANDRADE et al., 2015; DE BOER et al., 2017) e ao sedentarismo e obesidade, visto que, de acordo com dados do Ministério da Saúde colhidos através do Sistema de Vigilância de Fatores de Risco e Proteção para Doenças Crônicas por Inquérito Telefônico (BRASIL, 2018), há relação linear entre insuficiência de atividade física (inferior a 150 minutos semanais), o aumento de peso corporal e a elevação da PA.

Segundo a VII Diretriz Brasileira de Hipertensão Arterial, publicada pela Sociedade Brasileira de Cardiologia (SBC, 2016), esta doença mantém associação bem estabelecida com eventos críticos, como: acidente vascular encefálico (AVE), infarto agudo do miocárdio (IAM), insuficiência cardíaca (IC), doença renal fatal e não fatal. Sendo assim, a pressão sanguínea elevada contribui com $62 \%$ de todos os casos de AVE e com $49 \%$ de todas as doenças cardíacas, ocasionanso impacto elevado na perda da produtividade no trabalho e da renda familiar (estimado em US\$ 
4,18 bilhões entre 2006 e 2015), gastos com saúde pública (estimado em US\$ 671,6 milhões no ano de 2005 ), visto que $70 \%$ da população brasileira depende do Sistema Único de Saúde, e milhares de mortes (141. 878 mortes no ano de 2017) (ABEGUNDE et al., 2007; DIB; RIERA; FERRAZ, 2010; PEREIRA, 2010; WIDIMSKÝ, 2015; SMITH et al., 2016; BRASIL, 2017).

A HA, além dos importantes eventos supracitados, tem sido vindulada como causa de neuroparia periférica, a neuropatia hipertensiva (TOMASSONI et al., 2004; GREGORY et al., 2012). Embora sejam fenômenos aparentemente distintos, investigações clínicas e experimentais demonstraram que sujeitos hipertensos possuem percepção reduzida de estímulos dolorosos comparados aos normotensos (GHIONE, 1996; FRANCE, 1999; GUASTI et al., 1999). Ainda, foi observado que pessoas normotensas, com parentes hipertensos de primeiro grau, demonstram menor sensibilidade a dor experimental do que indivíduos sem histórico familiar da doença (AL'ABSI; BUCHANAN; LOVALLO, 1996).

Recentemente, procurou-se estabelecer a relação entre dor e HA utilizando questionários para quantificar a presença e intensidade da dor. Um desses estudos demonstrou que indivíduos hipertensos apresentavam até $60 \%$ menos dor musculoesquelética do que normotensos (HAGEN et al., 2002). Em outro, verificouse que a intensidade da dor está associada com pequeno, porém significativo aumento na prevalência de diagnóstico de HA (BRUEHL et al., 2005).

Considerando a dor um mecanismo que auxilia na proteção do corpo contra lesões potenciais, sua correlação com o quadro hipertensivo implica na redução dos sinais de advertência ao risco eminente da integridade física, expondo o organismo a possíveis danos (FERREIRA et al., 2015). 
Finalmente, com base nesta importante correlação clínica, nota-se a relevância da investigação a respeito da ação da HA sobre as vias nervosas periféricas por onde trafegam os sinais dolorosos. Para isso, destaca-se a ciência experimental e o uso de modelos animais de HA.

\subsection{RATOS ESPONTANEAMENTE HIPERTENSOS}

Por um longo período de tempo, os pesquisadores vêm se dedicando à encontrar o modelo experimental que melhor caracterize uma patologia tão importante para o ser humano como é a HA (FAZAN-JR; DA SILVA; SALGADO, 2001).

Dentre os principais modelos animais para essa doença encontrados na literatura, podemos citar os modelos de hipertensão genética espontânea (OKAMOTO; AOKI, 1963), hipertensão genética sal-sensível (DAHL; HEINE; TASSINARI, 1962), hipertensão neurogênica (DOYLE; SMIRK, 1955), hipertensão renovascular (GOLDBLATT et al., 1943), hipertensão por oclusão e desoclusão do pedículo renal (FAZAN-JR; DA SILVA; SALGADO, 2001), hipertensão renopriva (WILSON; BYRON, 1941; FERRARIO; PAGE; MCCUBBIN, 1970), hipertensão perinefrítica (PAGE, 1939; GROLLMAN, 1944), hipertensão por coartração da artéria Aorta (SALGADO; FAZAN-JR; SALGADO, 1997), hipertensão por inibição crônica do óxido nítrico (RIBEIRO et al., 1992; BAYLIS; MITRUKA; DENG, 1992) e hipertensão dependente de mineralocorticoides (SELYE; STONE, 1946; CARRETERO; ROMERO, 1977).

O modelo animal experimental ideal para as pesquisas científicas em HA deve possuir semelhanças etiológicas, anatômicas, hemodiâmicas e fisiológicas com o ser humano, além de desenvolver complicações relativas a esta condição, características às observadas no homem (BLANC; LAMBERT; ELGHOZI, 2000). 
Como o tipo de hipertensão mais comum nos seres humanos é do tipo essencial, na qual há contribuição de múltiplos genes, o modelo animal para seu estudo não pode ser derivado de uma única alteração genética. Com base nisto, dentre os modelos disponíveis, o que melhor preenche este critério são os ratos espontaneamente hipertensos (spontaneously hypertensive rats) (SHR), uma linhagem geneticamente homogênea com potencial hipertensivo de etiologia poligênica (NABIKA, 1999; LERMAN et al., 2005; SUN; ZHANG, 2005).

Os animais SHR foram desenvolvido por Okamoto e Aoki em 1963 a partir da procriação consanguínea de ratos Wistar Kyoto (WKY), ou seja, sem qualquer recurso farmacológico ou cirúrgico (FAZAN et al., 2006).

O desenvolvimento de uma PA elevada nesta cepa é observada já na $5^{a}$ semana de vida, quando os animais apresentam frequência cardíaca (FC) e resistência vascular periférica elevadas, e débito cardíaco ainda normal. Entre a $7^{\mathrm{a}} \mathrm{e}$ $15^{\mathrm{a}}$ semanas de vida, os SHR já demonstram nível de PA considerado como hipertensão espontânea, que continua se elevando até atingir um platô, entre a $20^{\mathrm{a}} \mathrm{e}$ $28^{a}$ semanas de vida, quando são considerados ratos adultos. Neste momento, seu nível pressórico corresponde a 190×20 mmHg (FAZAN-JR; DA SILVA; SALGADO, 2001).

No SHR adulto, a HA está associada a progressão do aumento da resistência vascular periférica. Além disso, com o evoluir da doença, seu músculo cardíaco se hipertrofia de maneira progressiva, até que, nos estágios finais, seu débito cardíaco reduz-se em decorrência de uma insuficiência cardíaca congestiva (FROHLICH, 1997; THOMAS et al., 1997; FLISER et al., 1998; POTTS; MCKEOWN; SHOUKAS, 1998).

Mesmo que os animais SHR não tenham sido o primeiro modelo de hipertensão espontânea (SMIRK; HALL, 1958), se não for o mais descrito na literatura, certamente 
destaca-se entre eles (FAZAN-JR; DA SILVA; SALGADO, 2001; FAZAN et al., 2006). Esta importância é decorrente da semelhança existente entre a hipertensão essencial humana e a observada neste modelo animal, de modo que ambos possuem predisposição genética para a doença sem origem bem definida, aumento da reisitência vascular periférica, hipertrofia da musculatura lisa vascular e miocárdica com constrição de arteríolas e vênulas, comprometimento renal e igual resposta a tratamentos medicamentosos (LAWAND, 2008).

Outros aspectos que depõem à favor do emprego do SHR nas pesquisas científicas são seu relativo curto período de vida, seu porte reduzido e a facilidade para a sua manutenção (FAZAN-JR; DA SILVA; SALGADO, 2001).

Apesar de toda excelência que permeia os ratos espontaneamente hipertensos, estes guardam algumas ressalvas em seus cuidados que podem interferir no desenvolvimento de sua PA, sendo elas relacionadas a sua reprodução, uma vez que características podem mudar levemente de uma geração para outra, ou entre diferentes colônias (MULLINS; BANKS, 1976; SINAIKO; MIRKIN, 1978) e ao ambiente onde são mantidos, considerando a alta ingestão de sódio (LOUIS; TABEl; SPECTOR, 1971) a presença de eventos estressores (YAMORI et al., 1969), as alterações sociais (HALLBACK; ISAKSSON; NORESSON, 1975) e do ciclo claro/escuro (LAIS; SHAFFER; BRODY, 1974).

A partir do exposto, é possível notar a importância e a aplicabilidade deste modelo experimental na pesquisa científica, fato que pode ser comprovado também pela variedade de estudos que se valem dos SHR. Neste aspecto, observa-se sua participação em trabalhos relacionados ao comportamento animal (BAYLESS; PEREZ; DANIEL, 2015; NIIGAKI et al., 2019), à origem e ao desenvolvimento natural da HA (NELSON et al., 2017; SCRIDON et al., 2017; AVOLIO et al., 2018), aos 
componentes genéticos desta cepa (ELY; TURNER, 1990; DICKEY et al., 2012; MAAN et al., 2017), a métodos de tratamento para esta doença (KIVIMÄKI et al., 2012; SHENGFENG et al., 2015; LOCATELLI et al., 2017) e às alterações morfológicas vinculadas à HA encontradas em diversos sistemas dos SHR, tais como: o ósseo (DODD et al., 2019), o muscular (ATRAKCHI; GRAY; CARLSEN; 1994), o vascular (RUSSO et al., 2017), o respiratório (AHARINEJAD et al., 1996), o digestório (STEWART et al., 2016), o reprodutor (MARIC-BILKAN; GILBERT; RYAN, 2014), o urinário (LAURENT et al., 2001), o genital (TOBLLI et al., 2000; BECHARA et al., 2003), o sistema nervoso central (NELSON et al., 2009) e também o sistema nervoso periférico, sendo o nervo Sural um exemplar frequentemente investigado nestes casos (SANADA et al 2012; SANADA et al., 2015; NUKADA et al., 2016; FONTANESI et al., 2019).

\subsection{NERVO SURAL}

A primeira descrição detalhada da origem e trajeto do nervo Sural de ratos data de 1963. Nela, Greene descereve como sendo um ramo do nervo fibular comum, que se continua por uma extensão variável, na coxa, inserido em uma bainha comum ao nervo Tibial. Quando alcança a região da fossa poplítea, o nervo Sural, segundo este autor, pode emitir o ramo Sural lateral, responsável pela invervação da pele da superfície lateral da sura (GREENE, 1963) (Fig. 1).

O nervo em questão segue seu trajeto entre o músculo Bíceps femoral e Gastrocnêmio (cabeça lateral), momento em que está enovelado aos vasos surais superficiais. Ao passar abaixo da borda posterior dos músculos do jarrete, ele se superficializa, quando, então, emite o ramo anastomótico fibular, localizado abaixo do tendão calcâneo, que alcança a pele da face lateral e do terço distal da perna. Esse 
ramo, ao se unir ao nervo plantar lateral, fornece inervação para a pele do dorso do quarto dígito, para a face lateral do quinto dígito, para os músculos lumbricais, para o músculo flexor curto do quinto dígito e também para os músculos abdutores do quinto dígito do rato (GREENE, 1963; NAKANISHI; NORRIS, 1970; POVLSEN et al.,1993). Finalmente, quando o nervo sural passa por atrás do maléolo lateral, se finda na pele e na fáscia da região do tornozelo e do calcanhar (GREENE, 1963) (Fig. 1).

Figura 1- Representação da anatomia do nervo Sural do rato.

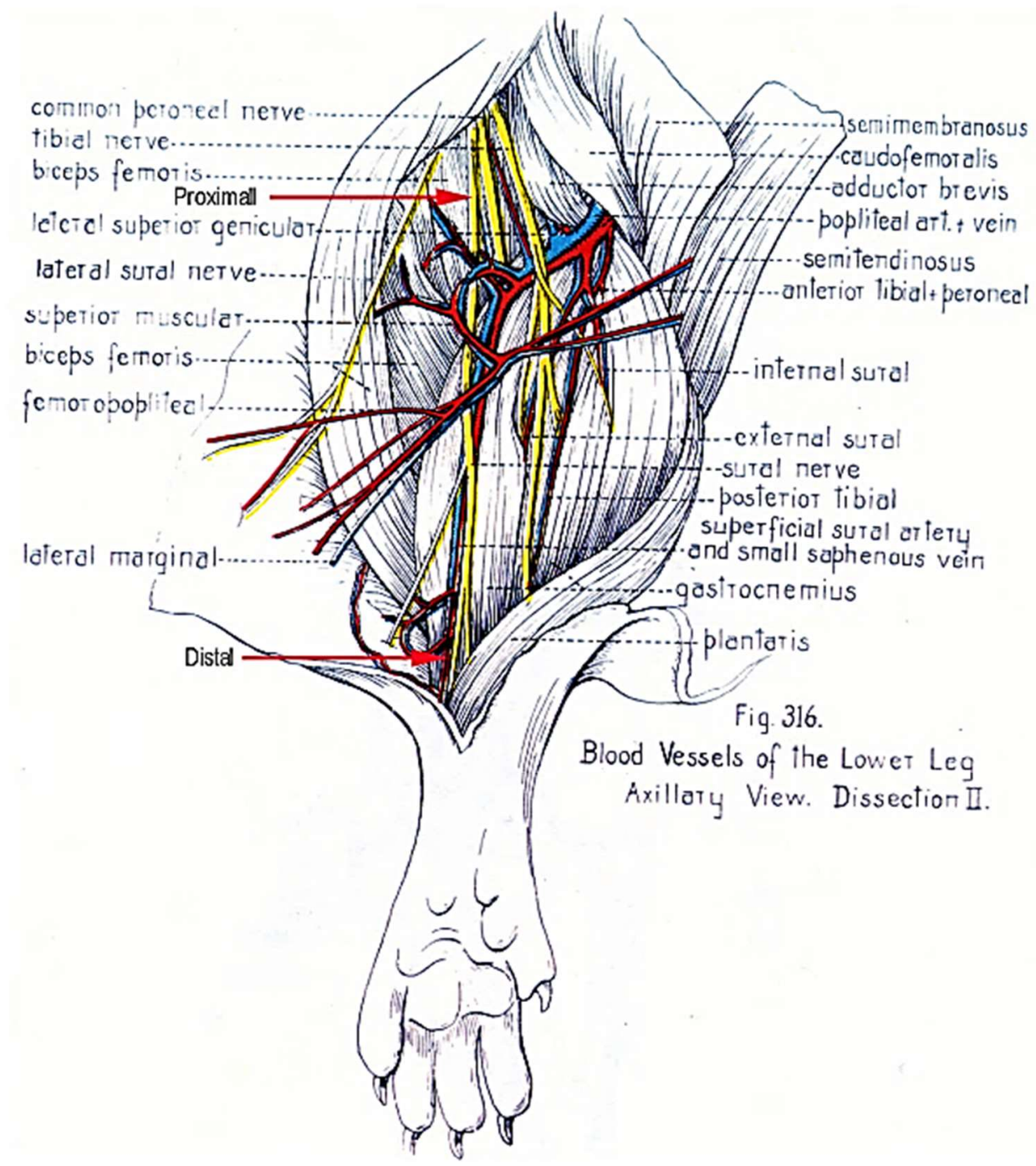

Fonte: Jeronimo (2007). 
Apesar da caracterização da origem do nervo Sural descrita por Greene (1963) parecer bem definida, alguns estudos mais rescentes se referem à eminênica deste nervo como sendo ramo direto do nervo Isquiático. Por exemplo, Schmalbruch (1986), ao analisar a composição das fibras do nervo Isquiático de ratos Wistar, relatou que o nervo Sural tem origem na face dorsal do nervo Tibial, ambos oriundos da porção tibial do nervo Isquiático. Ainda, Puigdellívol et al., (2000), ao investigarem a contribuição do nervo Femoral e do nervo Isquiático na formação dos feixes sensoriais para os dígitos do membro pélvico de ratos Sprague-Dawley, concluíram que o Sural é um dos quatro ramos diretos do nervo Isquiático.

É importante mencionar que toda esta descrição referente ao nervo Sural de ratos não é a observada normalmente nos seres humanos. Neles, este nervo tem origem na perna, devido a união do nervo Cutâneo medial da sura, descrito como ramo do nervo Tibial, com o ramo Comunicante fibular, descrito como ramo do nervo Fibular, união esta que ocorre mais precisamente entre as cabeças medial e lateral do músculo Gastrocnêmio (GARDNER et al., 1978; JERONIMO, 2007) (Fig. 2).

Durante seu percurso em direção distal, o nervo Sural margeia a veia Safena parva, emitindo ramos para a pele da região posterior da perna, o que permite sua comunicação com o nervo Cutâneo posterior da coxa. Ao passar posteriormente abaixo do Maléolo lateral, o nervo em questão segue ao longo da borda lateral do pé e do quinto dedo como nervo Cutâneo sural lateral que, no dorso do pé, une-se com o nervo Cutâneo dorsal intermédio, ramo do fibular superficial (GARDNER et al., 1978) (Fig. 2). 
Figura 2- Representação da anatomia do nervo Sural do ser humano.

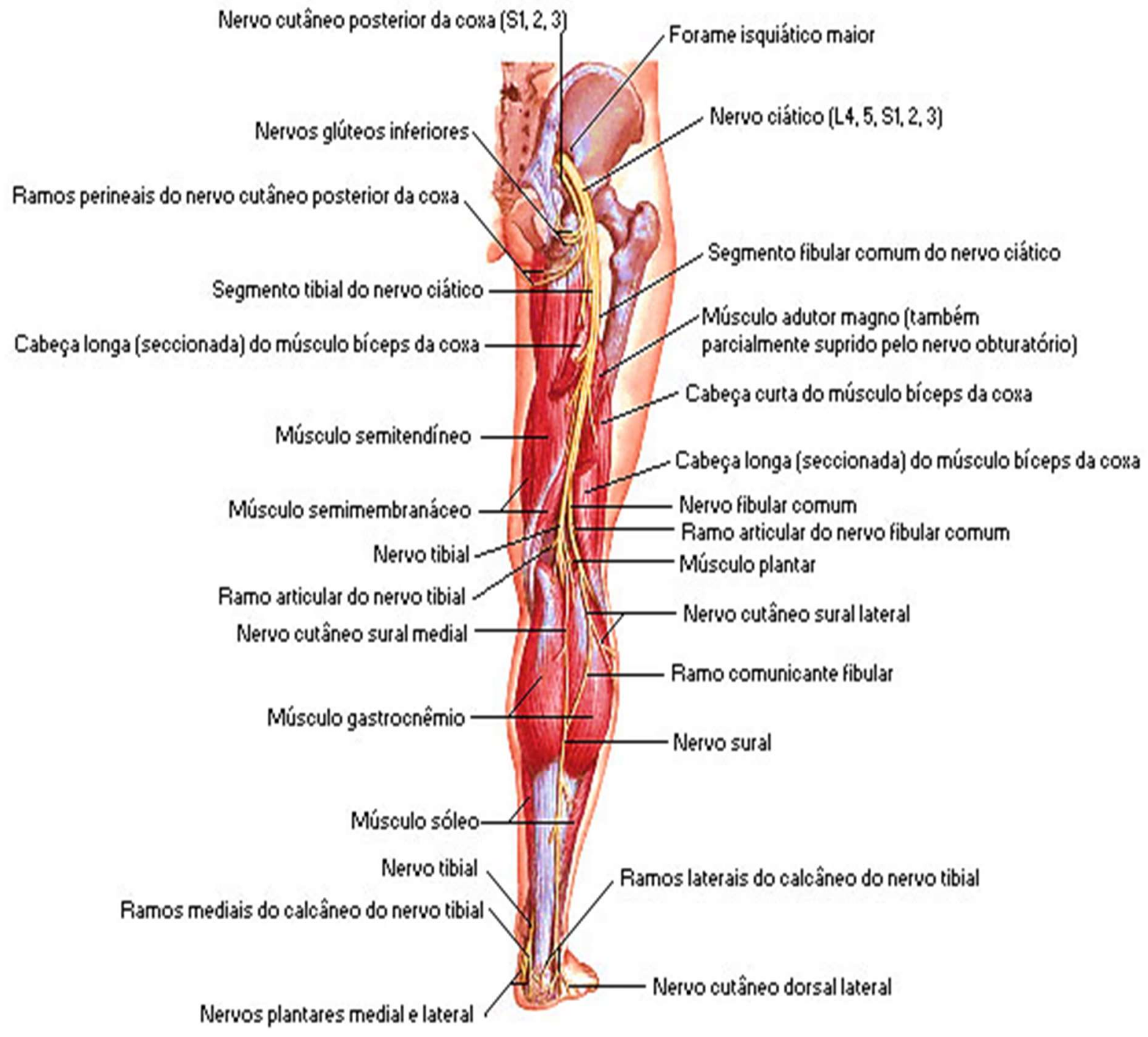

Fonte: Netter (2018)

Ao analisarmos os alvos dos nervos surais de ratos e de seres humanos, podemos inferir que as diferenças entre eles não se limitam apenas a seu trajeto, como também abrangem sua constituição. Enquanto no homem este elemento anatômico é considerado exclusivamente sensitivo, em ratos é tido como um nervo misto, constituído por axônios motores (3 a 4\%) e sensitivos (96 a 97\%) (DICK et al., 1984). Os axônios motores são formados por fibras mielínicas grossas a-Alfa, oriundas do nervo Isquiático, e são responsáveis pela contração e propriocepção de 
músculos esqueléticos (VEJSADA; PALECEK; HNIK; HOITSMA et al., 2004). Os axônios sentitivos são formados por fibras mielínicas finas a-Delta e amielínicas C, as quais correspondem aos prolongamentos periféricos dos neurônios residentes no gânglio da raíz dorsal e transmitem sinais de dor e temperatura (SWETT; WOOLF, 1985; HOITSMA et al., 2004).

O nervo Sural, devido a sua localização, composição e facilidade para obtenção de dados de normalidade na literatura, é amplamente utilizado nas investigações clínicas e experimentais referentes aos casos de manifestações de possíveis neuropatias periféricas (MARTINS; SIQUEIRA; TEDESCO-MARCHESE, 2002).

A biópsia deste elemento é uma prática importante no diagnóstico das manifestações neuropáticas. Diversas são as técnicas histológicas que permitem sua avaliação, fornecendo pistas relevantes, tanto para a etiologia quanto para a investigação dos mecanismos fisiopatológicos dessas doenças, bem como orientando a abordagem terapêutica de lesões inflamatórias, infecciosas, desmielinizantes ou degenerativas (KING; GINSBERG, 2013).

Visto isso, a abordagem do nervo Sural do rato SHR configura um importante recurso experimental, o qual poderia auxiliar a área clínica quanto ao esclarecimento dos déficits perceptuais, decorrentes da neuropatia hipertensiva, encontrados em sujeitos hipertensos (NUKADA et al., 2016; FONTANESI, 2019).

\subsection{IMUNOHISTOQUÍMICA NA ABORDAGEM HISTOLÓGICA DOS NERVOS PERIFÉRICOS}

O método de abordagem histológica mais frequentemente empregado para a análise dos nervos periféricos, tanto na pesquisa clínica quanto na pesquisa experimental, é a inclusão em resina epóxi, sendo os objetivos dos trabalhos que se 
valem dele voltados para a investigação de eventos biológicos relacionados ao desenvolvimento, envelhecimento, adoecimento, regeneração e às diferenças entre gêneros encontradas nos nervos (JERONIMO et al., 2005; LIMA et al., 2007; JERONIMO et al., 2008; MORIYAMA et al., 2016; CAZZATO et al., 2011; PONSVÁZQUEZ et al., 2011; UGRENOVIC' et al., 2016; ZIAGO et al., 2017; UCAY; UZUN, 2018).

Uma das vertentes para uso dessa técnica é a exposição de cortes semifinos dos nervos emblocados e corados com azul de toluidina à microscopia de luz. A partir disso, classes de fibras nervosas podem ser morfometricamente identificadas e estudadas (BILEGO-NETO et al., 2000) (Fig. 3). No entanto, vale destacar que as fibras mielínicas finas e as fibras amielínicas, alvos importantes das neuropatias, podem se tornar dificilmente observadas com este tipo de abordagem, principalmente quando o microambiente está alterado por presença de infiltrado de células imunes, necessitando, então, de amplos aumentos (BOZZOLA; RUSSEL, 1999; GIORGETTO, 2018).

Dessa forma, a microscopia eletrônica de transmissão, por gerar imagens acuradas da ultraestrutura do tecido, configura-se como um importante recurso para identificação, quantificação e análise dos axônios A-delta e C (Fig. 4). Porém, seu uso apresenta algumas desvantagens como o alto custo, o tempo demandado, a necessidade de treinamento técnico e o uso de substâncias altamente tóxicas, como o tetróxido de ósmio (BOZZOLA; RUSSEL, 1999). 
Figura 3- Fotomicrografia de corte semifino de nervo Sural de rato WKY

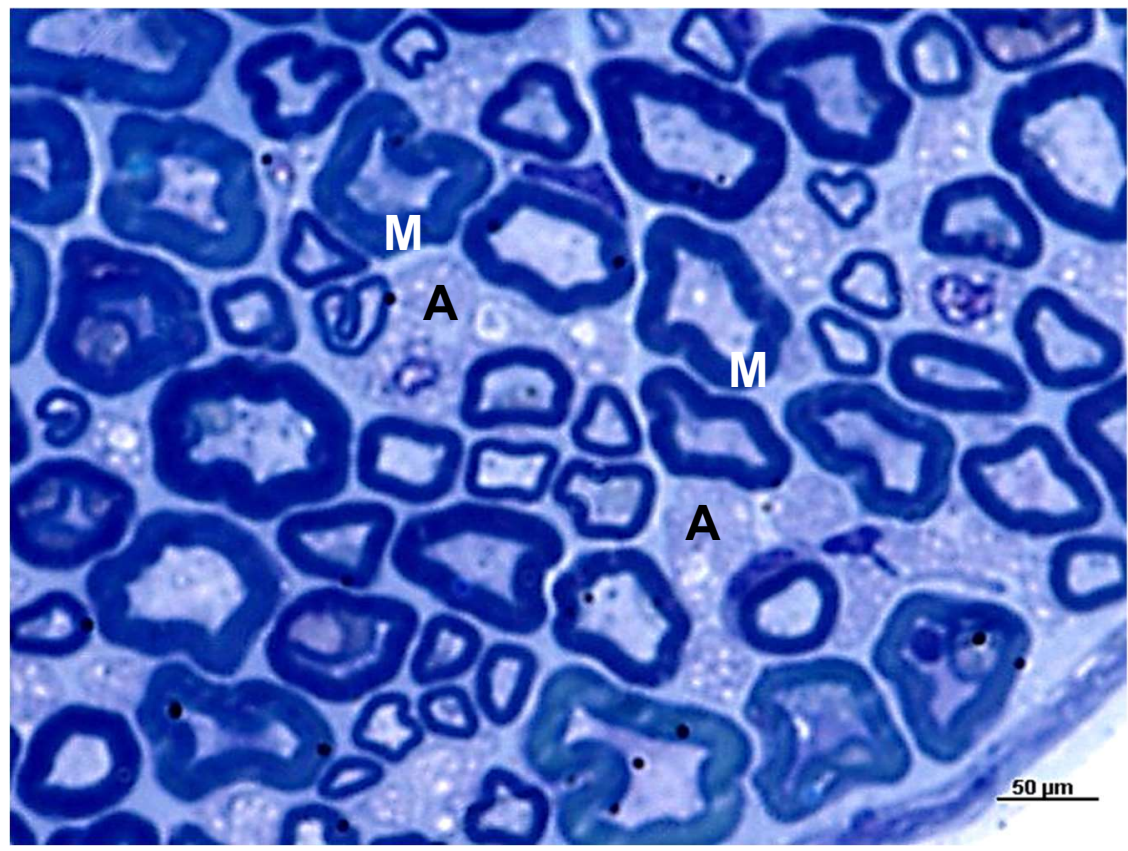

Em (M) fibras mielínicas grossas e em (A) fibras mielínicas finas e amielínicas no espaço endoneural de nervo Sural corado com azul de toluidina. Fonte: imagem modificada de Giorgetto et al. (2018).

Figura 4- Ultramicrografia eletrônica do nervo Isquiático de rato Wistar

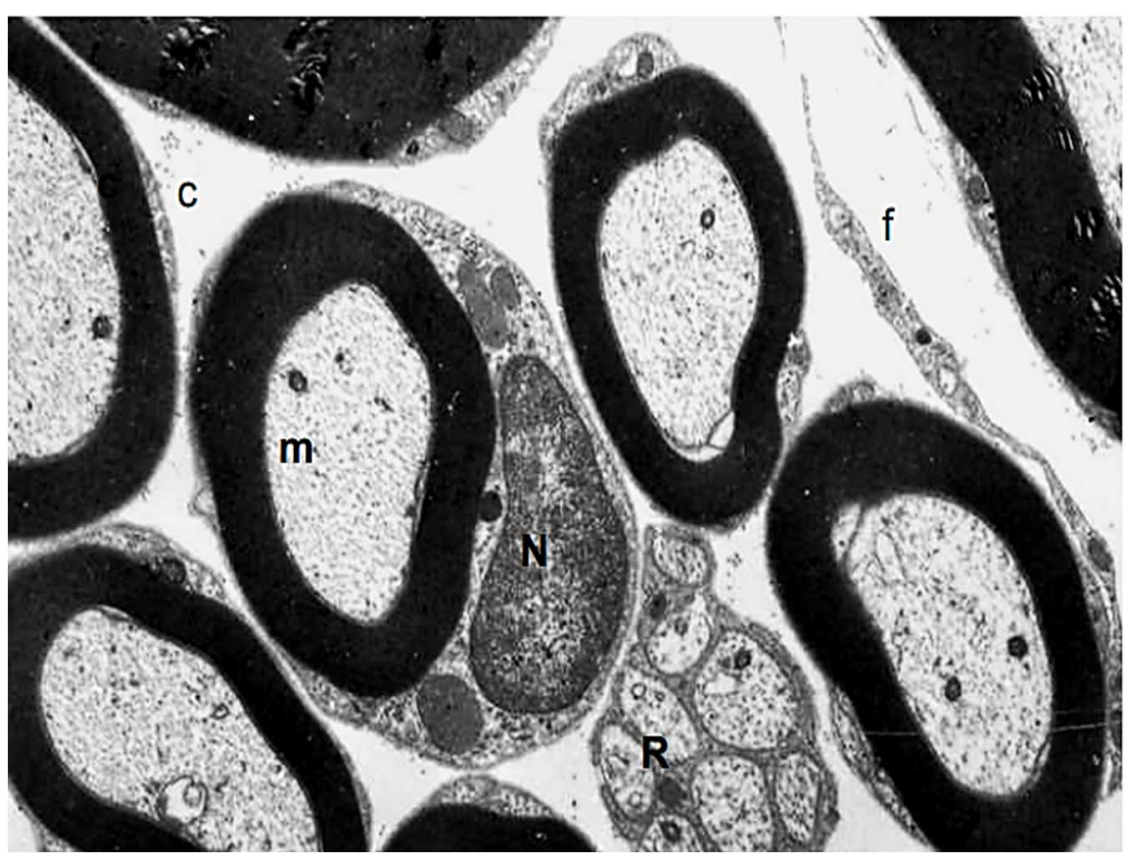

Em $(\mathbf{m})=$ fibras mielínicas; $(\mathbf{N})=$ núcleo de uma célula de Schwann, $(\mathbf{R})=$ fibras amielínicas e em $(C)=$ fibras colágenas no espaço endoneural de nervo Isquiático aumentado em 7500x. Fonte: Torres (2010). 
Neste contexto, a imunohistoquímica (IHQ) ganha destaque por permitir a abordagem, de maneira indireta, de fibras nervosas específicas através da aplicação de anticorpos contra seus neurotransmissores (GIORGETTO; SIMÕES; FAZAN, 2017). Além disso, por se preocupar com a preservação da morfologia tecidual, esta técnica torna sua análise mais acurada, diferentemente dos demais métodos de sua categoria, tais como radioimunoensaio (GAMSE; LEMBECK; CUELLO, 1979; ENGEL et al., 1980; GANEL; ENGEL; LUBOSHITZ, 1981; KIMURA et al., 1996), cromatografia (ULIN; GUSTAVII; PERSSON, 1976; MIWA et al., 1988; SUNDKVIST et al., 2000) e imunofluorescência (CAMPAGNOLO et al., 2015; RUSSI et al., 2018; SOMMER, 2018).

A IHQ apresenta aplicações bastante diversificadas, sendo elas classificadas como direta e indireta, incluindo suas variáveis (FERRO, 2014). O método direto é o meio mais simples de emprego desta técnica, no entanto, é o que apresenta menor sensibilidade. Nele, os anticorpos primários unidos a um marcador se acoplam diretamente ao seu antígeno, de modo que, para se obter sucesso, é necessário que os anticorpos se apresentem em quantidade suficiente nas amostras (RAMOS-VARA, 2005; FERRO, 2014) (Fig. 5).

Figura 5- Representação do método direto

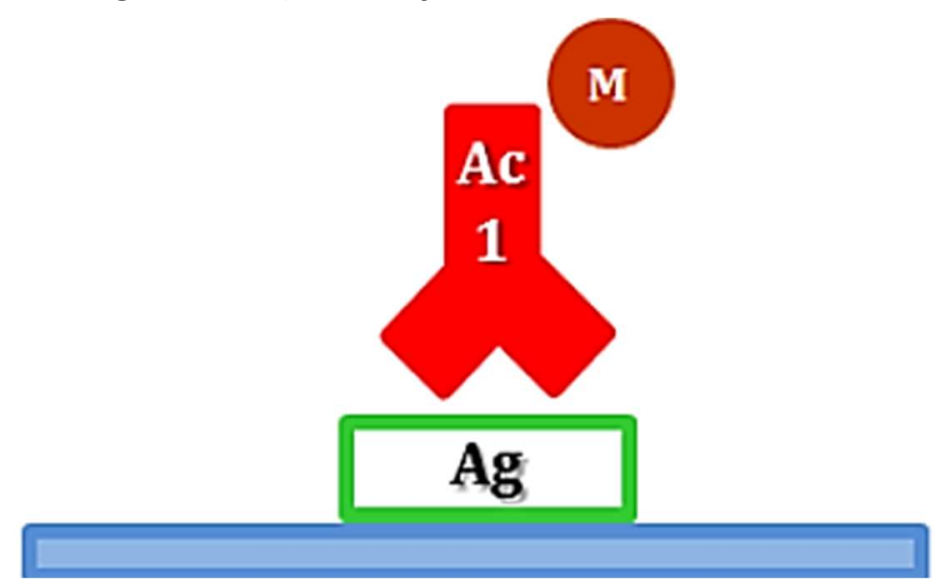

$\operatorname{Em}(\mathbf{A g})=$ antígeno; $(\mathbf{A c 1})=$ anticorpo primário e em $(\mathbf{M})=$ marcador. Fonte: Ferro (2014). 
Ao contrário do descrito anteriormente, o método indireto simples demonstra maior sensibilidade. Nele, o anticorpo primário, por não ser marcado, mantém maior atividade e, consequentemente, a reação se apresenta mais intensa. Outra vantagem da IHQ indireta é sua versatilidade e economia pois, basta a presença de um anticorpo secundário associado a um marcador que pode-se detectar diferentes anticorpos primários de maneira concomitante (FERRO, 2014; CARVALHO, 2016) (Fig. 6).

Figura 6- Representação do método indireto simples

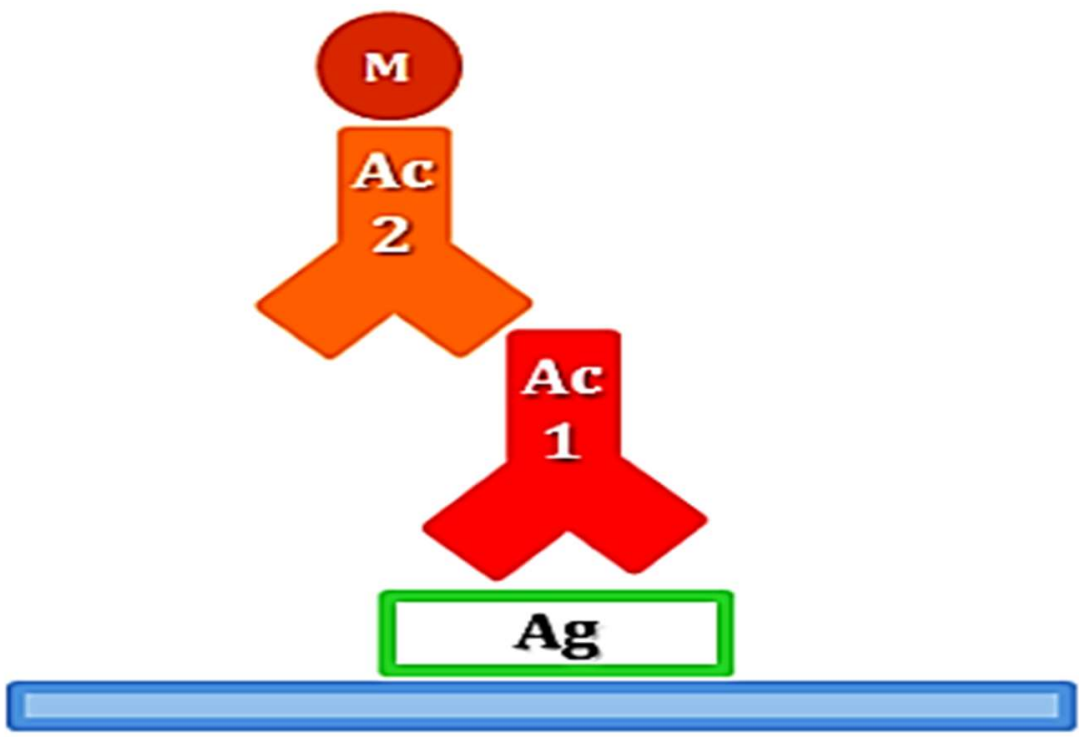

$\operatorname{Em}(\mathbf{A g})=$ antígeno; $(\mathbf{A c 1})=$ anticorpo primário; $(\mathbf{A c 2})=$ anticorpo secundário e em $(\mathbf{M})=$ marcador. Fonte: Ferro (2014).

Dentre os meios indiretos de se aplicar a IHQ, podem ser citados os polímeros, a peroxidade-antiperoxidase (PAP), avidina-biotina-peroxidase ( $\mathrm{ABC}$ ), a labelledavidin-biotin (LAB) e a labelled-streptavidin-biotin (LSAB) (RAMOS-VARA, 2005; FERRO, 2014; DO CARMO, 2016; SIMÕES et al., 2018), técnica que se baseia na aplicação de um anticorpo primário contra seu antígeno, seguida pela inserção de um anticorpo secundário biotinilado contra o primário, e finalizada com a inclusão da estreptavidina, normalmente marcada com HRP (Horseradish Peroxidase) (Fig. 7), 
elemento obtido a partir da raíz do rábano Armoracia rusticana que possui hematina em sua composição, a qual, em contato com o peróxido de oxigênio $\left(\mathrm{H}_{2} \mathrm{O}_{2}\right)$, oxida um doador de elétrons (VEITCH, 2004; RAMOS-VARA, 2005; FERRO, 2014; CARVALHO, 2016) (Fig. 8).

Figura 7- Representação do método indireto LSAB

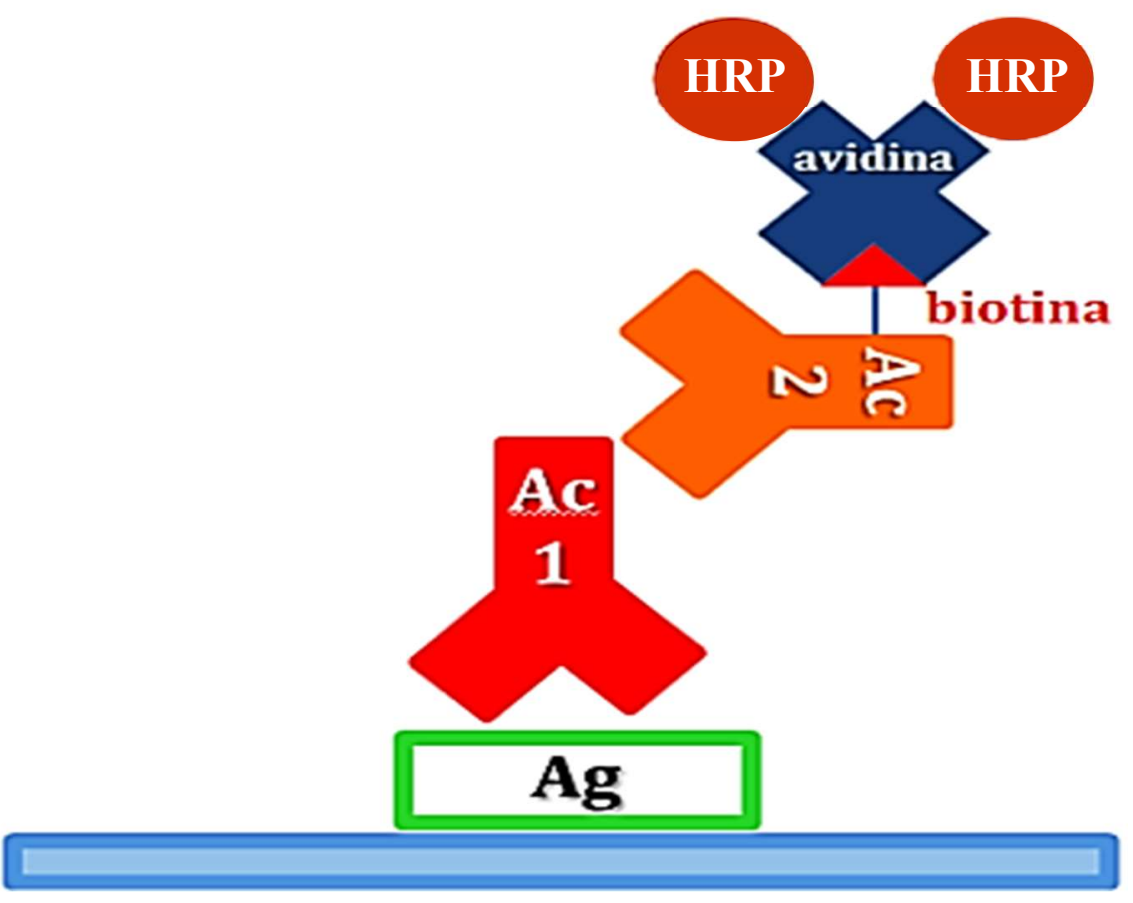

Em $(\mathbf{A g})=$ antígeno; $(\mathbf{A c 1})=$ anticorpo primário; $(\mathbf{A c 2})=$ anticorpo secundário e em $(\mathbf{H R P})=$ Horseradish Peroxidase. Fonte: Ferro (2014).

Alguns dadores de elétrons, uma vez oxidados, tornam-se coloridos e portanto são designados cromógenos, sendo o 3,3'-diaminobenzidina tetrahidrocloreto (DAB) o mais utilizado, o qual confere coloração marrom no local onde ocorreu a ligação antígeno-anticorpo, tornando-a visível (VEITCH, 2004; RAMOS-VARA, 2005; FERRO, 2014; CARVALHO, 2016) (Fig. 8). 
Figura 8- Representação esquemática da revelação por DAB

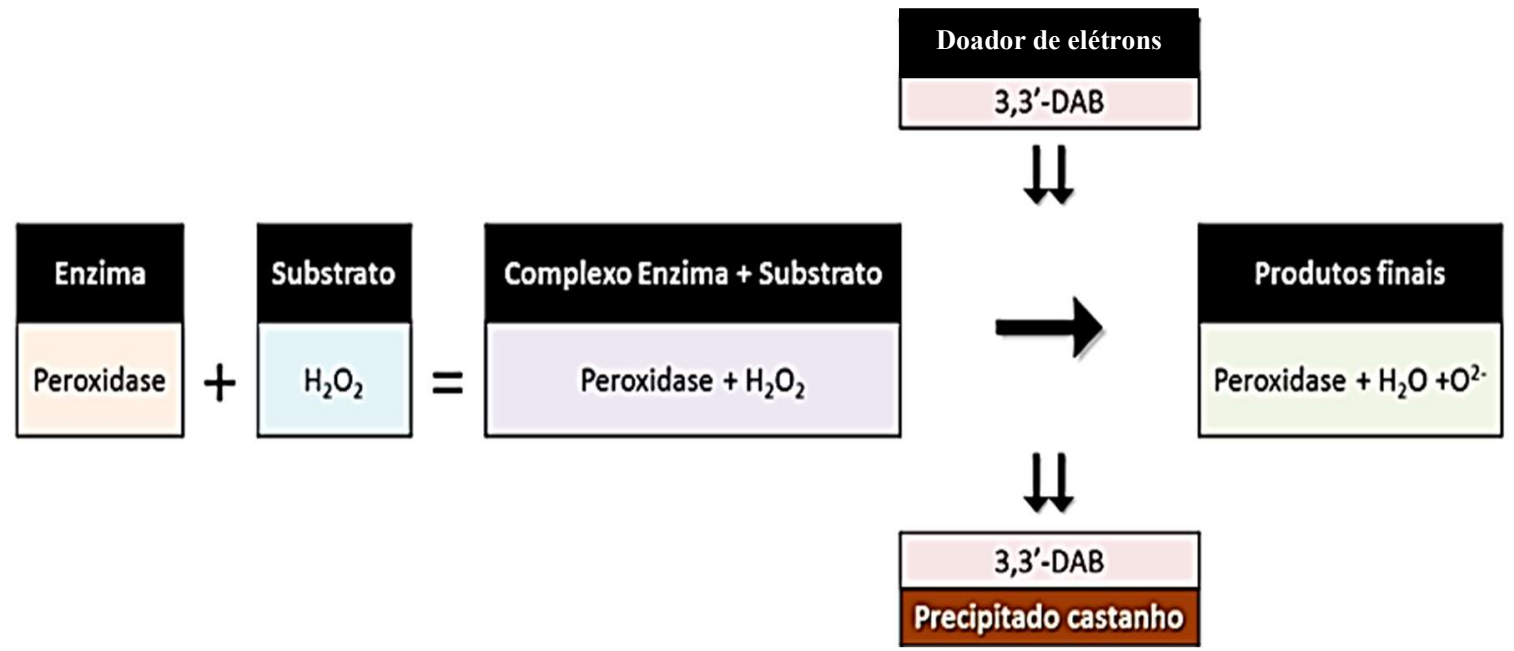

$\operatorname{Em}\left(\mathbf{H}_{2} \mathbf{O}_{2}\right)=$ peróxido de oxigênio; $\left(\mathrm{DAB}=3,3^{\prime}\right)=$ diaminobenzidina tetrahidrocloreto e em $\left(\mathbf{O}^{2}\right)=$ oxigênio livre. Fonte: Fonte: imagem modificada de Ferro (2014).

A IHQ vem sendo adicionada à investigação de neuropatias inflamatórias, de modo que, dos anticorpos disponíveis, os mais comumente empregados para este fim são aqueles que diferenciam linfócitos T (CD3pve) e B (CD20pve). Além destes, ainda estão incluídos nas rotinas de análises, os anticorpos contra macrófagos, proteína básica de mielina, neurofilamentos e antígeno da membrana epitelial para células perineurais. No entanto, anticorpos contra neurotransmissores produzidos pelas próprias fibras nervosas ou nelas localizados são muito menos explorados (KING; GINSBERG, 2013).

\subsection{SUBSTÂNCIA $P$}

A substância $P(S P)$ foi identificada no início do século $X X$ por Von Euler, quando extraída do cérebro e intestino de cavalos (VON EULER; GADDUM, 1931; HARRISON; GEPPETI, 2001), e nomeada em 1934 por Gaddum e Schild ao referirem-se ao pó ("P"), forma através da qual este elemento é obtido (GADDUM; SCHILD, 1934). No entanto, somente após 40 anos de seu descobrimento, em 1971, 
que a estrutura de aminoácidos que a compõe foi isolada e caracterizada (CHANG; LEEMAN; NIALL, 1971) (Fig. 9).

Figura 9- Representação da estrutura molecular da substância $P$

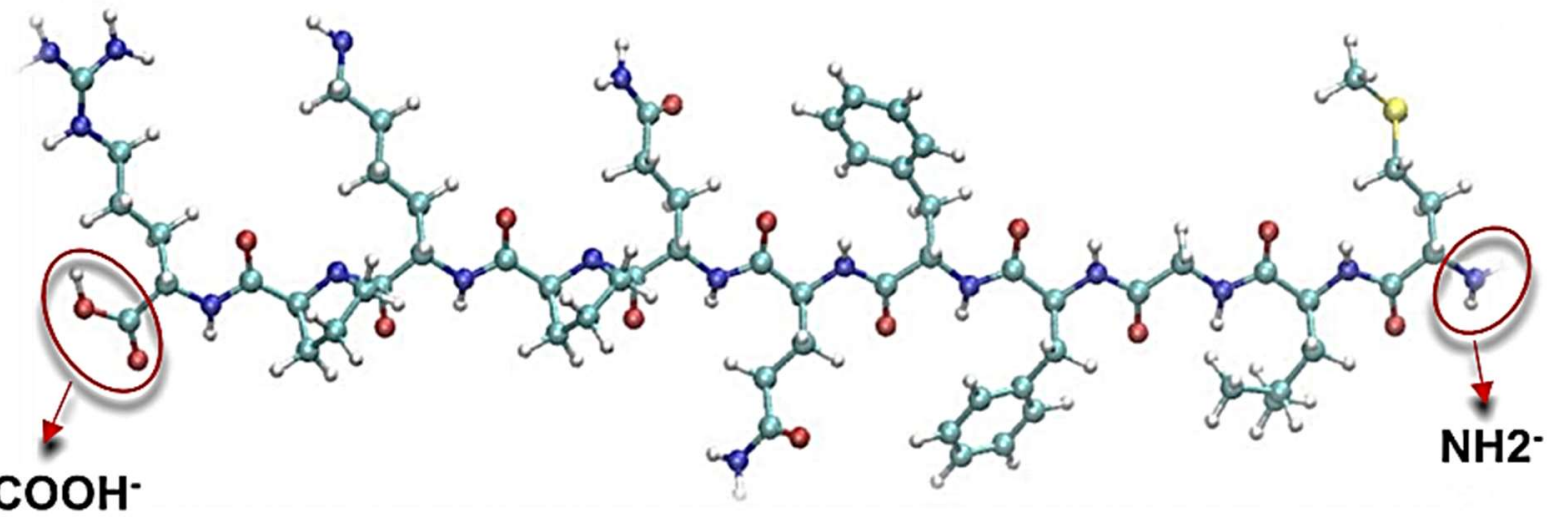

Imagem desenvolvida pelo programa Avogadro destacando as extremidades $\mathrm{COOH}^{-}$e $\mathrm{NH}^{-}$da molécula. Fonte: Carvalho (2016).

Sua origem é dependente do gene pré-protaquicinina-I que expressa quatro formas diferentes de RNAm (Messenger Ribonucleic Acid), das quais duas ( $\beta$ e $\mathrm{y}$ ) codificam tanto a síntese de SP quanto de neuroquinina A, enquanto outras duas ( $\alpha$ e ঠ) codificam somente a síntese SP, processos os quais ocorrem nos ribossomas das células neurais (BRENER, 2009).

Após sintetizada, a SP é armazenada em vesículas e transportada para terminações nervosas centrais e periféricas, locais onde passa por um processo enzimático final, destacando-se nele a endopeptidase neutra, envolvida no metabolismo da SP no cérebro e em tecidos periféricos, e a enzima conversora de angiotensina, que degrada a SP no plasma, no fluido cerebrospinal e na substância negra (HARRISON; GEPPETTI, 2001).

$A S P$, ao lado da neurocinina $A$, neurocinina $B$, neurocinina $\mathrm{K}$ e da neurocinina Y, é um neuropeptídeo da família das taquicininas, hormônios encontrados em 
vertebrados e invertebrados (HARRISON; GEPPETI, 2001). Esses peptídios possuem sequência C-terminal $\left(\mathrm{COOH}^{-}\right)$comum, importante na ativação de receptores neurocinina 1 (NK-1), neurocinina 2 (NK-2) e neurocinina (NK-3), e têm sequência Nterminal ( $\mathrm{NH}^{-}$) distinta, responsável pela especificidade ao receptor (KRAUSE et al., 1987; GUARD; WATSON, 1991; CASCIERI et al., 1992; PAGE, 2004).

Graças aos estudo que se dedicaram a investigar a interação da SP com seus receptores, sabe-se que os do tipo NK-1 possuem preferência para este neuropeptídeo, o que não o impede de atuar também em outras classes de receptores, como o NK-2 e o NK-3 (BRENER, 2009).

As ações da SP decorrentes de sua interação com seus receptores são variadas e ocorrem tanto central como perifericamente, uma vez que é encontrada, por exemplo, em neurônios, fibras mielínicas finas e amielínicas, células vasculares endoteliais, músculos e diferentes tipos de células imunes (MENO; KIYAMA; TOHYAMA, 1993; MAGGI, 1995; REGOLI et al., 1994; LIU et al., 1997; PENNEFATHER et al., 2004).

A SP exerce papel na regulação da inflamação neurogênica e da resposta imune, estando também relacionada com a percepção da dor (HARRISON; GEPPETTI, 2001). Como taquicinina que é, ainda é capaz de modificar a resposta de células inflamatórias, apresentando efeito potencializador da proliferação e diferenciação linfocítica, da secreção de citocinas e da produção de imunoglobulinas, sendo, portanto, um potente imunomodulador (WALSH et al., 1995; HARRISON; GEPPETTI, 2001; HÖKFELT; PERNOW; WAHREN, 2001).

Outras ações da SP incluem a regulação do sistema cardiovascular, a sobrevivência e degeneração neuronial, a regulação de mecanismos respiratórios (MUÑOZ et al., 2008), além de ser responsável pela contração da musculatura lisa e 
esquelética, pela salivação e vasodilatação (QUARTARA; MAGGI, 1988; NOWICKI et al., 2006).

Este neuropeptídeo também é associado à depressão, à doenças degenerativas do sistema nervoso central (QUARTARA; MAGGI, 1988; HARRISON; GEPPETTI, 2001) e do sistema nervoso periférico como, por exemplo, as neuropatias dolorosas, caracterizadas por hiperalgesia persistente HARRISON; GEPPETTI, 2001). Entretanto, não são conhecidas menções a respeito da relação deste neurotransmissor com outras doenças desta classe, como a neuropatia hipertensiva, o que ampliaria a compreensão a cerca dos efeitos de uma PA continuamente elevada sobre o sistema nervoso periférico, mais especificamente, sobre os axônios nos quais este neuropeptídeo se encontra. Existe, portanto, a necessidade de explorarmos tal levantamento utilizando as boas ferramentas experimentais que temos em mãos. 


\subsection{OBJETIVOS GERAIS:}

Os objetivos gerais do presente estudo são identificar a presença de SP, através da técnica de IHQ, e quantificar densidade de fibras mielínicas finas e amielínicas imunomarcadas com esse neurotransmissor em nervo Sural de ratos e ratas das linhagens Spontaneously Hypertensive Rat (SHR) e Wistar Kyoto (WKY), com 20 semanas de vida.

\subsection{OBJETIVOS ESPECÍFICOS:}

- Caracterizar os animais como sendo verdadeiramente hipertensos e normotensos através da análise do peso corporal, da frequencia cardíaca e de dados hemodinâmicos.

- Identificar a presença de SP, através da técnica de IHQ, e quantificar a densidade de fibras mielínicas finas e amielínicas imunomarcadas para esse neurotransmissor nos segmentos proximal e distal dos nervos surais direito e esquerdo de ratos e ratas da linhagem WKY, com 20 semanas de vida.

- Identificar a presença de SP, através da técnica de IHQ, e quantificar a densidade de fibras mielínicas finas e amielínicas imunomarcadas para esse neurotransmissor nos segmentos proximal e distal dos nervos surais direito e esquerdo de ratos e ratas da linhagem SHR, com 20 semanas de vida.

- Comparar os valores da quantificação das fibras mielínicas finas e amielínicas imunomarcadas para SP nos nervos surais de cada gênero das linhagens estudadas, confrontando segmentos proximais com distais de mesmo lado e confrontando segmentos iguais de lados opostos. 
- Comparar os valores da quantificação das fibras mielínicas finas e amielínicas imunomarcadas para SP nos nervos surais dos pares (macho e fêmea) das linhagens estudadas, confrontando mesmos segmentos de mesmos lados.

- Comparar os valores da quantificação das fibras mielínicas finas e amielínicas imunomarcadas para SP nos nervos surais de animais de mesmos gêneros e linhagens diferentes, confrontando mesmos segmentos de mesmos lados. 


\subsection{ANIMAIS}

Foram utilizados 24 ratos machos e fêmeas, das linhagens WKY e SHR, com 20 semanas de vida, pesando entre 200 a $300 \mathrm{~g}$. Os animais foram alojados no biotério do Laboratório de Neurociências e Ciências do Comprotamento da Faculdade de Medicina de Ribeirão Preto (FMRP) da Universidade de São Paulo, sob controle de temperatura $\left(23^{\circ} \mathrm{C} \pm 1^{\circ} \mathrm{C}\right)$, umidade relativa do ar entre 40 e $70 \%$ e ciclo claro/escuro de 12/12 horas. Os animais permaneceram em trios em gaiolas de polipropileno (34 $\mathrm{x}$ $42 \times 37 \mathrm{~cm}$ ) forradas com serragem. Até o dia do experimento, tiveram livre acesso à água e ração padrão para pequenos roedores (Nuvilab CR1 - Nuvital ${ }^{\circledR}$ ).

Os procedimentos aqui descritos estão de acordo com as normas éticas de experimentação animal aprovado pela Comissão de Ética no Uso de Animais (CEUA), sob o protocolo de número 153/2017 (Anexo, seção 8.1).

Os animais foram alocados em 4 grupos independentes, seguindo o seguinte protocolo:

I- Wistar Kyoto Machos (WKY-M): Ratos da linhagem WKY, normotensos, com 20 semanas de vida, cujos segmentos proximais e distais dos nervos surais direito e esquerdo foram submetidos à técnica de IHQ $(n=6)$.

II- Wistar Kyoto Fêmeas (WKY-F): Ratas da linhagem WKY, normotensas, com 20 semanas de vida, cujos segmentos proximais e distais dos nervos surais direito e esquerdo foram submetidos à técnica de $\mathrm{IHQ}(\mathrm{n}=6)$.

III- Spontaneously Hypertensive Rats Machos (SHR-M): Ratos da linhagem SHR, hipertensos, com 20 semanas de vida, cujos segmentos proximais e distais dos nervos surais direito e esquerdo foram submetidos à técnica de IHQ $(n=6)$. 
IV- Spontaneously Hypertensive Rats Fêmeas (SHR-F): Ratas da linhagem SHR, hipertensas, com 20 semanas de vida, cujos segmentos proximais e distais dos nervos surais direito e esquerdo foram submetidos à técnica de IHQ $(n=6)$.

\subsection{PROCEDIMENTO CIRÚRGICO}

Imediatamente antes do experimento, os animais foram pesados, e anestesiados com a associação de quetamina $(75 \mathrm{mg} / \mathrm{Kg})$ e xilazina $(10 \mathrm{mg} / \mathrm{Kg})$, por via intraperitoneal. Os animais foram posicionados na mesa cirúrgica em decúbito dorsal, com as patas fixadas em abdução, e submetidos a cervicotomia para dissecção da artéria carótida direita. Esta foi, então, canulada com um tubo de polietileno PE-10 preenchido com solução salina isotônica $(0,9 \%)$, o qual foi introduzido até a artéria Aorta, para medida direta da pressão arterial. Esse cateter foi conectado a um transdutor de pressão (Statham, $\mathrm{Pb} 23 \mathrm{Db}$ ) e a pressão arterial foi registrada por aproximadamente 5 minutos em um microcomputador IBM/PC, equipado com uma interface analógico-digital (CAD 12/36 Lynx tecnologia Eletrônica). Os valores da pressão arterial sistólica, diastólica e média, bem como a frequência cardíaca, foram obtidos "off-line" a partir dos registros de pressão arterial pulsátil.

Após o término do registro, a sensibilidade dolorosa foi novamente verificada, a fim de constatar a eficácia do anestésico. Em seguida, o animal foi posicionado na mesa cirúrgica em decúbito ventral, para retirada cirúrgica dos nervos surais direito e esquerdo na face posterior dos membros pélvicos, em toda sua extensão, desde sua origem, a partir do nervo isquiático, até o nível do maléolo lateral, imediatamente antes de sua bifurcação para o território cutâneo correspondente (Fig. 10). 
Figura 10: Procedimento cirúrgico para dissecação de nervo Sural do animal
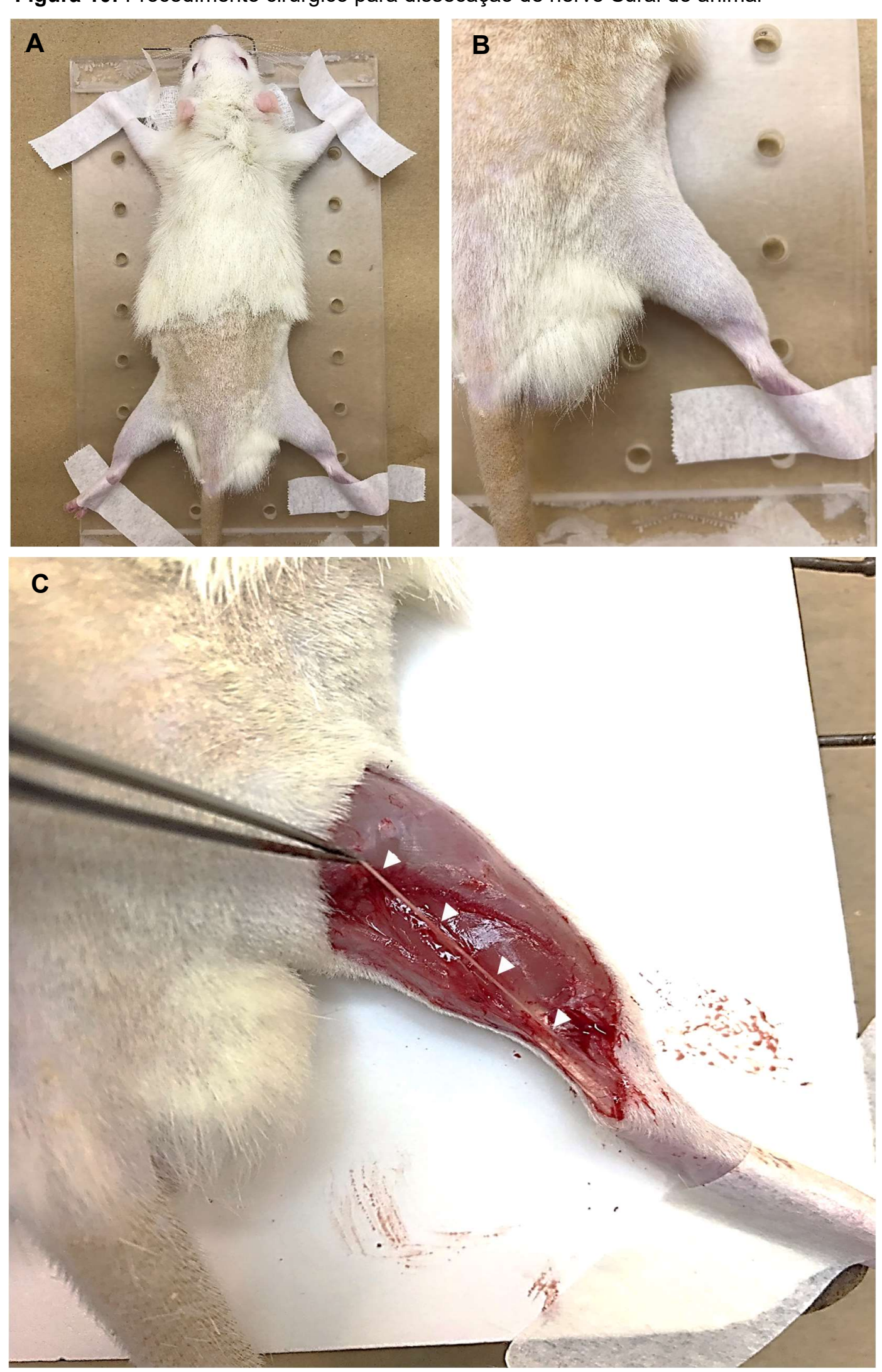

Em (A) animal posicionado em decúbito ventral; em (B) destaque para o membro pélvico, local de interesse cirúrgico e em (C) nervo Sural exposto sendo indicado pelas cabeças de seta brancas. 
Ao término da cirurgia, como método de eutanásia, os animais foram submetidos à dose excessiva de anestésico, neste caso foi usado o triplo do volume aplicado anteriormente.

Caso fosse notado sofrimento dos animais antes do período previsto para a data do experimento, estes eram eutanasiados com inalação de gás carbônico.

\subsection{PROCEDIMENTO HISTOLÓGICO}

Os nervos surais dissecados foram estendidos sobre uma tira de papel filtro, para evitar retração dos mesmos, separados em segmentos proximal e distal (Fig. 11) para, então, serem imersos em solução fixadora composta por paraformoldeído (4\%) em tampão fosfato de sódio $0.2 \mathrm{M}, \mathrm{pH} 7.4$, por 16 horas a $4^{\circ} \mathrm{C}$, preparada imediatamente antes do procedimento cirúrgico.

Figura 11: Nervo Sural dissecado

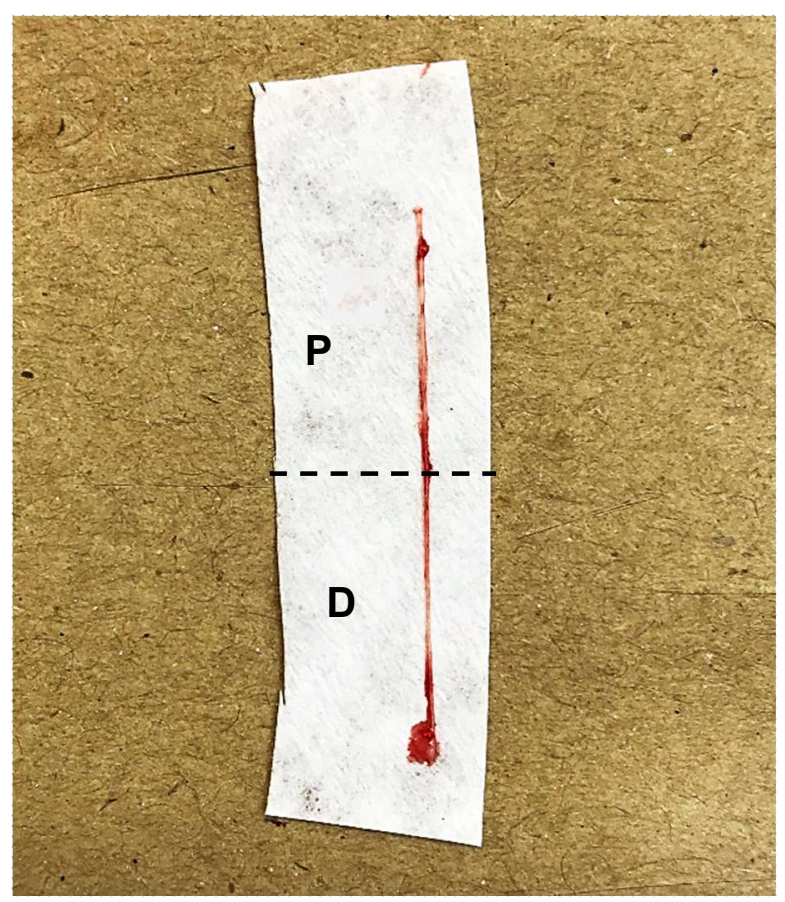

Nervo Sural dissecado, estendido sobre papel filtro e representativamente separado pela linha tracejada em segmentos proximal (P) e distal (D). 
Após esta etapa, os segmentos dos nervos foram imersos em concentrações crescentes de sacarose a $10 \%$ por 4 horas a $4^{\circ} \mathrm{C}$ e a $20 \%$ overnight também à $4^{\circ} \mathrm{C}$. Posteriormente, esse material foi congelado em OCT (Optimal Cutting Temperature), Acetona (A.C.S.) e gelo seco, sendo armazenado a $-20^{\circ} \mathrm{C}$, até o momento do corte do material para futura análise por IHQ.

\subsection{IMUNOHISTOQUÍMICA PARA SUBSTÂNCIA P}

Os segmentos dos nervos surais congelados em OCT foram cortados sequencialmente em toda sua extensão em secções longitudinais com $10 \mu \mathrm{m}$ de espessura. Para isso, foi utilizado um equipamento Criostato (CM 1850 UV - Leica Biosystems, Ltda) a $-19^{\circ} \mathrm{C}$. Os cortes foram posicionados em lâminas silanizadas (Starfrost, Waldemar Knittel, Alemanha). Nesse processo, foram obtidas 6 lâminas para cada segmento do nervo, sendo que as secções foram nelas posicionadas horizontalmente até o máximo de 8 secções por lâmina, as quais passaram por secagem em câmara de vácuo por 3 horas antes de iniciar as etapas da IHQ.

Após a secagem das lâminas, iniciou-se a IHQ para caracterização da SP. Inicialmente, os criocortes foram lavados com Tris-PBS-Triton (IB) (3 lavagens, 10 minutos) seguida de bloqueio com soro de cavalo (NHS) a $10 \%$ em IB, por 40 minutos sob temperatura controlada $\left(20^{\circ} \mathrm{C}\right)$. Em seguida, fez-se a incubação com o anticorpo primário policlonal de coelho anti-substância-P (Abcam - ab 67006), diluído em soro de cavalo $10 \%$ NHS-IB (1:5000), por 20 horas à $4^{\circ} \mathrm{C}$.

Finalizada a incubação com o anticorpo primário, o material foi lavado com TrisPBS (pH 7.4) (3 lavagens, 10 minutos) seguida por incubação com o anticorpo secundário biotinilado (anti-lgG de coelho, Jackson Immuno Research), diluído em soro de cavalo $1 \%$ NHS-IB (1:500), por 2 horas sob temperatura controlada $\left(20^{\circ} \mathrm{C}\right)$. 
Após serem lavadas com Tris-PBS (pH 7.4) (3 lavagens, 10 minutos), as secções foram incubadas em solução contendo Estreptavidina-Peroxidase HRP (SigmaAldrich) diluída em IB (1:1500) por 2 horas sob temperatura controlada $\left(20^{\circ} \mathrm{C}\right)$. A revelação foi feita em solução de diaminobenzidina intensificada com níquel (Ni-DAB),

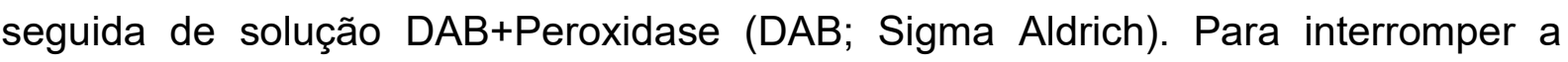
reação, as secções foram lavadas em Tris-PBS ( $\mathrm{pH} 7.4$ ) (1 lavagem, 1 minuto) seguida por lavagem em água Milli-Q (1 lavagem, 1 minuto).

Todas as etapas de incubação e de revelação foram realizadas em câmara úmida sob temperatura controlada, a fim de evitar o ressecamento do material biológico.

Após a revelação da reação, as lâminas foram desidratadas em concentrações crescentes de etanol $(25 \%, 35 \%, 50 \%, 70 \%, 75 \%, 80 \%, 95 \%$, e duas vezes em $100 \%$, 1 minuto cada etapa, diafanizadas com xilol puro (duas vezes, 1 minuto cada etapa) e montadas, sendo cobertas com Permount ${ }^{\circledR}$ (Fisher Scientific) e lamínula.

Todas as reações foram acompanhadas por lâminas de controles negativos, onde os anticorpos primários e secundários foram omitidos, procedimento que assegura a especificidade e a reprodutibilidade do método.

Este protocolo de imunomarcação utilizado foi primeiramente descrito por Llewellyn-Smith et al. (1989) e adaptado por Giorgetto et al. (2018).

\subsection{ANÁLISE HISTOLÓGICA}

As secções dos nervos surais submetidas à técnica de IHQ empregada neste trabalho foram observadas em um microscópio de luz Axiophot II light microscope (Carl Zeiss) usando lentes de 40x em imersão em óleo. Quando necessário, lentes auxiliares (optovar 1.6x) foram usadas para prover ganhos nas imagens. As imagens 
foram digitalizadas usando uma câmera de alta resolução (Modelo Axiocam MRc) anexada ao microcomputador (IBM /PC).

Após o processo de digitalização, foi realizado cálculo de densidade de marcação através do programa Image J (versão 1.49, National Institute of Health, Wayne Rasband, EUA). A quantidade de pixels foi sistematicamente mensurada em todas as secções dos segmentos proximal e distal dos nervos surais direito e esquerdo, considerando seu comprimento total. Ao final desta quantificação, foi obtida a média dos valores de densidade de marcação de fibras mielínicas finas e amielínicas imonomarcadas para SP para cada segmento de cada lado, as quais foram normalizadas para $50 \mu \mathrm{m}^{2}$.

\subsection{ANÁLISE ESTATÍSTICA}

Todos os testes estatísticos citados a seguir foram realizados utilizando o aplicativo SigmaPlot, versão 11.0, (Systat 2011).

O teste de Kolmogorov-Smirnov foi aplicado para testar a normalidade da distribuição de todo os dados obtidos. Em seguida a equivalência das variâncias foi testada automaticamente, através do teste de medianas de Levene, antes de prosseguir com o teste desejado.

A análise estatística do peso corporal, da frequência cardíaca e também dos dados hemodinâmicos consistiu da aplicação do teste t de student não pareado para dados com distribuição normal ou teste de Mann-Whitney para dados com distribuição não normal ou que não passaram no teste de equivalência das variâncias.

A comparação entre segmentos proximais entre lados, entre segmentos distais entre lados, bem como as comparações entre diferentes gêneros de mesma linhagem e entre mesmos gêneros de linhagens distintas foram realizada através do teste $t$ de 
Student não pareado para dados com distribuição normal ou teste de Mann-Whitney para dados com distribuição não normal ou que não passaram pelo teste de equivalência das variâncias.

A comparação entre segmentos proximal e distal de um mesmo lado foi realizada através do teste t de Student pareado para dados com distribuição normal ou teste de Wilcoxon para dados com distribuição não normal ou que não passaram pelo teste de equivalência das variâncias.

Os resultados foram considerados diferentes estatisticamente para $p<0,05$. 
4. RESULTADOS 


\subsection{PESO CORPORAL}

A figura 12 mostra os valores médios do peso corporal em gramas dos animais dos grupos WKY-M, WKY-F, SHR-M e SHR-F obtidos imediatamente antes do procedimento cirúrgico. Observamos diferenças significativas $(p<0.05)$ entre WKY-M e WKY-F, entre WKY-M e SHR-M, entre WKY-F e SHR-F e entre SHR-M e SHR-F, sendo os WKY mais pesados que os SHR em ambos os gêneros e os machos mais pesados que as fêmeas em ambas as linhagens.

Figura 12- Comparação dos pesos corporais entre os grupos experimentais.

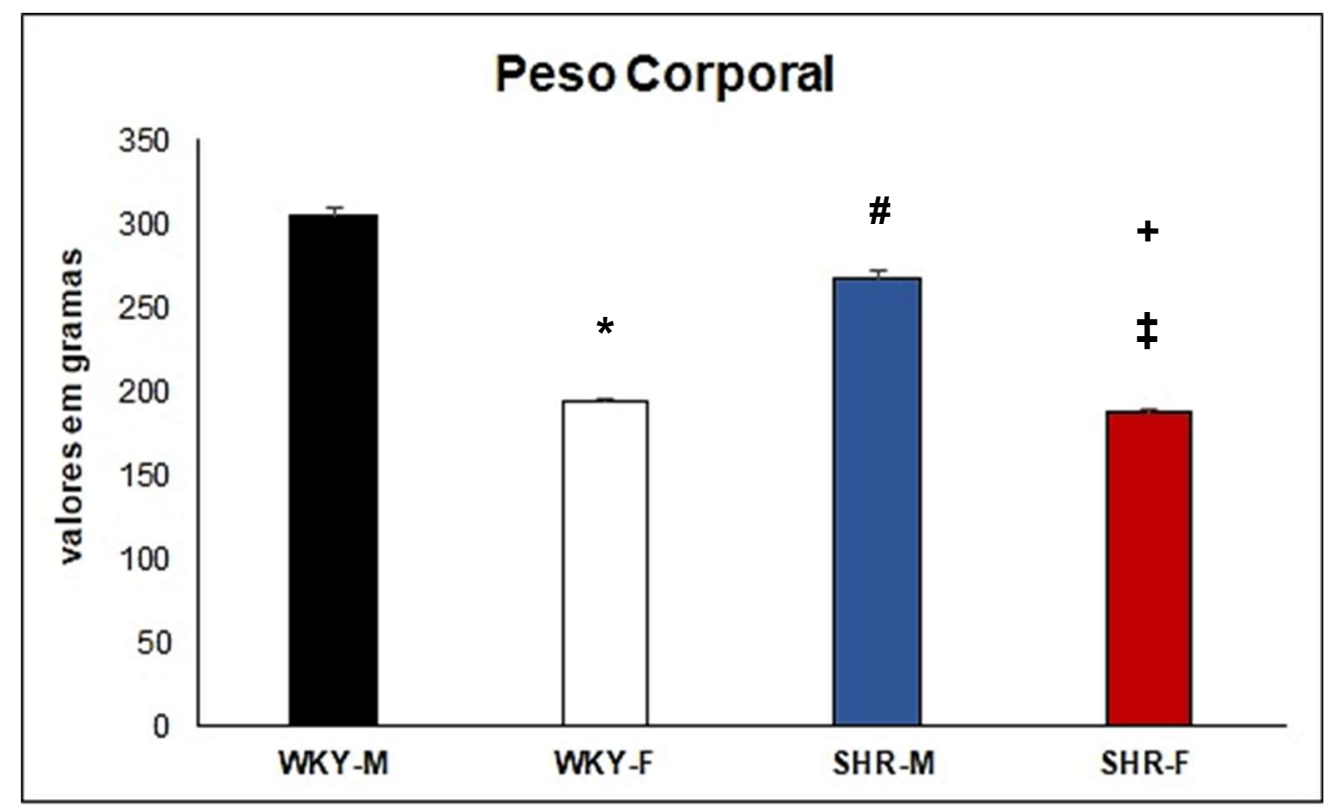

As colunas representam a média do peso corporal dos animais em gramas e as barras representam o erro padrão \pm da média (EPM). * em relação a WKY-M, \# em relação a WKY- M, + em relação a WKY-F e $\ddagger$ em relação a SHR-M. $p<0.05$ teste $t$ de student não pareado para dados com distribuição normal ou teste de Mann-Whitney para dados com distribuição não normal. WKY-M = ratos da linhagem WKY; WKY-F= ratas da linhagem WKY; SHR-M= ratos da linhagem SHR; SHR-F= ratas da linhagem SHR. 


\subsection{FREQUÊNCIA CARDÍACA}

A figura 13 mostra os valores médios da frequência cardíaca (FC) dos animais dos grupos WKY-M, WKY-F, SHR-M e SHR-F. Para estes dados, observamos aumento significativo $(p<0.05)$ de SHR-M em relação a WKY-M e a SHR-F e de SHR-F em relação a WKY-F.

Figura 13- Comparação da frequência cardíaca entre grupos experimentais

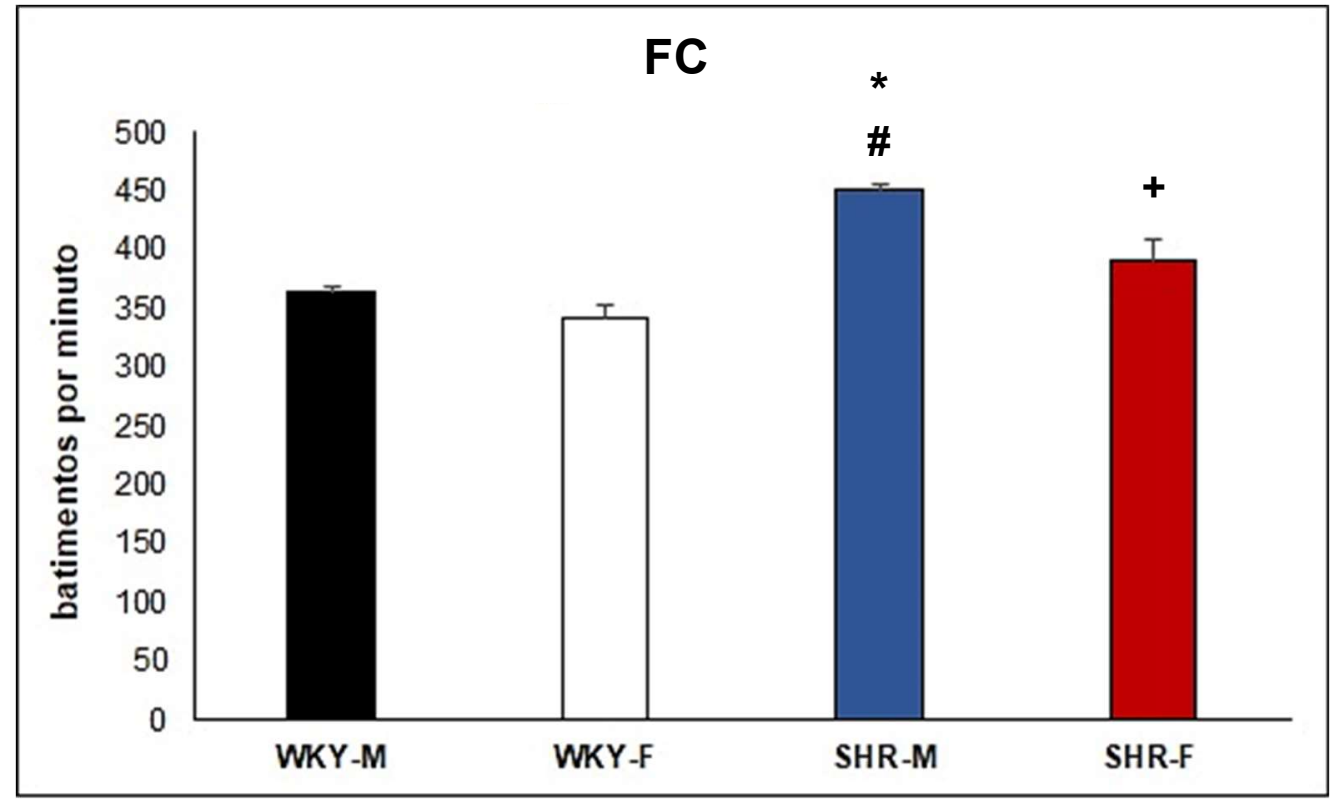

As colunas representam a média da frequência cardíaca dos animais em batimentos por minuto e as barras representam o erro padrão \pm da média (EPM). * em relação a WKY- $M$, \# em relação a SHR-F, + em relação a WKY-F. p<0.05 teste t de student não pareado para dados com distribuição normal ou teste de Mann-Whitney para dados com distribuição não normal. WKY-M = ratos da linhagem WKY; WKY-F= ratas da linhagem WKY; SHR-M= ratos da linhagem SHR; SHR-F= ratas da linhagem SHR. 


\subsection{DADOS HEMODINÂMICOS}

\subsubsection{Pressão arterial sistólica}

A figura 14 mostra os valores médios da pressão arterial sistólica (PAS) dos animais dos grupos WKY-M, WKY-F, SHR-M e SHR-F. Para estes dados, observamos aumento significativo $(p<0.05)$ de SHR-M em relação a WKY-M e a SHR-F e de SHR$\mathrm{F}$ em relação a WKY-F.

Figura 14- Comparação da pressão arterial sistólica entre os grupos experimentais

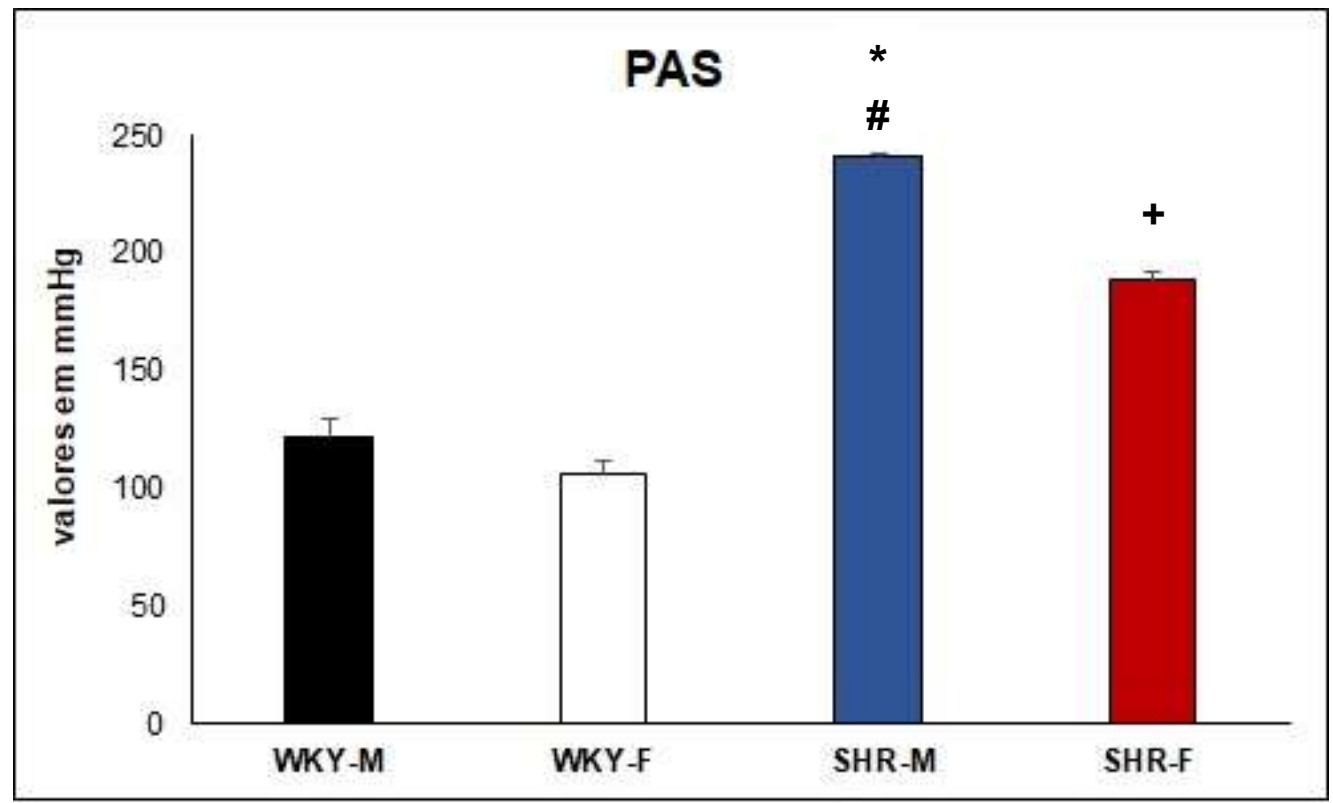

As colunas representam a média da PAS dos animais em milímetros de mercúrio $(\mathrm{mmHg})$ e as barras representam o erro padrão \pm da média $(E P M)$. * em relação a WKY-M, \# em relação a SHR-F e + em relação a WKY-F. $p<0.05$ teste $t$ de student não pareado para dados com distribuição normal ou teste de Mann-Whitney para dados com distribuição não normal. WKY-M= ratos da linhagem WKY; WKY-F= ratas da linhagem WKY; SHR-M= ratos da linhagem SHR; SHR-F= ratas da linhagem SHR. 


\subsubsection{Pressão arterial diastólica}

A figura 15 mostra os valores médios da pressão arterial diastólica (PAD) dos animais dos grupos WKY-M, WKY-F, SHR-M e SHR-F. Para estes dados, observamos aumento significativo $(p<0.05)$ de SHR- M em relação a WKY-M e de SHR-F em relação a WKY-F.

Figura 15- Comparação da pressão arterial diastólica entre os grupos experimentais.

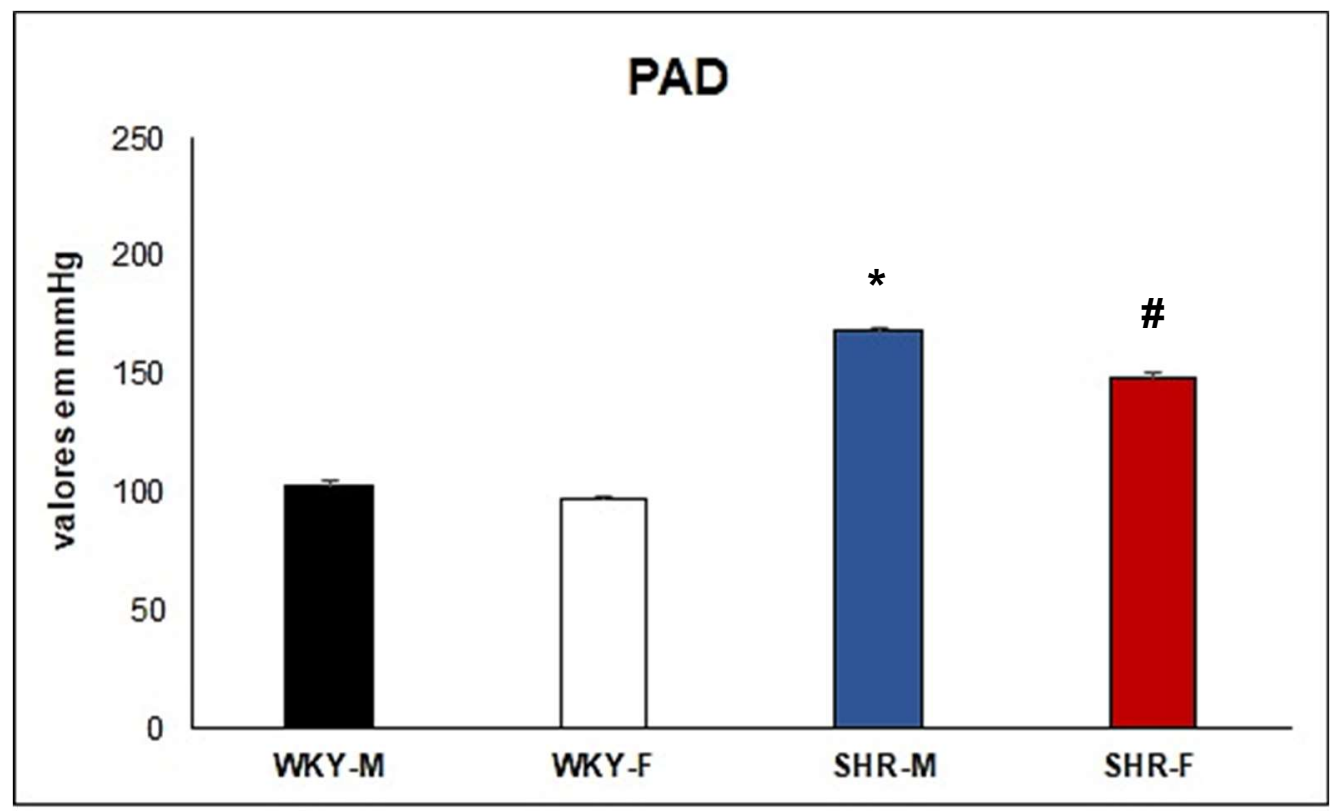

As colunas representam a média da PAD dos animais em milímetros de mercúrio $(\mathrm{mmHg})$ e as barras representam o erro padrão \pm da média (EPM). * em relação a WKY-M, \# em relação a WKY-F. $p<0.05$ teste $t$ de student não pareado para dados com distribuição normal ou teste de Mann-Whitney para dados com distribuição não normal. WKY-M = ratos da linhagem WKY ; WKY-F= ratas da linhagem WKY; SHR-M= ratos da linhagem SHR; SHR-F= ratas da linhagem SHR.

\subsubsection{Pressão arterial média}

A figura 16 mostra os valores médios entre as pressões arteriais sistólica e diastólica (PAM) dos animais dos grupos WKY-M, WKY-F, SHR-M e SHR-F. Para 
estes dados, observamos aumento significativo $(p<0.05)$ de SHR-M em relação a WKY-M e de SHR-F em relação a WKY-F.

Figura 16- Comparação da média das pressões cardíacas entre os grupos experimentais.

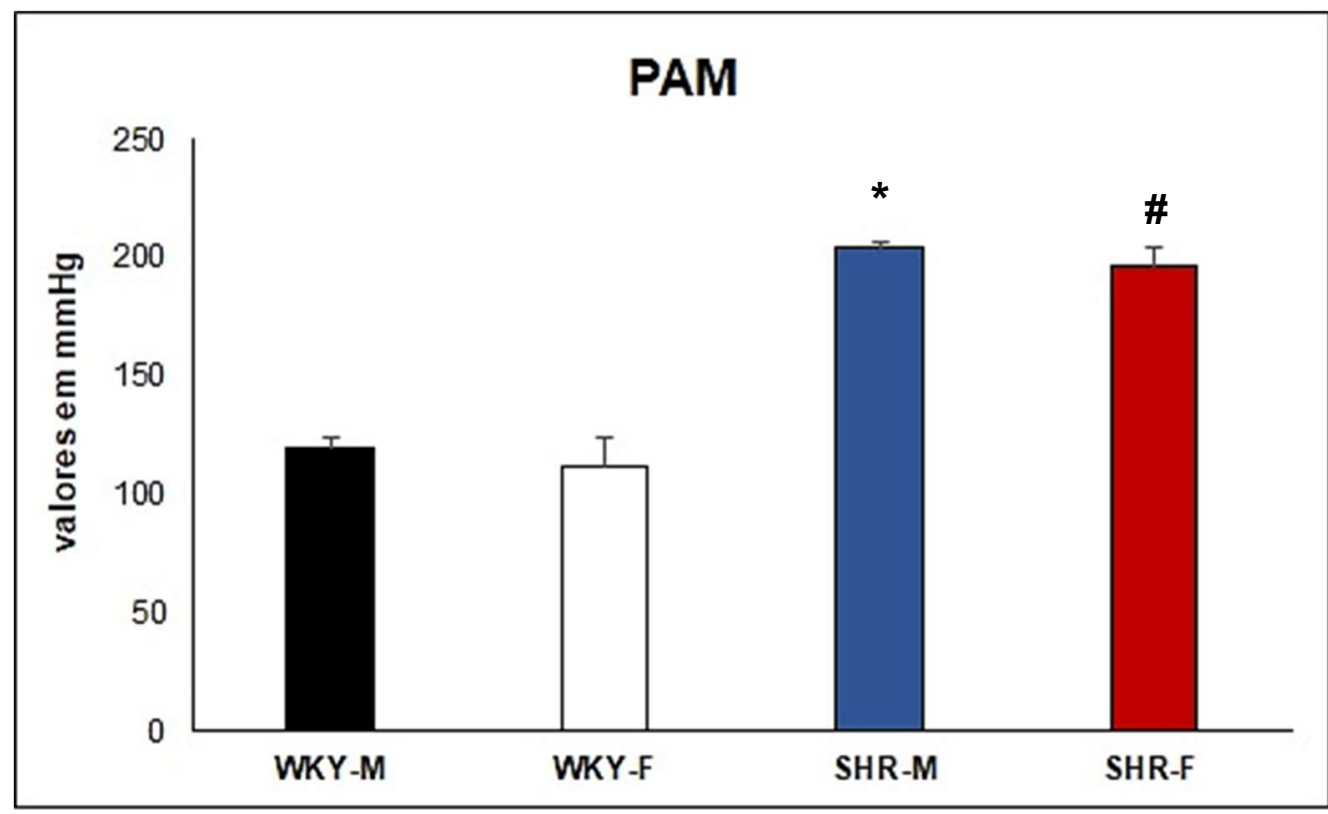

As colunas representam a média da PAM dos animais em milímetros de mercúrio $(\mathrm{mmHg})$ e as barras representam o erro padrão \pm da média (EPM). * em relação a WKY- M e \# em relação a WKYF. $p<0.05$ teste $t$ de student não pareado para dados com distribuição normal ou teste de Mann-Whitney para dados com distribuição não normal. WKY-M = ratos da linhagem WKY; WKY-F= ratas da linhagem WKY; SHR-M= ratos da linhagem SHR; SHR-F= ratas da linhagem SHR.

\subsection{DENSIDADE DE FIBRAS IMUNOMARCADAS PARA SUBSTÂNCIA P}

\subsubsection{Análises intragrupo: ratos da linhagem WKY}

A figura 17 mostra os valores médios da densidade de fibras mielínicas finas e amielínicas imunomarcadas para SP nos segmentos proximal e distal dos nervos surais direito e esquerdo dos animais do grupo WKY-M. As comparações entre segmentos de mesmo lado e entre mesmos segmentos de lados opostos não 
revelaram diferenças estatisticamente significativas $(p \geq 0,05)$ para os animais deste grupo.

Figura 17- Comparação da densidade de fibras imunomarcadas nos animais do grupo WKY-M

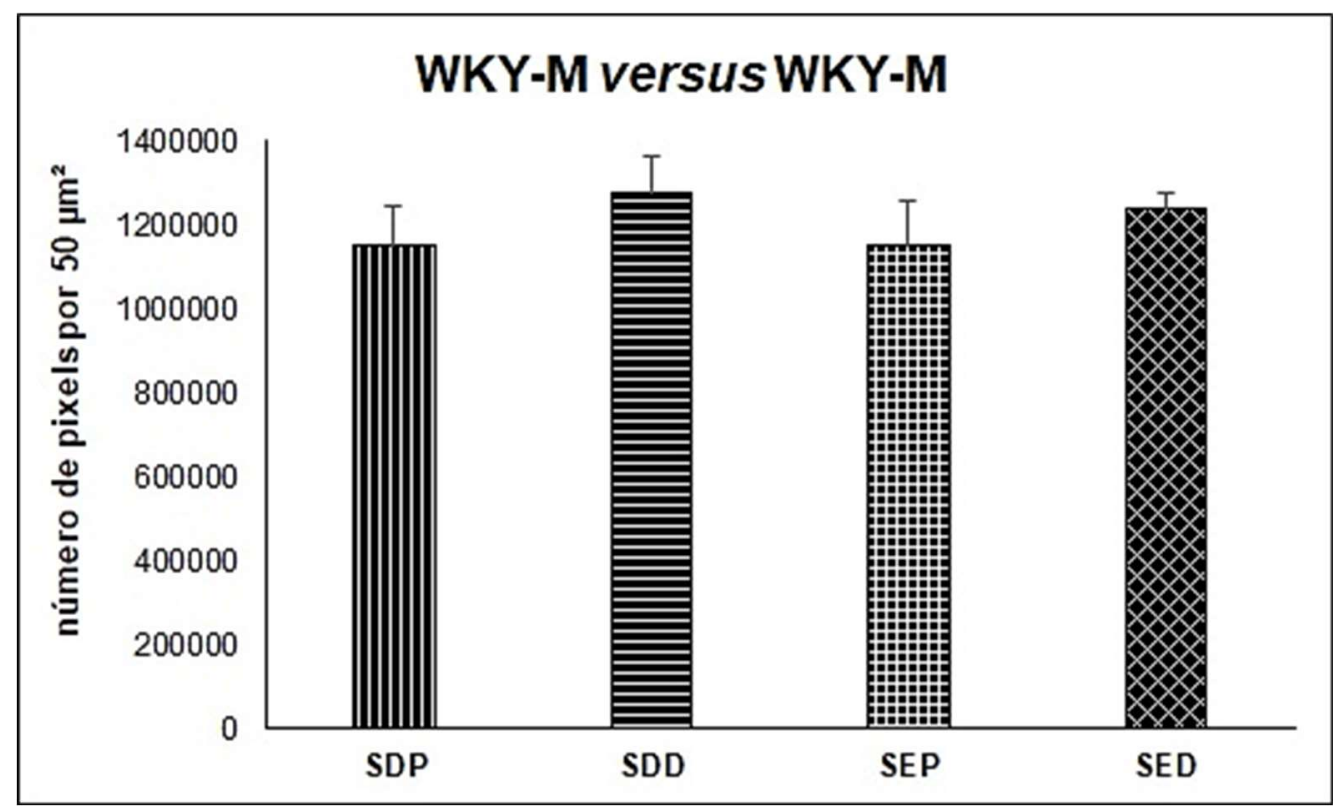

As colunas representam a média da densidade das fibras mielínicas finas e amielínicas imunomarcadas para SP, dada em número de pixels por $50 \mu \mathrm{m}^{2}$, nos segmentos proximal e distal dos nervos surais direito e esquerdo dos animais do grupo WKY-M e as barras representam o erro padrão \pm da média (EPM). $p \geq 0.05$ teste $t$ de student não pareado para dados com distribuição normal ou teste de Mann-Whitney para dados com distribuição não normal ou que não passaram no teste de equivalência das variâncias. $p \geq 0.05$ teste t de Student não pareado para dados com distribuição normal ou teste de Mann-Whitney para dados com distribuição não normal ou que não passaram pelo teste de equivalência das variâncias. $S D P=$ Sural direito proximal; $S D D=$ Sural direito distal; SEP= Sural esquerdo proximal; SED= Sural esquerdo distal . 
Figura 18- Fotomicrografias aleatoriamente selecionadas de cortes longitudinais de nervos surais de animais representativos do grupo WKY-M.

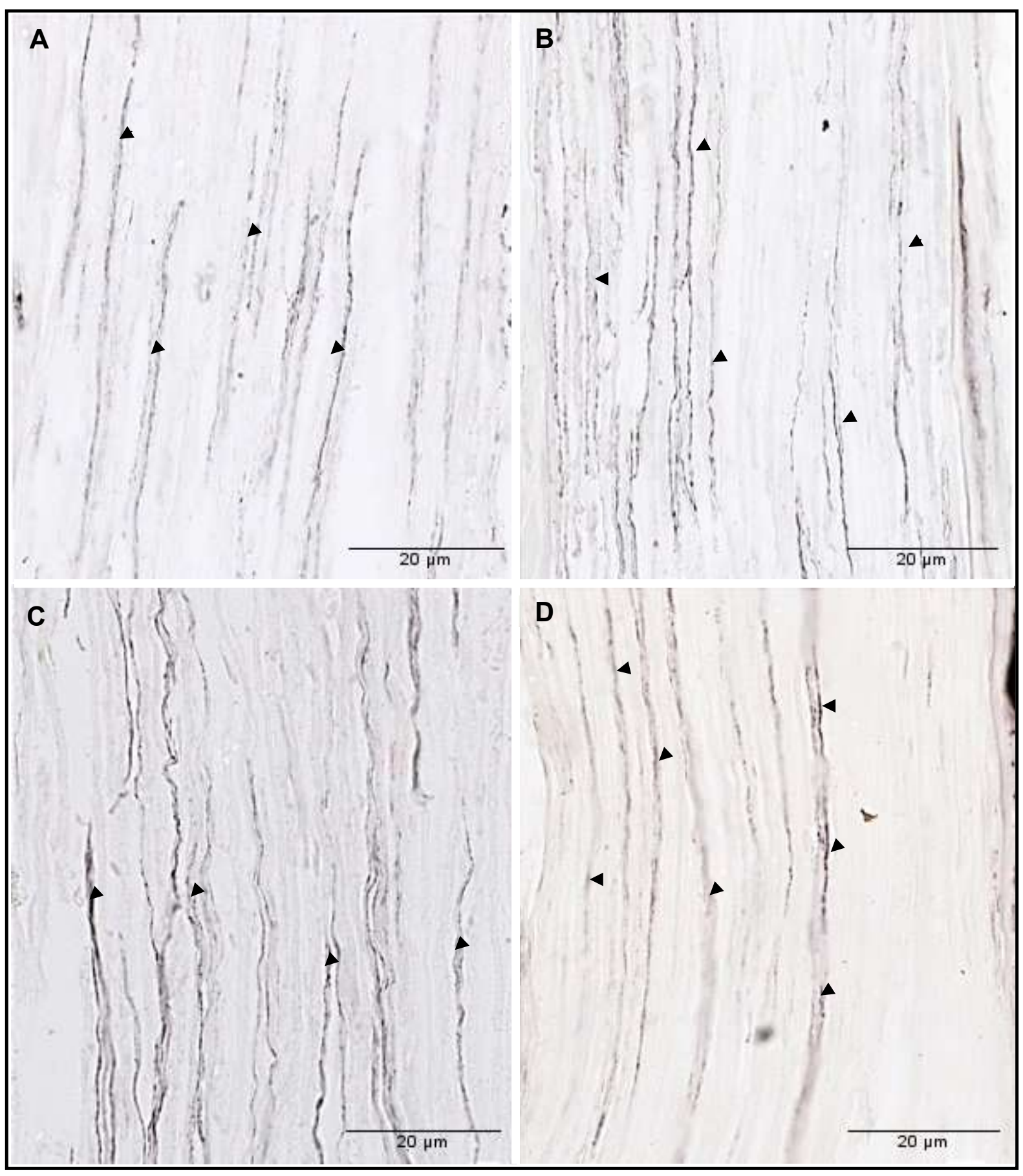

Em (A) segmento proximal do nervo Sural direito, (B) segmento distal do nervo Sural direito, (C) segmento proximal do nervo Sural esquerdo e em (D) segmento distal do nervo Sural esquerdo. As cabeças de setas sinalizam granulações positivas a SP. 


\subsubsection{Análises intragrupo: ratas da linhagem WKY}

A figura 19 mostra os valores médios da densidade de fibras mielínicas finas e amielínicas imunomarcadas para SP nos segmentos proximal e distal dos nervos surais direito e esquerdo dos animais do grupo WKY-F. Assim como observado na análise anterior, as comparações entre segmentos de mesmo lado e entre mesmos segmentos de lados opostos também não revelaram diferenças estatisticamente significativas $(p \geq 0,05)$ para os animais deste grupo.

Figura 19- Comparação da densidade de fibras imunomarcadas nos animais do grupo WKY-F

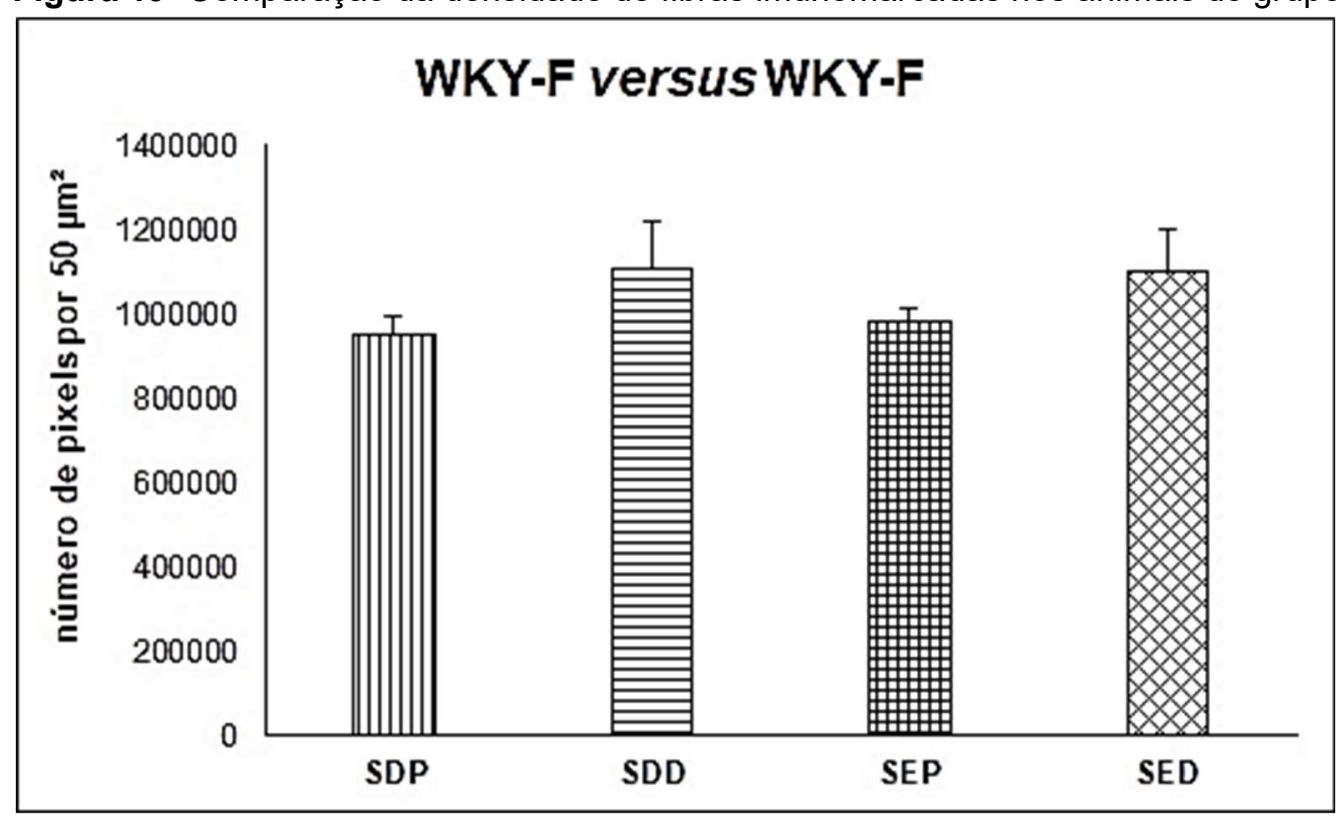

As colunas representam a média da densidade das fibras mielínicas finas e amielínicas imunomarcadas para SP, dada em número de pixels por $50 \mu \mathrm{m}^{2}$, nos segmentos proximal e distal dos nervos surais direito e esquerdo dos animais do grupo WKY-F e as barras representam o erro padrão \pm da média (EPM). $p \geq 0.05$ teste $t$ de student não pareado para dados com distribuição normal ou teste de Mann-Whitney para dados com distribuição não normal ou que não passaram no teste de equivalência das variâncias. $p \geq 0.05$ teste t de Student não pareado para dados com distribuição normal ou teste de Mann-Whitney para dados com distribuição não normal ou que não passaram pelo teste de equivalência das variâncias. SDP= Sural direito proximal; SDD= Sural direito distal; SEP= Sural esquerdo proximal; SED= Sural esquerdo distal. 
Figura 20- Fotomicrografias aleatoriamente selecionadas de cortes longitudinais de nervos surais de animais representativos do grupo WKY-F.

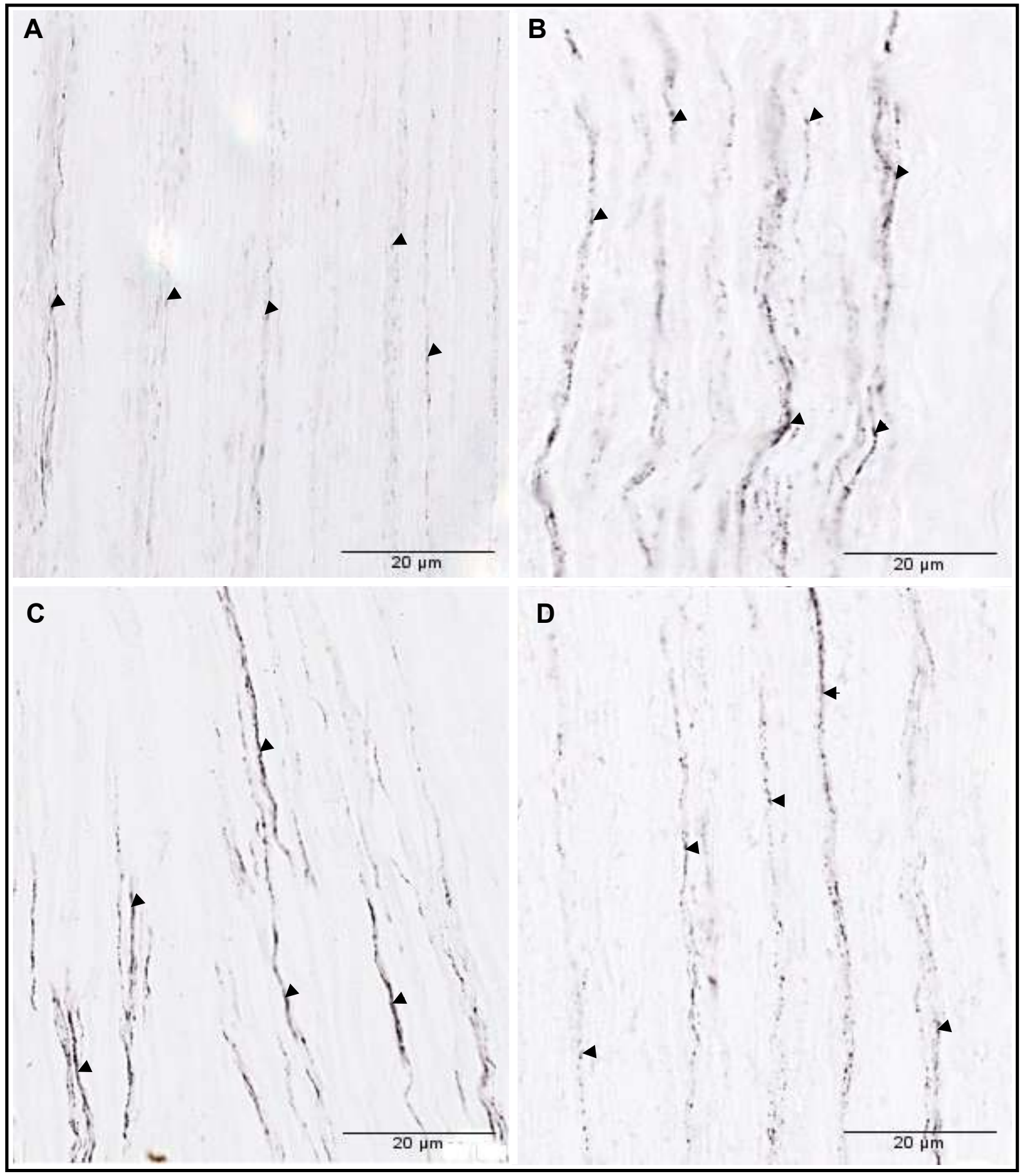

Em (A) segmento proximal do nervo Sural direito, (B) segmento distal do nervo Sural direito, (C) segmento proximal do nervo Sural esquerdo e em (D) segmento distal do nervo Sural esquerdo. As cabeças de setas sinalizam granulações positivas a SP. 


\subsubsection{Análises intergrupos: ratos e ratas da linhagem WKY}

A figura 21 mostra os valores médios da densidade de fibras mielínicas finas e amielínicas imunomarcadas para SP nos segmentos proximal e distal dos nervos surais direito e esquerdo dos animais dos grupos WKY-M e WKY-F. As comparações entre mesmos segmentos de mesmos lados não revelaram diferenças estatisticamente significativas $(p \geq 0,05)$ entre os gêneros da linhagem de animais normotensos.

Figura 21- Comparação da densidade de fibras imunomarcadas entre os grupos WKY-M e WKY-F

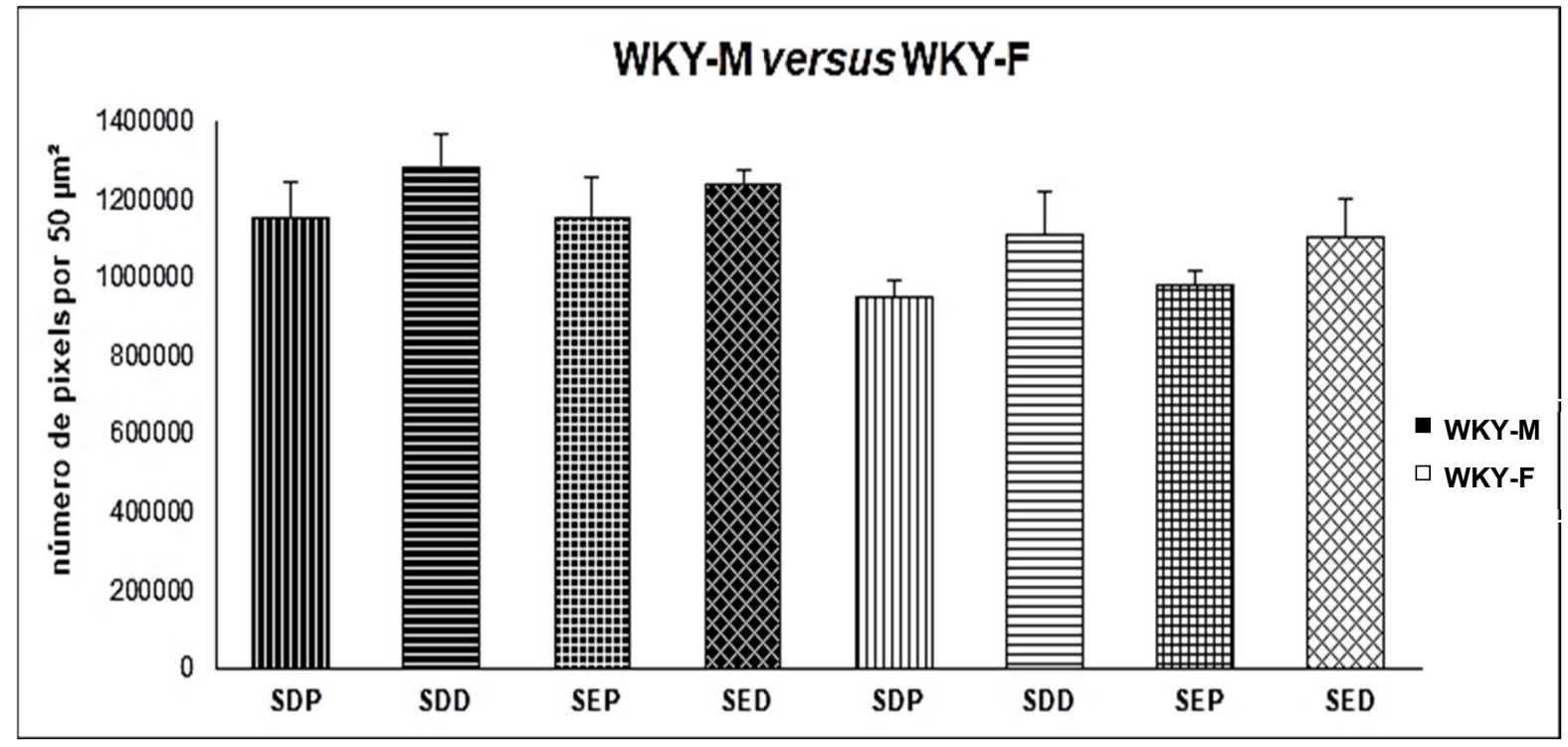

As colunas representam a média da densidade das fibras mielínicas finas e amielínicas imunomarcadas para SP, dada em número de pixels por $50 \mu \mathrm{m}^{2}$, nos segmentos proximal e distal dos nervos surais direito e esquerdo dos animais dos grupos WKY-M e WKY-F e as barras representam o erro padrão \pm da média (EPM). $p \geq 0.05$ teste $t$ de Student não pareado para dados com distribuição normal ou teste de Mann-Whitney para dados com distribuição não normal ou que não passaram pelo teste de equivalência das variâncias. SDP= Sural direito proximal; SDD= Sural direito distal; $S E P=$ Sural esquerdo proximal; SED= Sural esquerdo distal. 


\subsubsection{Análises intragrupo: ratos da linhagem SHR}

A figura 22 mostra os valores médios da densidade de fibras mielínicas finas e amielínicas imunomarcadas para SP nos segmentos proximal e distal dos nervos surais direito e esquerdo dos animais do grupo SHR-M. As comparações entre segmentos de mesmo lado e entre mesmos segmentos de lados opostos não revelaram diferenças estatisticamente significativas $(p \geq 0,05)$ para os animais deste grupo.

Figura 22- Comparação da densidade de fibras imunomarcadas no grupo SHR-M

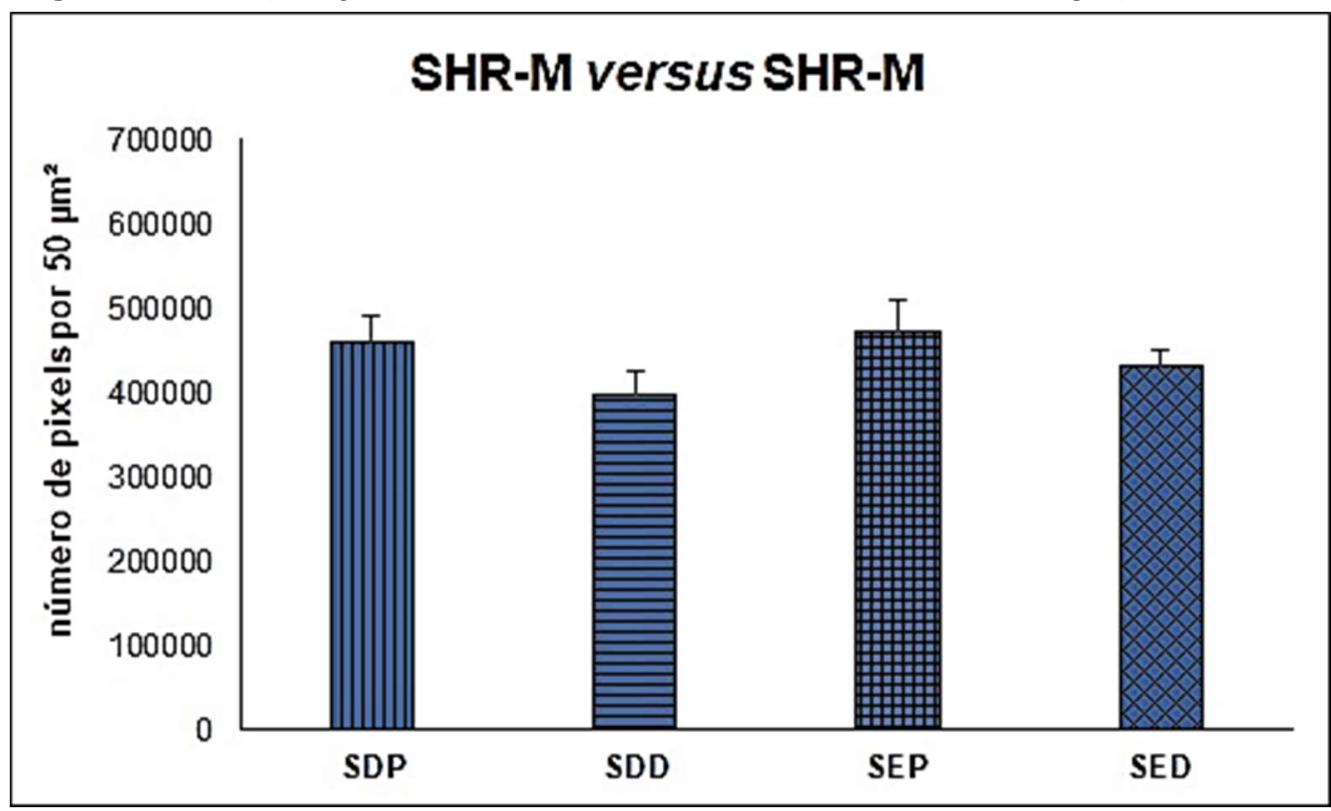

As colunas representam a média da densidade das fibras mielínicas finas e amielínicas imunomarcadas para SP, dada em número de pixels por $50 \mu \mathrm{m}^{2}$, nos segmentos proximal e distal dos nervos surais direito e esquerdo dos animais do grupo SHR-M e as barras representam o erro padrão \pm da média (EPM). $p \geq 0.05$ teste $t$ de student não pareado para dados com distribuição normal ou teste de Mann-Whitney para dados com distribuição não normal ou que não passaram no teste de equivalência das variâncias. $p \geq 0.05$ teste t de Student não pareado para dados com distribuição normal ou teste de Mann-Whitney para dados com distribuição não normal ou que não passaram pelo teste de equivalência das variâncias. $\mathrm{SDP}=$ ural direito proximal; $\mathrm{SDD}=$ sural direito distal; $\mathrm{SEP}=$ sural esquerdo proximal; SED= sural esquerdo distal. 
Figura 23- Fotomicrografias aleatoriamente selecionadas de cortes longitudinais de nervos surais de animais representativos do grupo SHR-M.

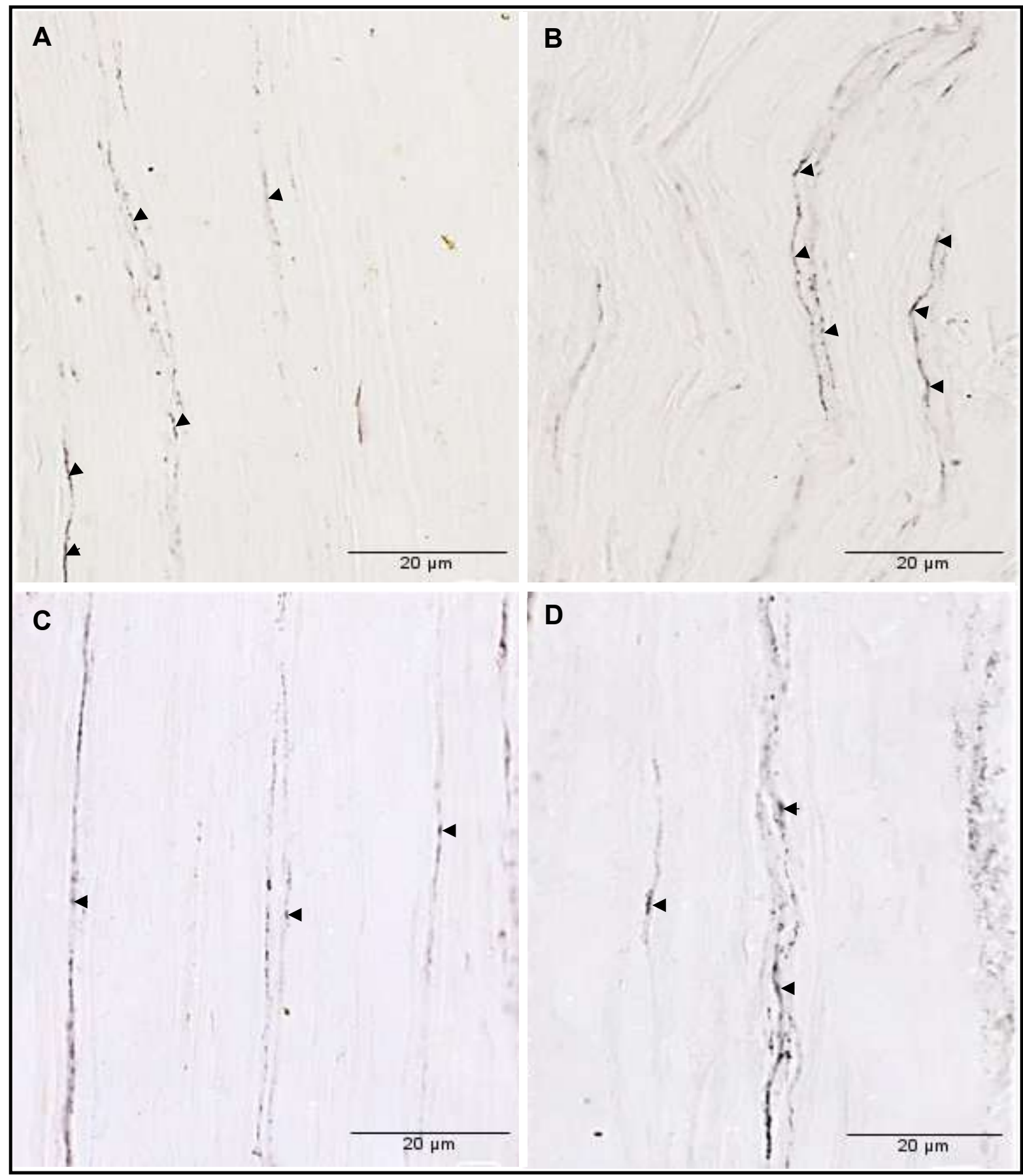

Em (A) segmento proximal do nervo Sural direito, (B) segmento distal do nervo Sural direito, (C) segmento proximal do nervo Sural esquerdo e em (D) segmento distal do nervo Sural esquerdo. As cabeças de setas sinalizam granulações positivas a SP. 


\subsubsection{Análises intragrupo: ratas da linhagem SHR}

A figura 24 mostra os valores médios da densidade de fibras mielínicas finas e amielínicas imunomarcadas para SP nos segmentos proximal e distal dos nervos surais direito e esquerdo dos animais do grupo SHR-F. Seguindo mesmo padrão da análise anterior, as comparações entre segmentos de mesmo lado e entre mesmos segmentos de lados opostos também não revelaram diferenças estatisticamente significativas $(p \geq 0,05)$ para os animais deste grupo.

Figura 24- Comparação da densidade de fibras imunomarcadas nos animais do grupo SHR-F

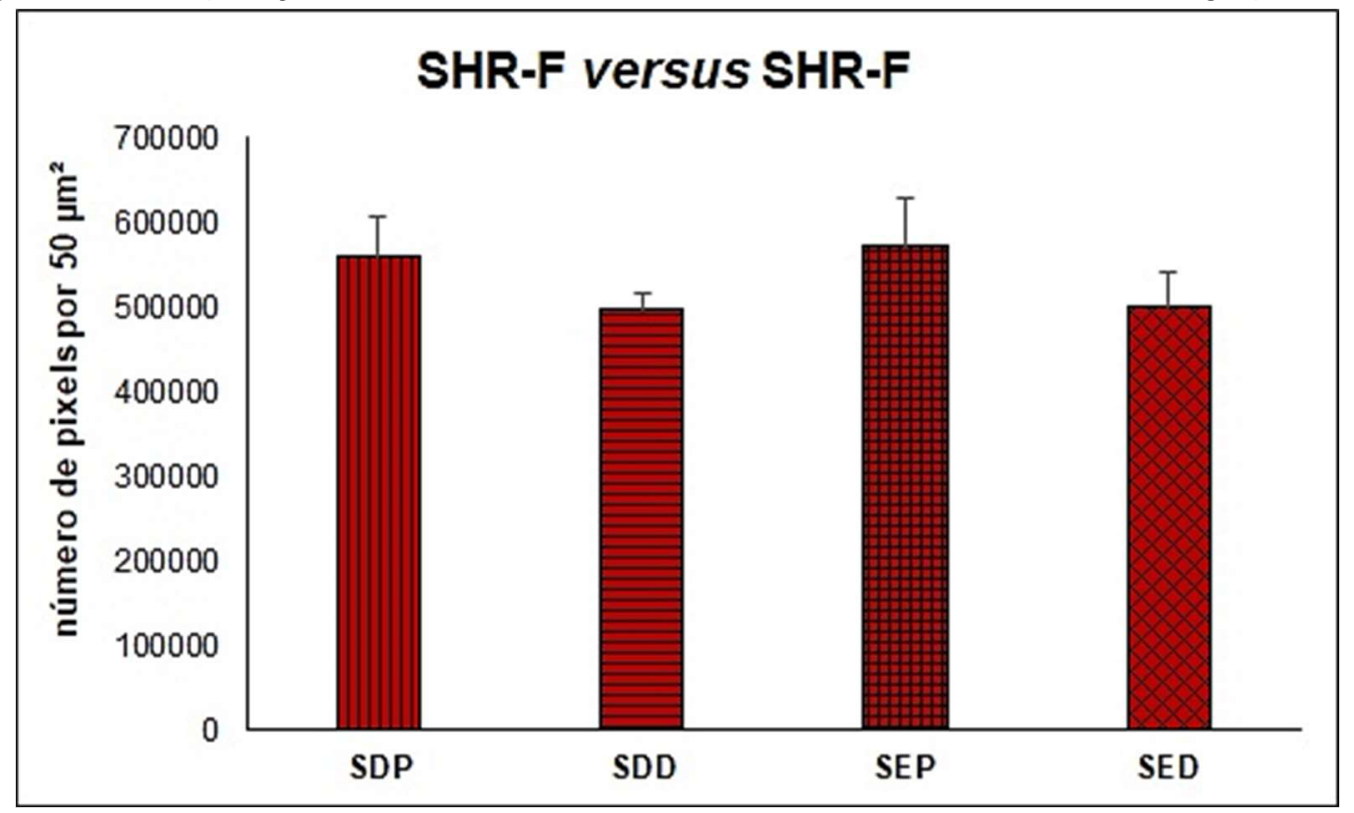

As colunas representam a média da densidade das fibras mielínicas finas e amielínicas imunomarcadas para SP, dada em número de pixels por $50 \mu \mathrm{m}^{2}$, nos segmentos proximal e distal dos nervos surais direito e esquerdo dos animais do grupo SHR-F e as barras representam o erro padrão \pm da média (EPM). $p \geq 0.05$ teste $t$ de student não pareado para dados com distribuição normal ou teste de Mann-Whitney para dados com distribuição não normal ou que não passaram no teste de equivalência das variâncias. $p \geq 0.05$ teste $t$ de Student não pareado para dados com distribuição normal ou teste de Mann-Whitney para dados com distribuição não normal ou que não passaram pelo teste de equivalência das variâncias. $\mathrm{SDP}=$ Sural direito proximal; $\mathrm{SDD}=$ Sural direito distal; $\mathrm{SEP}=$ Sural esquerdo proximal; SED= Sural esquerdo distal. 
Figura 25- Fotomicrografias aleatoriamente selecionadas de cortes longitudinais de nervos surais de animais representativos do grupo SHR-F.

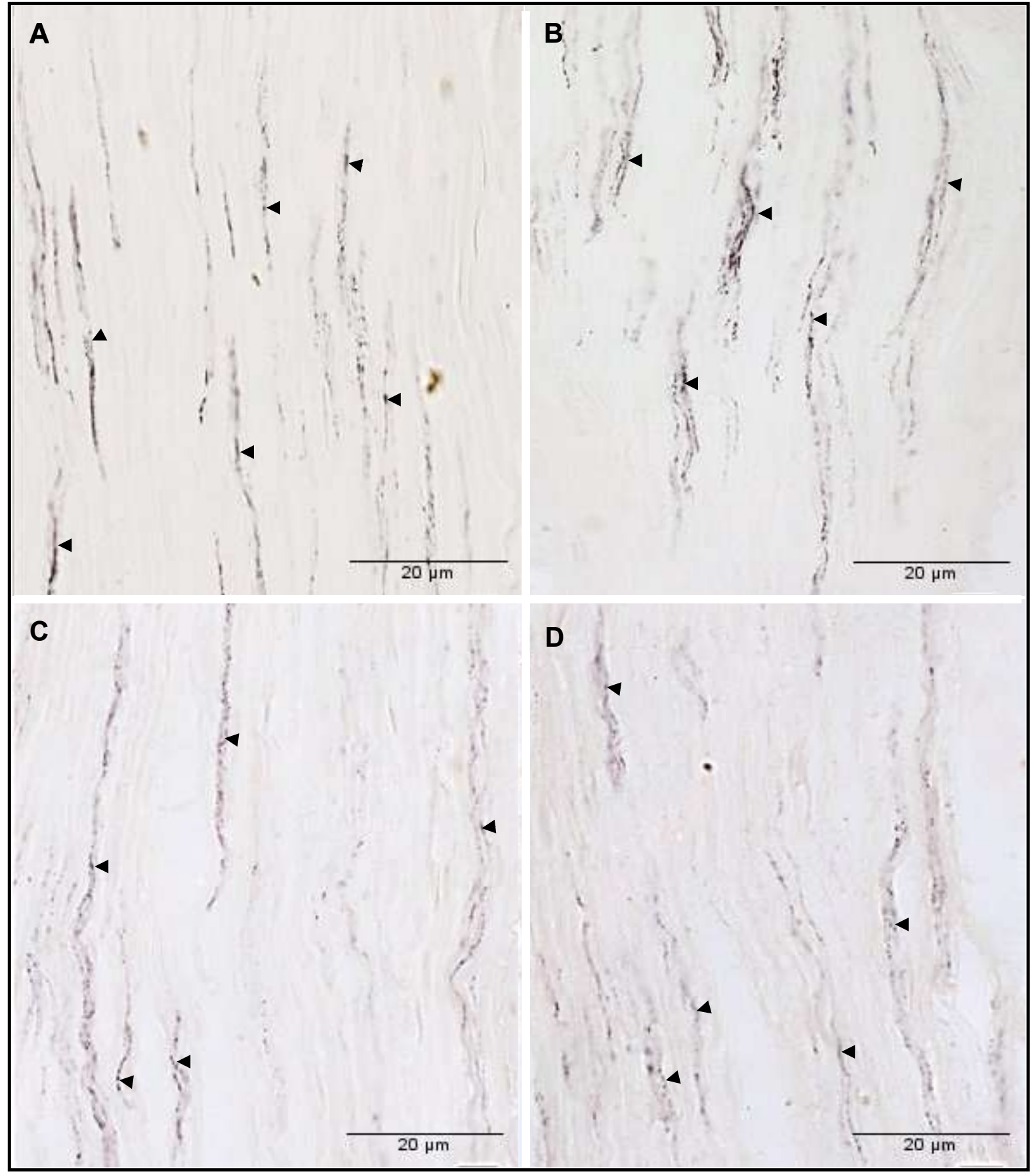

Em (A) segmento proximal do nervo Sural direito, (B) segmento distal do nervo Sural direito, (C) segmento proximal do nervo Sural esquerdo e em (D) segmento distal do nervo Sural esquerdo. As cabeças de setas sinalizam granulações positivas a SP. 


\subsubsection{Análises intergrupos: ratos e ratas da linhagem SHR}

A figura 26 mostra os valores médios da densidade de fibras mielínicas finas e amielínicas imunomarcadas para SP nos segmentos proximal e distal dos nervos surais direito e esquerdo dos animais dos grupos SHR-M e SHR-F. As comparações entre mesmos segmentos de mesmos lados não revelaram diferenças estatisticamente significativas $(p \geq 0,05)$ entre os gêneros da linhagem de animais hipertensos.

Figura 26- Comparação da densidade de fibras imunomarcadas entre os grupos SHR-M e SHR-F

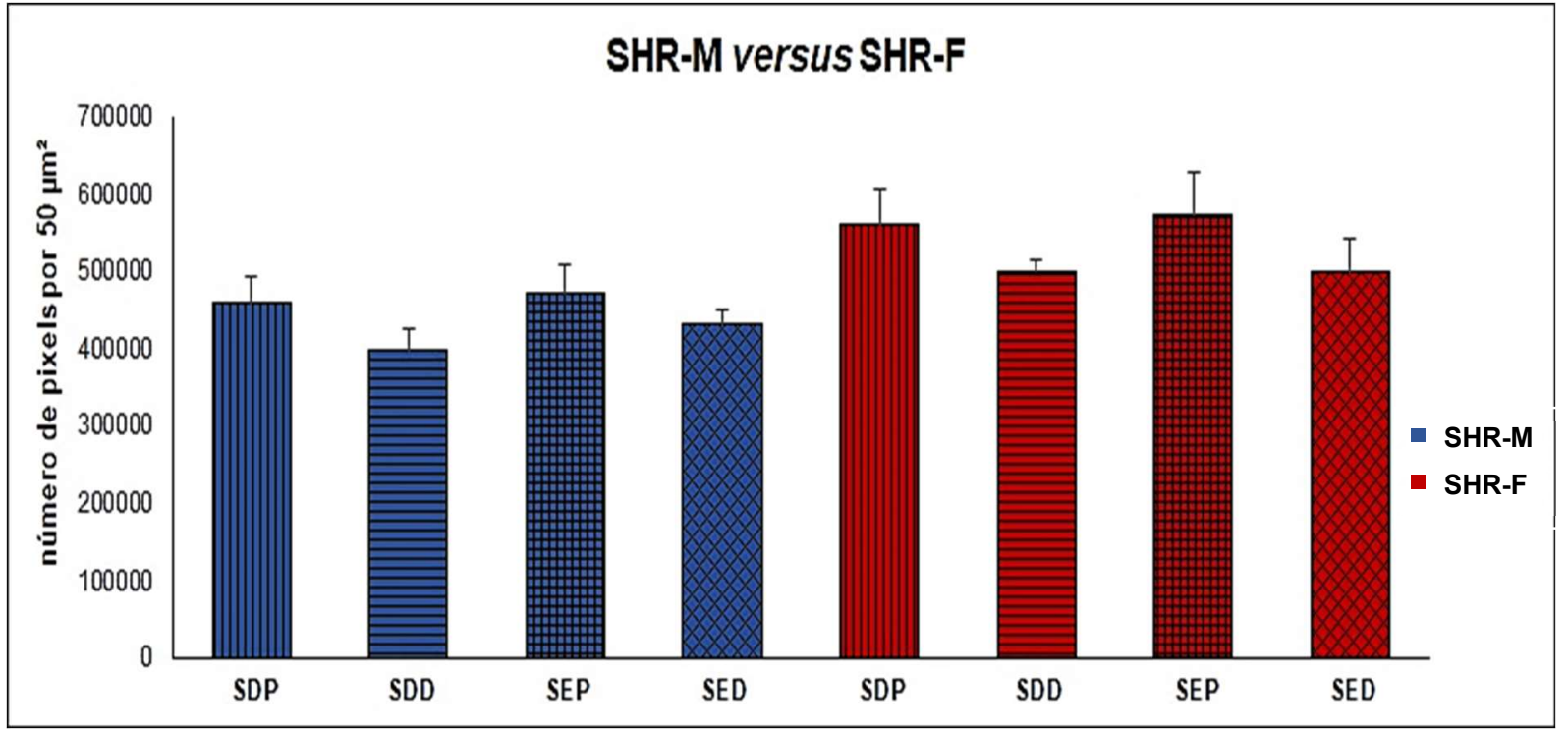

As colunas representam a média da densidade das fibras mielínicas finas e amielínicas imunomarcadas para SP, dada em número de pixels por $50 \mu \mathrm{m}^{2}$, nos segmentos proximal e distal dos nervos surais direito e esquerdo dos animais dos grupos SHR-M e SHR-F e as barras representam o erro padrão \pm da média (EPM). $p \geq 0.05$ teste $t$ de Student não pareado para dados com distribuição normal ou teste de Mann-Whitney para dados com distribuição não normal ou que não passaram pelo teste de equivalência das variâncias. $S D P=$ Sural direito proximal; $S D D=$ Sural direito distal; $S E P=$ Sural esquerdo proximal; SED= Sural esquerdo distal. 


\subsubsection{Análises intergrupos: ratos das linhagens WKY e SHR}

A figura 27 mostra os valores médios da densidade de fibras mielínicas finas e amielínicas imunomarcadas para SP nos segmentos proximal e distal dos nervos surais direito e esquerdo dos animais dos grupos WKY-M e SHR-M. As comparações entre mesmos segmentos de mesmos lados revelaram redução significativa $(p<0,05)$ de SDP do grupo SHR-M relação a SDP do grupo WKY-M; de SDD do grupo SHR-M em relação a SDD do grupo WKY-M; de SEP do grupo SHR-M em relação a SEP do grupo WKY-M e de SED do grupo SHR-M em relação a SED do grupo WKY-M.

Figura 27- Comparação da densidade de fibras imunomarcadas entre os grupos WKY-M e SHR-M

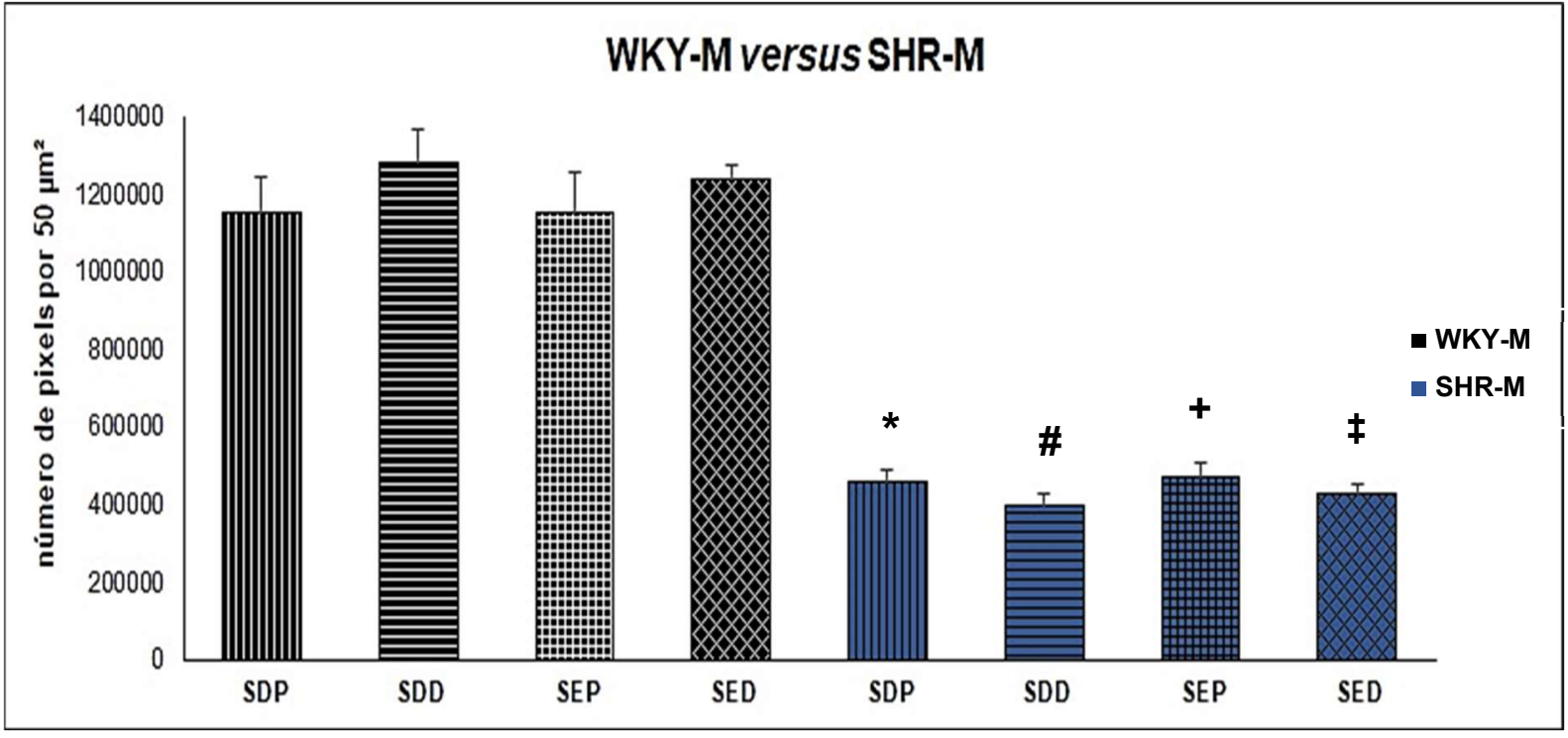

As colunas representam a média da densidade das fibras mielínicas finas e amielínicas imunomarcadas para SP, dada em número de pixels por $50 \mu \mathrm{m}^{2}$, nos segmentos proximal e distal dos nervos surais direito e esquerdo dos animais dos grupos WKY-M e SHR-M e as barras representam o erro padrão \pm da média (EPM). * em relação a SDP; \# em relação a SDD; + em relação a SEP; $\ddagger$ em relação a SED. $p<0.05$ teste $t$ de Student pareado para dados com distribuição normal ou teste de Wilcoxon para dados com distribuição não normal ou que não passaram pelo teste de equivalência das variâncias. $\mathrm{SDP}=$ Sural direito proximal; $\mathrm{SDD}=$ Sural direito distal; $\mathrm{SEP}=$ Sural esquerdo proximal; SED $=$ Sural esquerdo distal. 
Estas análises ainda evidenciaram que os segmentos nervosos dos animais do grupo SHR-M que mais perderam densidade de fibras imunomarcadas para o neurotransmissor estudado, de maneira proporcional, foram os segmentos distais de ambos os nervos surais, mostrando redução de $60 \%$ desta medida para SDD e de $62 \%$ para SED, enquanto SDP e SEP mostraram redução de $51 \%$ e $50 \%$, respectivamente.

\subsubsection{Análises intergrupos: ratas das linhagens WKY e SHR}

A figura 28 mostra os valores médios da densidade de fibras mielínicas finas e amielínicas imunomarcadas para SP nos segmentos proximal e distal dos nervos surais direito e esquerdo dos animais dos grupos WKY-F e SHR-F. As comparações entre mesmos segmentos de mesmos lados revelaram redução significativa $(p<0,05)$ de SDP do grupo SHR-F relação a SDP do grupo WKY-F; de SDD do grupo SHR-F em relação a SDD do grupo WKY-F; de SEP do grupo SHR-F em relação a SEP do grupo WKY-F e de SED do grupo SHR-F em relação a SED do grupo WKY-F.

Ainda, foi possível observar que os segmentos nervosos dos animais do grupo SHR-F que mais perderam densidade de fibras imunomarcadas para o neurotransmissor estudado, de maneira proporcional, foram os segmentos distais de ambos os nervos surais, mostrando redução de $49 \%$ desta medida para SDD e de $54 \%$ para SED, ao passo que o SDP e o SEP mostraram redução de $41 \%$ e $42 \%$, respectivamente. 
Figura 28- Comparação da densidade de fibras imunomarcadas entre os grupos WKY-F e SHR-F

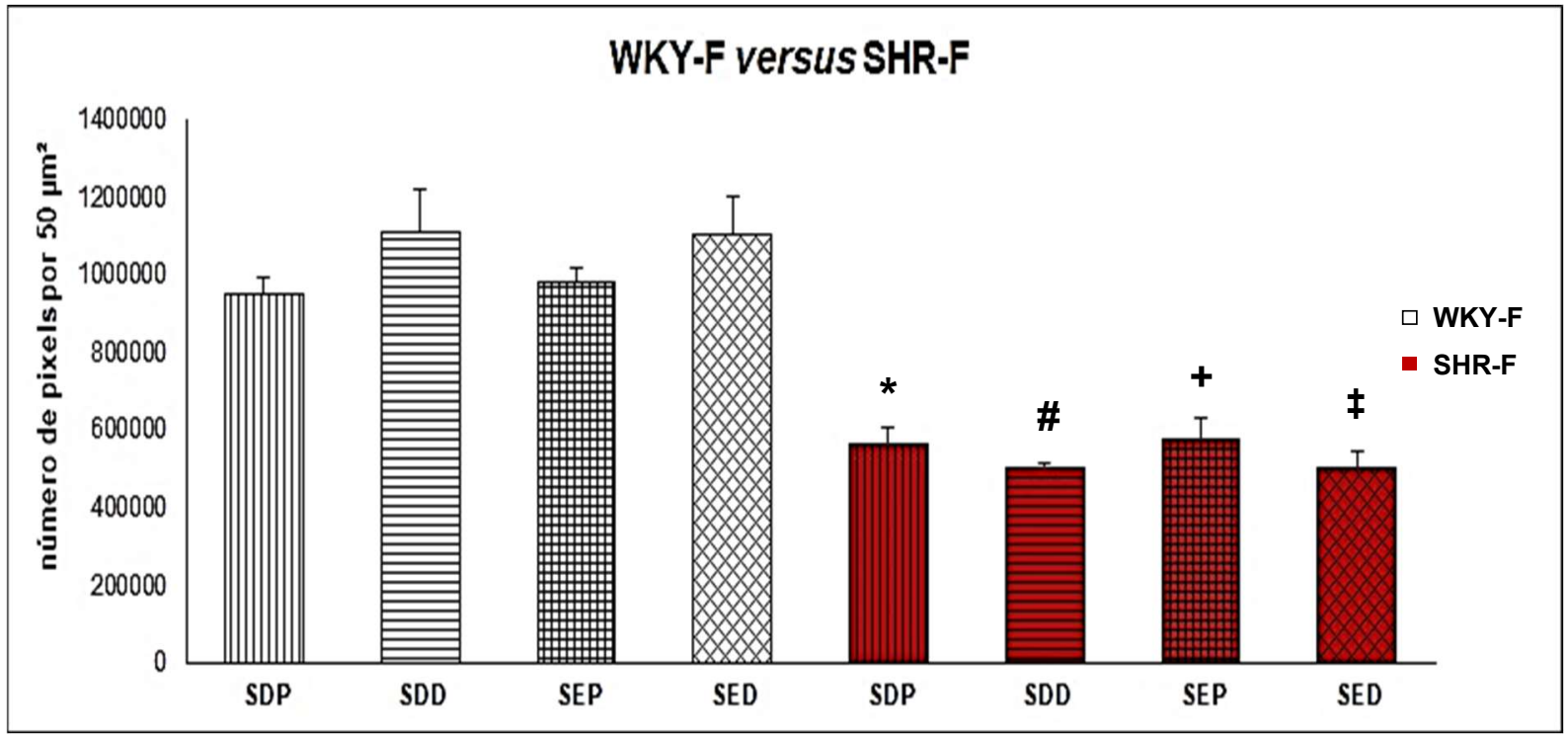

As colunas representam a média da densidade das fibras mielínicas finas e amielínicas imunomarcadas para SP, dada em número de pixels por $50 \mu \mathrm{m}^{2}$, nos segmentos proximal e distal dos nervos surais direito e esquerdo dos animais dos grupos WKY-F e SHR-F e as barras representam o erro padrão \pm da média (EPM). * em relação a SDP; \# em relação a SDD; + em relação a SEP; ¥ em relação a SED. $p<0.05$ teste $t$ de Student pareado para dados com distribuição normal ou teste de Wilcoxon para dados com distribuição não normal ou que não passaram pelo teste de equivalência das variâncias. $\mathrm{SDP}=$ Sural direito proximal; $\mathrm{SDD}=$ Sural direito distal; $\mathrm{SEP}=$ Sural esquerdo proximal; SED $=$ Sural esquerdo distal. 
5. DISCUSSÃO 
Durante um longo tempo, nosso laboratório vem se dedicando a investigar alterações morfológicas e morfométricas nos componentes dos diversos nervos periféricos, alterações estas possivelmente eliciadas por um quadro de HA. De fato, pacientes que enfrentam cronicidade desta situação clínica, e cujo complicador é a ausência de tratamento, podem desenvolver complicações da função nervosa (EDWARDS et al., 2008). Esta correlação nos levou a investigar esta associação sob condições experimentais bem controladas, a partir do emprego do modelo animal mais fidedigno da doença, os ratos da linhagem SHR.

\subsection{PESO CORPORAL}

Nossos resultados indicaram que os animais dos grupos WKY-M e SHR-M possuem peso corporal mais elevado que os dos grupos WKY-F e SHR-F, respectivamente, e que os animais do grupo WKY-M possuem peso corporal mais elevado que os dos grupos SHR-M e SHR-F. Estas diferenças observadas no presente estudo, estão em concordância com dados bem estabelecidos na literatura científica (OKAMOTO; AOKY, 1963; REN, 2007; WANG et al., 2017).

\subsection{FREQUÊNCIA CARDÍACA}

Dickhout e Lee (1998), em sua pesquisa sobre o desenvolvimento da PA e da FC em SHR machos, definiram que a FC desses animais se encontrava mais elevada que a de seus controles normotensos, WKY, desde a $3^{\mathrm{a}}$ semana de vida, o que ocorre em função do aumento da frequência intrínseca do marca-passo cardíaco. Os ratos hipertensos utilizados em nosso trabalho tinham 20 semanas de vida e, como 
esperado, mostraram ter FC mais elevada que a de seus controles de mesmo gênero, dessa forma, foram satisfeitos os critérios definidos para este índice.

Revelamos ainda que os animais do grupo SHR-M possuem FC mais elevada que os animais do grupo SHR-F, dado também citado por Maris et al. (2005) em sua pesquisa sobre a diferença da PA e da FC entre gêneros de animais das linhagens SHR e WKY.

Segundo Fazan et al. (2006), a instalação persistente de uma FC elevada nos animais da linhagem SHR pode estar intimamente relacionada a níveis mais altos de sua PA, sendo a taxa da FC um fator preditivo para o desenvolvimento da HA nesta população.

\subsection{DADOS HEMODINÂMICOS}

Os autores Okamoto e Aoky (1963), ao caracterizarem pela primeira vez os animais da linhagem SHR, definiram que estes seriam considerados hipertensos quando sua PAS excedesse $150 \mathrm{mmHg}$. Os ratos desta linhagem utilizados em nosso estudo mostraram como média da PAS os valores $249 \mathrm{mmHg}$, para SHR-M, e $189 \mathrm{mmHg}$, para SHR-F, sendo assim, mais uma vez, foram satisfeitos os critérios considerados.

Novamente nossos dados se alinham com achados científicos bem estabelecidos na literatura ao mostrarmos a existência de diferenças significativas para as três variáveis da PA testadas. Assim, observamos que os níveis da PAS, da PAD e da PAM se revelaram elevados nos animais dos grupos SHR-M e SHR-F quando comparados respectivamente a WKY-M e a WKY-F, o que foi igualmente observado em trabalhos que utilizaram mesma rigidez metodológica (OKAMOTO; AOKY, 1963; REN, 2007; LIN et al., 2016). 
Observamos ainda que o nível da PAS foi significativamente diferente entre os animais dos grupos SHR-M e SHR-F, sendo mais elevado no primeiro, o que também pode ser encontrado por Okamoto e Aoky (1963) e por Maris et al. (2005).

Os estudos de Sabbatini, Vega e Amenta (1996) e de Sabbatini et al. (2001), bem como uma recente revisão sistemática da literatura a respeito das mudanças estruturais e funcionais da vasculatura vistas em animais hipertensos escrita por Lee, Dickhout e Sandow (2017), explicam nossos dados hemodinâmicos, ao revelarem a existência de padrões morfológicos alterados nos vasos sanguíneos endoneurais de animais da linhagem SHR. Neles, foram observadas por estes autores, a presença de vasos sanguíneos mais espessos, de lúmen mais estreito ou até mesmo colabados, situações que podem impor maior resistência vascular, interferindo, assim, na PA.

\subsection{DENSIDADE DE FIBRAS IMUNOMARCADAS PARA SUBSTÂNCIA P}

Nossos resultados demonstraram de forma inédita a presença da SP no nervo Sural de ratos das linhagens WKY e SHR machos e fêmeas através de abordagem IHQ.

As imagens obtidas das secções longitudinais dos segmentos proximais e distais dos nervos destes animais nos permitiu identificar, no espaço endoneural, acompanhando o eixo longitudinal do nervo, feixes de axônios amielínicos e de fibras mielínicas finas com grânulos densamente corados e imunorreativos a SP, mesmo padrão de marcação obtido por Carvalho (2016) em seu trabalho sobre imurreatividade à SP dos componentes axonais do nervo Depressor aórtico de ratos WKY. 
Ainda, quanto a localização das fibras imunomarcadas, notamos que estas não se limitam a regiões específicas do nervo, mas sim, preenchem grande parte do espaço endoneural, fato que, por sua vez, corrobora com a localização relatada por Sanada et al. (2011) em um trabalho que confirmou a possibilidade do uso de animais das linhagens Wistar e WKY como controle dos animais da linhagem SHR a partir da investigação morfológica e morfométrica detalhada deste nervo periférico.

As informações sobre a densidade de fibras mielínicas finas e amielínicas nos nervos surais dos animais dos grupos WKY-M, WKY-F, SHR-M e SHR-F não revelaram significância estatística quando feitas comparações intragênero nem quando feitas comparações intergênero dentro de cada linhagem. Desse modo, podemos dizer que os animais normotensos e os espontaneamente hipertensos, machos e fêmas, possuem simetria anatômica na composição de seus nervos surais relacionada às fibras estudadas.

Nossos resultados são amparados por outros semelhantes, estabelecidos em trabalhos de extrema relevância para esta área da ciência experimental, os quais, a partir do emprego de refinadas técnicas morfométricas, mostraram a existência desta mesma simetria, tanto em fibras amielínicas como em fibras mielínicas de diâmetros variados, nos nervos Depressor aórtico, Frênico, Safeno, Vago e também no nervo Sural de ratos de machos e fêmeas, com idades variadas, das linhagens WKY e SHR (FAZAN et al., 1999; SCHIAVONNI; FAZAN, 2006; DE ALCÂNTARA; SALGADO; FAZAN, 2007; RODRIGUES et al., 2011; SANADA et al., 2011; NERI et al., 2015; SANADA, 2015).

A presença de elementos simétricos nos nervos periféricos é um fator importante que, de acordo com Sanada et al. (2011), permite que o lado contralateral 
do nervo seja usado, por exemplo, como controle em investigações que envolvam lesão e regeneração nervosa.

Apesar desta simetria anatômica, é importante considerar a presença de uma tendência a maior concentração das fibras imunomarcadas nos segmentos nervosos distais dos animais dos grupos WKY-M e WKY-F quando comparados aos proximais. Estes dados são confirmados por Fazan, Salgado e Barreira (2001) quando descreveram de maneira sistemática os aspectos morfológicos e morfométricos do nervo depressor aórtico de ratos de ambos os gêneros das linhagens WKY e SHR.

Em oposição ao descrito para os animais controle, a existência de uma tendência a menor concentração de fibras mielínicas finas e amielínicas nos segmentos nervosos distais dos animais dos grupos SHR-M e SHR-F quando comparados aos proximais foi notada. De maneira semelhante, Da Silva et al. (2016), ao investigarem a evolução dos aspectos morfológicos e morfométricos do nervo Laríngeo recorrente de ratos e ratas da linhagem SHR, com diferentes idades, identificaram valores mais baixos para a densidade de axônios mielínicos dos segmentos distais deste nervo nos animais de ambos os gêneros, sendo as fibras finas, as mais comprometidas. Resultados estes que se encontram consonantes com os por nós aqui descritos.

Observamos ainda que, em todos os segmentos nervosos dos animais do grupo WKY-M houve, de maneira não significativa, maior existência das fibras alvo de nossa investigação que nos segmentos nervosos correspondentes dos animais do grupo WKY-F. Uma vez que os animais do primeiro grupo tinham peso corporal significativamente maior que os do segundo, consideramos que o comportamento destas fibras pode estar relacionado ao desenvolvimento corporal dos animais, conforme mostrado por Jerônimo et al. (2005), em um estudo que correlacionou a 
simetria do nervo Sural ao desenvolvimento pós-natal de ratas da linhagem WKY, e também mostrado por Neri et al. (2015), em um trabalho que analisou os componentes dos nervos Sural e Safeno de ratas desta mesma linhagem com idades avançadas.

Novamente de maneira contrária aos dados expostos sobre os grupos de animais normotensos, notamos haver tendência a redução das fibras reativas a SP principalmente nos segmentos nervosos distais dos animais do grupo SHR-M comparado animais do grupo SHR-F, resultado que ocorreu na presença de peso corporal e de dados hemodinâmicos (PAS e PAD) significativamente mais elevados nos animais machos. Esta descrição se alinha com os resultados publicados por Sanada et al. (2012) em um estudo morfométrico completo do nervo Sural de ratos e ratas das linhagens WKY e SHR. Estes autores ainda sugerem que as alterações observadas no nervo sural dos animais hipertensos podem estar mais relacionadas ao desenvolvimento da HA do que apenas ao peso corporal do animal.

Os dados descritos até o momento ficam claros quando comparamos cada gênero dos animais hipertensos aos seus respectivos controles normotensos, como será feito na sequência.

As comparações realizadas entre os animais dos grupos WKY-M e SHR-M e também entre os animais dos grupos WKY-F e SHR-F revelaram haver redução significativa das fibras mielínicas finas e amielínicas em todos os segmentos dos nervos surais dos animais hipertensos, sendo que os segmentos mais afetados, proporcionalmente, foram os distais de ambos os lados. Com base na porcentagem de perda axonal, ainda é possível inferir que os segmentos distais dos animais do grupo SHR-M sofreram perdas mais intensas destes componentes que os das fêmeas de sua linhagem, achados que se alinham com os de trabalhos que empregaram técnicas padrão ouro em suas investigações a cerca da influência de uma PA 
constantemente alta sobre o tecido nervoso periférico de ratos e ratas SHR, de modo que os principais dados destes estudos que apontam em direção a um comprometimento nervoso desta linhagem são os relativos a diminuição significativa da razão $\mathrm{G}$ (inferior a 0.6) e a direção do desvio dos histogramas de distribuição de fibras dos nervos testados (FAZAN et al., 1999; FAZAN; SALGADO; BARREIRA, 2001; RODRIGUES et al., 2011; SANADA et al., 2012; SANADA et al., 2015).

Modelos experimentais de infarto de nervos periféricos sugerem que as fibras nervosas finas e as amielínicas são as mais vulneráveis à isquemia (PARRY; BROWN, 1982; GIANNINI; DICKY, 1994; LIM et al., 2015).

Considerando o caso de animais espontaneamente hipertensos, a perda desses axônios se deve, de acordo com Teunissen et al. (2002) e com Edwards et al. (2008), à hipoperfusão e consequente redução do aporte de oxigênio para seu tecido nervoso, fatores causados por alterações vasculares endoneurais, aqui já descritas como vasos sanguíneos mais espessos, de lúmen mais estreito ou até mesmo colabados, relacionadas ao quadro de HA crônica característica desta linhagem (DICKHOUT; SANDOW, 2017). Esses resultados vão ao encontro dos obtidos por SANADA et al. (2012) que demonstraram histologicamente lesões dos capilares endoneurais em nervos surais de SHR. A lesão vascular endoneural parece ser uma característica do quadro hipertensivo apresentado pelos SHR, uma vez que o nervo Frênico também apresenta alterações dos capilares endoneurais semelhantes às descritas para o nervo Sural (RODRIGUES et al., 2011).

Como já apresentado, a perda das fibras abordadas em nossa pesquisa se caracterizou por ocorrer em sentido longitudinal, de proximal para distal, nos nervos surais de ambos os lados dos animais dos grupos SHR-M e SHR-F. Da Silva et al. (2016), demonstraram que as alterações vasculares endoneurais que acomentem 
animais SHR já podem ser observadas na quinta semana de vida, sendo mais expressivas nos segmentos nervosos distais, o que pode ser considerado uma característica própria do vasa nervorum desta linhagem. Os autores ainda sugerem que tais alterações vasculares precoces podem estar associadas a perda axonal nestes segmentos em idades mais avançadas, como 20 semanas de vida. Relatos estes que explicam a direção da perda axonal observada no presente estudo.

Esse padrão de perda de densidade de fibras nervosas, em nosso caso, as mielínicas finas e amielínicas, é bem conhecido por estar relacionado às neuropatias periféricas, sendo a neuropatia diabética a mais conhecida (DE OLIVEIRA et al., 2013). Dessa forma, a redução mais acentuda dessas fibras nos segmentos distais dos nervos surais dos animais SHR pode sugerir a instalação precoce de uma neuropatia relacionada à $\mathrm{HA}$, a neuropatia hipertensiva, a qual, em nosso trabalho e também nos estudos de Rodrigues et al. (2011) e de Sanada et al. (2012), se mostrou prevalente no gênero masculino. Dá-se, então, a importância das extensas comparações entre os segmentos proximais e distais dos nervos periféricos de machos e fêmeas hipertensos.

Ainda que não tenha sido parte dos nossos objetivos investigar a função dos nervos surais dos grupos experimentais utilizados, é esperado que, devido às diferenças na densidade das fibras imunomarcadas, hajam alterações eletrofisiológicas, como as descritas por Fontanesi et al. (2019) quando confirmaram haver redução na velocidade de condução do nervo Sural de ratos SHR de ambos os gêneros e de idades variadas quando comparados a seus controles, WKY. Mais ainda, estes autores demonstraram que, entre 20 e 40 semanas de idade, as fêmeas SHR evidenciam velocidade de condução constante, enquanto os machos dessa linhagem apresentam redução desse parâmetro. 
Na literatura, são bem estabelecidos dados a respeito de diferenças no sistema nervoso periférico entre machos e fêmeas, sendo a maioria destes referentes à regeneração nervosa (KOENING; GONG; PELISSIER, 2000; JIANG et al, 2014; STENBERG; DAHLIN, 2014; MORIYAMAA et al., 2016; STENBERG, 2019).

Nesse sentido, há relatos publicados sobre a susceptibilidade dos gêneros dos animais da linhagem SHR para o desenvolvimento de neuropatias periféricas. Estes trabalhos mostram que os machos são mais sensíveis a esta condição, tal qual pudemos demonstrar em nossa pesquisa (MAJEED, 1992; SCHIAVONI; FAZAN, 2006; FONTANESI et al., 2019).

Apesar de não termos correlacionado estatisticamente o nível da PA com a densidade das fibras imunomarcadas para SP, concordamos com a observação de Sanada et al., (2012) quando os autores sugerem que níveis mais altos de PA nos machos SHR afetam mais intensamente o desenvolvimento axonal que nas fêmeas.

É bem sabido que há dimorfismo sexual sobre os nives de PA nos animais SHR, sendo que valores mais altos são observados nos machos dessa linhagem. Embora os mecanismos responsáveis pela diferença citada não estejam claros, há evidências importantes de que andrógenos exerçam um importante papel nas diferenças da regulação da PA relacionada ao gênero (LIU et al., 2010; BOROWICZ et al., 2011; SIDDIQUI et al., 2016). Fato que pode estar relacionado à maior fragilidade do grupo SHR-M e, por sua vez, a maior resistência do grupo SHR-F identificadas nesta pesquisa.

As diferenças relacionadas ao gênero no resultado de distúrbios e lesões do sistema nervoso periférico têm sido uma questão científica importante investigada nos últimos anos (AMMENDOLA et al., 2000; ROBERTOSON et al., 2004; O’BRIEN et al., 2016; SIMÕES et al., 2018). 
É em um ambiente experimental onde a maioria destas pesquisas se destinam a abordar o nervo Sural de ratos a partir do método clássico de imersão em resina epóxi (JERÔNIMO et al., 2005; JERÔNIMO et al., 2008; GARCÍA-CHÁVEZ et al., 2007; SANADA et al., 2012; YAMAGUCHI et al., 2012; SEGURA et al., 2014; NERI et al., 2015; SANADA et al., 2015), que finalmente demonstramos ser possível realizar uma abordagem axonal indireta, rápida e fidedígna, via IHQ para SP, deste nervo. Abordagem esta, que revelou haver alterações em fibras nervosas surais específicas, principalmente relacionadas à linhagem, o que coincide com os relatos encontrados em trabalhos de metodologia clássica, o que fortalece nossos resultados. 
6. CONCLUSÕES 
O presente trabalho demonstrou de maneira pioneira a caracterização indireta de fibras mielínicas finas e amielínicas no nervo Sural de ratos e ratas das linhagens WKY e SHR, a partir do emprego de técnicas de imunomarcação para SP.

Com isso, demonstramos com fidelidade estatística a densidade dessas fibras nos diferentes segmentos nervosos de cada um dos gêneros e para cada uma das espécies, o que revelou ausência de diferenças significativas entre os grupos WKY-M e WKY-F e entre os grupos SHR-M e SHR-F, mas importante redução deste parâmetro quando confrontados os grupos WKY-M com SHR-M e WKY-F com SHR$\mathrm{F}$, o que permite concluir que a alteração na densidade das fibras imunomarcadas do nervo Sural não possui correlação com gênero, mas sim com linhagem.

Finalmente, o presente estudo coletou evidências hemodinâmicas e, sendo os animais SHR confirmadamente hipertensos, nossos dados apontam para a presença de uma neuropatia hipertensiva, neste caso, relacionada a fibras mielínicas finas e amielínicas, sendo que houve uma redução significativa das fibras mielínicas finas e amielínicas nos dois segmentos do nervo Sural e os segmentos distais foram os mais afetados. 
7. REFERÊNCIAS 
ABEGUNDE, D. O.; MATHERS, C. D.; ADAM, T.; ORTEGON, M.; STRONG, K. The burden and costs os chronic diseases in low-income and middle-income conutriens. The Lancet, v. 370, n. 9603, p. 1929-1938, 2007.

AHARINEJAD, S.; SCHRAUFNAGEL, D. E.; BÖCK, P.; MACKAY, C.A.; LARSON, E. K.; MIKSOVSKY, A.; MARKS, C. S. Spontaneously hypertensive rats develop pulmonary hypertension and hypertrophy of pulmonary venous sphincters. The American Journal of Pathology, v. 148, n. 1, p. 281-290, 1996.

AL' ABSI, M.; BUCHANAN, T.; LOVALLO, W. R. Pain perception and cardiovascular responses in men with positive parental history for hypertension. Psychophysiology, v. 33, n. 6, p. 655-661, 1996.

AMMENDOLA, A.; GEMINI, D.; IANNACCONFE, S.; ARGENZIO, F.; CICCONE, G.;AMMENDOLA, E.; SERIO, L.; UGOLINI, G.; BRAVACCIO, F. Gender and peripheral neuropathy in chronic alcoholism: a clinical-electroneurographic study. Journal of the peripheral Nervous System, v. 35, n. 4, p. 268-371, 2000.

ANDRADE, S. S. A.; STOPA, S. R.; BRITO, A. S.; CHUERI, P. S.; SZWARCWALD, C. L.; MALTA, D, C. Prevalência de hipertensão arterial autorreferida na população brasileira: análise da Pesquisa Nacional de Saúde. Epidemiologia e Serviços de Saúde, v. 24, n. 2, p. 297-304, 2015. 
ATRAKCHI, A.; GRAY, S. D.; CARLSEN, R. C. Development of soleus muscles in SHR: relationship of muscle deficits to rise in blood pressure. American Journal of Physiology, v. 267, n. 3, p. C827-C835, 1994.

AVOLIO, E.; PASQUA, T.; DI VITO, A.; FAZZARIN G.; CARDILLO, G.; ALÒ, R.; CERRA, M. C.; BARNI, T.; ANGELONE, T.; CANONASCO, M. Role of brain neuroinflammatory factors on hypertension in the spontaneously hypertensive rat. Neuroscience, v. 375, p. 158-168, 2018.

BAYLESS, D. W.; PEREZ, M. C.; DANIEL, J. M. Comparison of the validity of the use of the spontaneously hypertensive rat as a model of attention deficit hyperactivity disorder in males and females. Behavioural Brain Research, v. 286, p. 85-92, 2015.

BAYLIS, C.; MITRUKA, B.; DENG, A. Chronic blockade of nitric oxide synthesis in the rat produces systemic hypertension and glomerular damage. Journal of Clinical Investigation, v. 90, p. 278-281, 1992.

BECHARA, A. J.; CAO, G.; CASABÉ, A. R.; ROMANO, S. V.; TOBLLI, J. E. Morphological modifications in clitoris and vagina in spontaneously hypertensive rats. International Journal of Impotence Research, v. 15, p. 166-172, 2003.

BILEGO-NETO, A. P. C.; SILVEIRA, F. B. C.; DA SILVA, G, A, R.; SANADA, L. S.; FAZAN, V. P. S. Pathological changes of human unmyelinated nerve fibers: a review. Histology and Histopathology, v. 15, p. 313-324, 2000. 
BLANC, J.; LAMBERT, G.; ELGHOZI, J. L. Endogenous renin and related short-term blood variability in the conscious rat. European Journal of Pharmacology, v. 394, p. 311-320, 2000.

BOROWICZ, K. K.; PISKORSKA, B.; BANACH, M.; CZUCZWAR, S. J. Neuroprotective actions of neurosteroids. Frontiers in Endocrinology, v. 50, p. 2-10, 2011.

BOZZOLA, J. J.; RUSSELL, L. D. Electron Microscopy: principles and techniques for biologists. 2. ed. Sudbury: Mass.: Jones and Bartlett Publishers, 1999.

BRASIL. Ministério da Saúde. Vigitel 2018: Vigilância de farores de risco e proteção para doenças crônicas por inquérito telefônico. Brasília: Ministério da Saúde, 2018. Disponível em <https://portalarquivos2.saude.gov.br/images/pdf/2019/julho/25/vigitelbrasil-2018.pdf>. Acesso em: 19 nov. 2019.

BRASIL. Ministério da Saúde. Sistema de Informações sobre Mortalidade. Brasília: Ministério da Saúde, 2017. Disponível em: <http://www.saude.gov.br/noticias/agenciasaude/45446-no-brasil-388-pessoas-morrem-por-dia-por-hipertensao>.Acesso em: 25 nov. 2019.

BRENER, S. Expressão de substância $P$ e seu receptor Neuroquinina 1 em carcinomas espinocelulares de boca e sua implicação na atividade proliferativa tumoral. 2009. 154f. Tese (Doutorado) - Universidade de São Paulo, Bauru. 2009. 
BRUEHL, S.; CHUNG, O. Y.; JIRJIS, J. N.; BIRIDEPALLI, S. Prevalence of clinical hypertension in patients with chronic pain compared to nonpain general medical patients. The Clinical Journal of Pain, v. 21, n. 2, p. 147-53, 2005.

CAMPAGNOLO, M.; FERRARI, S.; DALLA TORRE, C.; CABRINI. I.; CACCIAVILLANI, M.; LUCCHETTA, M.; RUGGERO, S.; TOFFANIN, E.; CAVALLARO, T.; BRIANI, C. Polyneuropathy with anti-sulfatide and anti-MAG antibodies: clinical, neurophysiological, pathological features and response to treatment. Journal of Neuroimmunology, v. 15, n. 281, p. 1-4, 2015.

CARRETERO, A. O.; ROMERO, J. C. Production and characteristics of experimental hypertension in animals. In: GENEST, G.; KOIW, E.; KUCHEL, O., eds. Hypertension. New York: McGraw- Hill, 1977. p. 485-507.

CARVALHO, C. S. Identificação dos neurotransmissores das fibras mielínicas e amielínicas do nervo depressor aórtico de ratos: uma abordagem imunohistoquímica. 2016. 117f. Tese (Doutorado) - Universidade de São Paulo, Ribeirão Preto. 2016.

CASCIERI, M. A.; HUANG, R. R.; FONG, T. M.; CHEUNG, A. H. SADOWSKI, S. BER, E.; STRADE, C. D. Determination of the amino acid residues in substance $P$ conferring selectivity and specificity for the rat neurokinin receptors. Molecular Pharmacology, v. 41, n. 6, p. 1096-1099, 1992. 
CEBALlOS, D.; CUARDAS, J.; VERDÚ, E.; NAVARRO, X. Morphometric and ultrastructural changes with ageing in mouse peripheral nerve. Journal of Anatomy, v. 195, p.563-576, 1999.

CHANG, M. M.; LEEMAN, S. E.; NIALL, H. D. Amino-acid sequence of substance P. Nature: New Biology, v. 232, n. 29, p. 86-97, 1971.

CHIONG, J. R.; ARONOW, W. S.; KHAN, I. A.; NAIR, C. K.; VIJAYARAGHAVAN K.; DART, R. A.; BEHRENBECK, T. R.; GERACI, S. A. Secondary hypertension: current diagnosis and treatment. International Journal of Cardiology, v. 124, n. 1, p. 6-21, 2008.

CHOCKALINGAM, A. Impact of world hypertension day. The Canadian Journal of Cardiology, v. 23, n. 7, p. 517-519, 2007.

CLARKE, K.; TYLER, J. D. In vivo alterations in cardiac metabolism and function in the spontaneously hypertensive rat heart. Cardiovascular Research, v. 95, n. 1, p. 69-76, 2012.

DAHL.; L. K.; HEINE, M.; TASSINARI, L. Role of genetic factors in susceptibility to experimental hypertension due to chronic excess salt ingestion. Nature, n. 194, p. 480482, 1962.

DA SILVA, G. A. R.; MENDES, V. A. A.; GENARI, A. B.; CASTANIA, J. A.; SALAGADO, H. C.; FAZAN, V. P. S. Recurrent laryngeal nerve alterations in 
developing spontaneously hypertensive rats. The Laryngoscope, v. 126, p. 40-47, 2016.

DE ALCÂNTARA, A. C. L.; SALGADO, H. C.; FAZAN, V. P. S. Morphology and morphometry of the vagus nerve in male and female spontaneously hypertensive rats. Brain Research, v. 1197, p. 170-180, 2007.

DE BOER, I. H.; BANGALORE, S.; BENETOS, A.; DAVIS, A. M.; MICHOS, E. D.; MUNTNER, P.; ROSSING, P.; ZOUNGAS, S.; BAKRIS, G. Diabetes and Hypertension: A Position Statement by the American Diabetes Association. Diabete Care Journal, v. 40, n. 9, p. 1273-1284, 2017.

DE OLIVEIRA, F. S.; NESSLER, R. A.; CASTANIA, J. A.; SALGADO, H. C.; FAZAN, V.P. S. Ultrastructural and morphometric alterations in the aortic depressor nerve of rats due to long term experimental diabetes: Effects of insulin treatment. Brain Research, v. 1491, p. 197-203, 2013.

DIB, M. W.; RIERA, R.; FERRAZ, M. B. Estimated annual cost of arterial hypertension treatment in Brazil. Revista Panamericana de Salud Pública, v. 27, n. 2, p. 125131, 2010.

DICKEY, C.; TOOT, J.; TERWILLIGER, M.; PAYNE, R.; TURNER, M.; ELY, D. The SHR Y chromosome increases cardiovascular, endocrine, and behavioral responses to stress compared to the WKY Y chromosome. Physiology \& Behavior, v. 106, n. 2, p. 101-108, 2012. 
DICKHOUT, J. G.; LEE, R. M. K. W. Blood pressure and heart rate development in young spontaneously hypertensive rats. American Journal of Physiology-Heart and Circulatory Physiology, v. 274, n. 3, p. 794-800, 1998.

DO CARMO, E. C. Efeitos da estimulação nociceptiva no período neonatal na pele de ratos Wistar, machos e fêmeas, em curto e longo prazo. 2016. 138f. Tese (Doutorado) - Universidade de São Paulo, Ribeirão Preto. 2016.

DODD, M. S.; BALL, D. R.; SCHROEDER, M. A.; LE PAGE, L, M.; ATHERTON, H. J.; HEATHER, L. C.; SEYMOUR, A. M.; ASHRAFIAN, H.; WATKINS, H.; UCHIKAWA, Y.; HOSOMICHI, J.; JUN-ICHI, S.; YAMAGUCHI, H.; ISHIDA, Y.; HATANO, K.; USUMIFUJITA, R.; SHIMIZU, Y.; KANEKO, S.; UESUGI, S.; ONO, T. Differential growth of craniofacial and tibial bones to sympathetic hyperactivity-related hypertension in rats. Archives of Oral Biology, v. 99, p. 73-81, 2019.

DOYLE, A. E.; SMIRK, F. H. The neurogenic component in hypertension. Circulation, v. 2, p. 543-52, 1955.

DYCK, P. J.; KARNES, J.; LAIS, A.; LOFGREN, E. P.; STEVENS, J. C. Pathologic alterations oh the peripheral nervous system of humans. 2. ed. Philadelphia: WB Saunders Company, 1984.

EDWARDS, L.; RING, C.; MCINTYRE, D.; WINER, J. B.; MARTIN, U. Cutaneous sensibility and peripheral nerve function in patients with unmedicated essential hypertension. Psychophysiology, v. 45, p. 141-147, 2008. 
ELY, D. L.; TURNER, M. E. Hypertension in the spontaneously hypertensive rat is linked to the $\mathrm{Y}$ chromosome. Hypertension, v. 16, p. 277-281, 1990.

ENGEL, J.; GANEL, A.; MELAMED, R.; SIMON, S.; FARINE, I. Choline acetyltransferase for differentiation between human motor and sensory nerve fibers. Annals of Plastic Surgery, v. 4, p. 376-380, 1980.

FAZAN, V. P. S.; JÚNIOR, R. F.; SALGADO, C. H.; BARREIRA, A. A. Morphology of aortic depressor nerve myelinated fibers in normotensive rats and spontaneous hypertensive rats. Journal of Autonomic Nervous System, v. 77, p. 133-139, 1999.

FAZAN, V. P. S.; SALGADO, C. H.; BARREIRA, A. A. Aortic depressor nerve unmyelinated fiber in spontaneous hypertensive rats. American Journal of Physiology-Heart and Circulatory Physiology, v. 280, p. 1560-1564, 2001.

FAZAN, V. P. S.; KALIL.; A. L. R.; DE ALCÂNTARA, A. C. L.; GENARI, A. B.; TAVARES, M. R.; RODRIGUES, A. R.; SALGADO, C. H. Ratos espontaneamente hipertensos e neuropatias periféricas. Medicina, v. 39, n. 1, p. 39-50, 2006.

FAZAN-JR, R.; DA SILVA, V. J. D.; SALGADO, H. C. Modelos de hipertensão arterial. Revista Brasileira de Hipertensão, v. 8, n. 1, p. 19-29, 2001.

FERRARIO, C. M.; PAGE, I. H.; MCCUBBIN, J. W. Increased cardiac output as a contributory factor in experimental renal hypertension in dogs. Circulation Research, v. 27, p. $799-810,1970$. 
FERREIRA, S. A.; KOKUBUN, E.; GOBBI, S.; FERNANDES, R. A.; QUEIROGA, M. R. Musculoskeletal pain perception and hypertension. Dor, v. 16, n. 1, p. 43-47, 2015.

FLISER, D.; VELDHUIS, J. D.; DIKOW, R.; SCHMIDT-GAYK, H.; RITZ, E. Effects of acute CE inhibition os pulsatile rennin and aldosterone secretion and their synchrony. Hypertension, v. 32, p. 929-934, 1998.

FOËX, P. D; SEAR, J. W. Hypertension: pathophysiology and treatment. Continuing Education in Anaesthesia Critical Care \& Pain, v. 4, n. 3, p. 71-75, 2004.

FONTANESI, L. B.; FAZAN, F. S.; DIAS, F. J.; SCHIAVONI, M. C. L.; JUNIOR, W. M.; FAZAN, V. P. S. Sensory and motor conduction velocity in spontaneously hypertensive rats: sex and aging investigation. Frontiers in Systems Neuroscience, v. 13, n. 62, p. 1-10, 2019.

FRANCE, C. R. Decreased pain perception and risk for hypertension: considering a common physiological mechanism. Psychophysiology, v. 36, n. 6, p. 683-692,1999.

FROHLICH, E. D. The adrenergic nervous system and hypertension: State of the art. Mayo Clinic Proceedings, v. 52, p. 361-3688, 1977.

GADDUM, J. H.; SCHILD, H. O. Depressor substance in extracts of intestine. The Journal of Physiology, v. 83, n. 1, p. 1-14, 1934. 
GAMSE, R.; LEMBECK, F.; CUELLO, A. C. Substance P in the vagus nerve. NaunynSchmiedeberg's Archives of Pharmacology, v. 306, p. 37-44, 1979.

GANEL, A.; ENGEL, J.; LUBOSHITZ: Choline acetyltransferase nerve identification methods in early and late nerve repair. Annals of Plastic Surgery, v. 6, p. 228- 230, 1981.

GARCÍA-CHÁVEZ, E.; SEGURA, B.; MERCHANT, H.; JIMÉNEZ, I.; DEL RAZO, L. M. Functional and morphological effects of repeated sodium arsenite exposure on rat peripheral sensory nerves. Journal of the Neurological Sciences, v. 258, p. 104110, 2007.

GHIONE, S. Hypertension-associated hypalgesia. Evidence in experimental animals and humans, pathophysiological mechanisms, and potential clinical consequences. Hypertension, v. 28, n. 3. p. 494-504, 1996.

GIANNINI, C.; DICKY, P. J. Ultrastructural morphometric abnormahties of surd nerve endoneurial microvessels in diabetes mellitus. Annals of Neurology, v. 36, p. 408415, 1994.

GIORGETTO, C.; SIMÕES, A. L. B.; FAZAN, V. P. S. Identification of the Neurotransmitter Substance P in Sural Nerve of Rats: An Immunohistochemistry Approach. The Faseb Journal_supplement, v. 31, n. 1, p. 748.7-748.7, 2017. 
GIORGETTO, C.; SIMÕES, A. L. B.; ZANON, R. G.; FAZAN, V. P. S. Immunohistochemestry for nerve morphometry? The Faseb Journal_supplement, v. 32, n. 1, p. 781.9- 781.9, 2018.

GIORGETTO, C. Imunomarcação de fibras nervosas como ferramenta de análise alternativa à inclusão em resina e a microscopia eletrônica de transmissão. 2018. 21f. Monografia (Especialização) - Universidade Federal de Uberlândia, Uberlândia. 2018.

GOIT, R. K.; ANSARI, A. H. Reduced parasympathetic tone in newly diagnosed essential hypertension. Indian Heart Journal, v. 68, n. 2, p. 153-157, 2016.

GOLDBLATT, H.; LYNCH, J.; HANZAL, R. F. E.; SUMMERVILLE, W. W. Studies on experimental hypertension. I The production of persistent elevation of systolic blood pressure by means of renal ischemia. The Journal of Experimental Medicine, v. 59, p. 347-349, 1934.

GREENE, E. C. Anatomy of the rat. 1. ed. New York: Hafner Publishing Company, 1963.

GREGORY, J. A.; JOLIVALT, C. G.; GOOR, J.; MIZISIN, A. P.; CALCUTT, N. A. Hypertension-induced peripheral neuropathy and the combined effects of hypertension and diabetes on nerve structure and function in rats. Acta Neuropathologica, v. 124, p. 561-573, 2012. 
GROLLMAN, A. A simplified procedure for inducing chronic renal hypertension in mammal. Proceedings of the Society for Experimental Biology and Medicine, v. 57, n. 1, p. 102-104, 1944.

GUARD, S.; WATSON, S. P. Tachykinin receptor types: Classification and membrane signaling mechanisms. Neurochemistry International, v. 18, n. 2, p. 149-165, 1991.

GUASTI, L.; GAUDIO, G.; ZANOTTA, D.; GRIMOLDI, P.; PETROZZINO, M. R.; TANZI, F.; BERTOLIN, A.; DANDI, A-M.; VENCO, A. Relationship between a genetic predisposition to hypertension, blood pressure levels and pain sensitivity. Pain, v. 82, n. 3, p- 311- 317, 1999.

HAGEN, K.; STOVNER, L. J.; VATTEN, L.; HOLMEN, J.; ZWART, J. A.; BOVIM, G. Blood pressure and risk of headache: a prospective study of 22685 adults in Norway. Journal of Neurology, Neurosurgery and Psychiatry, v. 72, n. 4, p. 463-466, 2002.

HALLBACK, M.; ISAKSSON, O.; NORESSON, E. Consequences of myocardial structural adaptation on left ventricular compliance and the Frank Starling relationship in spontaneously hypertensive rats. Acta Physiologica Scandinavica, v. 94, p. 259$270,1975$.

HARRISON, S.; GEPPETTI, P. Substance P. The International Journal of Biochemistry \& Cell Biology, v. 33, n. 6, p. 555-576, 2001. 
HE, F. J.; MacGREGOR, G.A. Reducing population salt intake worldwide: from evidence to implementation. Progress in Cardiobascular Diseases, v. 52, n. 5, p. 363-382, 2010.

HOITSMA, E.; REULEN, J. P.; DE BAETS, M.; DRENTE, M.; SPAANS, F.; FABER, C. G. Small fiber neuropathy: a common and important clinical disorder. Journal of the Neurological Sciences, v. 227, n. 1, p. 119-130, 2004.

HÖKFELT, T.; PERNOW, B.; WAHREN, J. Substance P: a pioneer amongst neuropeptides. Journal of Internal Medicine, v. 249, p. 26-40, 2001.

INSTITUTO BRASILEIRO DE GEOGRAFIA E ESTATÍSTICA- IBGE. Pesquisa Nacional de Saúde 2013. Percepção do estado de saúde, estilos de vida e doenças crônicas: Brasil, grandes regiões e unidades da Federação. In: Diagnóstico médico de hipertensão arterial. Rio de Janeiro, 2013. Disponível em: <https://biblioteca.ibge.gov.br/visualizacao/livros/liv91110.pdf >. Acesso em: 25 nov. 2019.

JARARI, N.; RAO, N,. PEELA, J. R.; ELLAFI, K. A.; SHAKILA, S.; SAID, A. R.; NELAPALLI, N. K.; MIN, Y.; TUN, K. D.; JAMALLULAIL, S. I.; RAWAL, A. K.; RAMANUJAM, R.; YEDLA, R. N.; KANDREGULA, D. K.; ARGI, A.; PEELA, L. T. A review on prescribing patterns of antihypertensive drugs. Clinical Hypertension, v. 22, n. 7, p. 1-8, 2016. 
JERONIMO, A.; JERÔNIMO, C. A. D.; RODRIGUES FILHO, O. A.; SANADA, L. S.; FAZAN, V. P. S. Microscopy anatomy of the sural nerve in the postnatal developing rat a longitudinal and lateral symmetry study. Journal of Anatatomy, v. 206, p. 9399, 2005.

JERONIMO, A. Avaliação morfológica e morfométrica do nervo sural de ratas wistar em diferentes fases do envelhecimento: estudo em nível de microscopia de luz. 2007. 174f. Tese (Doutorado) - Universidade Federal do Triângulo Mineiro, Uberaba. 2007.

JERONIMO, A.; JERÔNIMO, C. A. D.; RODRIGUES FILHO, O. A.; SANADA, L. S.; FAZAN, V. P. S. A morphometric study on the longitudinal and lateral symmetry of the sural nerve in mature and aging female rats. Brain Research, v. 1222, p. 51-60, 2008.

JIANG, N.; LI, H.; SUN, Y.; YIN, D.; ZHAO, Q.; CUI, S.; YAO, D. Differential gene expression in proximal and distal nerve segments of rats with sciatic nerve injury during Wallerian degeneration. Neural Regeneration Research, v. 9, n. 12, p. 1186-1994, 2014.

KIMURA, L. K.; RODRIGUES, C. J.; RODRIGUES-JÚNIOR, A. J.; MATTAR-JÚNIOR, R.; PAULA, E. J. L.; OKANE, S. Y.; DE REZENDE, M. R.; JORGE, R. Mapeamento fascicular de nervos periféricos por método histoquímico da acetilcolinesterase. Revista Brasileira de Ortopedia, v. 31, n. 3, 1996. 
KING, R.; GINSBERG, L. The nerve biopsy: indications, technical aspects, and contribution In: AMONOFF, M. J.; BOLLER, F.; SWAAB, D. F. Handbook of clinical neurology. London: Elsevier, 2013. p 155-170.

KIVIMÄKI, A. S.; EHLERS, P. I.; SILTARI, A.; TURPEINEN, A. M.; VAPATAALO, H.; KORPELA, R. Lingonberry, cranberry and blackcurrant juices affect mRNA expressions of inflammatory and atherothrombotic markers of SHR in a long-term treatmen. Journal of Functional Foods, v. 4, n. 2, p. 496-503, 2012.

KOENIG, H. L.; GONG, W. H.; PELISSIER, P. Role of progesterone in peripheral nerve repair. Reviews of Reproduction, v. 5, p. 189-199, 2000.

KRAUSE, J. E.; CHIRGWIN, J. M.; CARTER, M. S. XU, Z. S.; HERSHEY, A. D. Three rat preprotachykinin mRNAs encode the neuropeptides substance $\mathrm{P}$ and neurokinin $\mathrm{A}$. Proceedings of the National Academy of Sciences of the United States of America, v. 84, n. 3, p. 881-885, 1987.

LAIS, L. T.; SHAFFER, R. A.; BRODY, M. J. Neurogenic and humoral factors controlling vascular resistance in the spontaneously hypertensive rat. Circulation Research, v. 335, p. 764-74, 1974.

LAURENT, D.; POIRIER, K.; WASVARY, J.; RUDIN, M. Effect of essential hypertension on kidney function as measured in rat by dynamic MRI. Magnetic Ressonance in Medicine, v. 47, n. 1, p. 127-134, 2001. 
LAURIA, G.; CAZZATO, D.; PORRETTA-SERAPIGLIA, C.; CASANOVA-MOLLA, J.; TAIANA, M.; PENZA, P.; LOMBARDI, R.; FABER, C. G.; MARKIES, I. S. J. Morphometry of dermal nerve fibers in human skin. Neurology, v. 77, n. 3, p. 242-249, 2011.

LAWAND, M. J. Comportamento da pressão arterial nos ratos SHR e WistarKyoto expostos ao penumoperitônio prolongado: estudo experimental com uso de dióxido de carbono para insuflação. 2008. 155f. Tese (Doutorado) Universidade de São Paulo, São Paulo. 2008.

LEE, R. M. K. W.; DICKHOUT, J. G.; SANDOW, S. L. Vascular structural and functional changes: their association with causality in hypertension: models, remodeling and relevance. Hypertension Research, v. 40, p. 311-323, 2017.

LERMAN, L. O.; CHADE, A. R.; SICA, V.; NAPOLI, C. Animals models of hyperntension: an overview. Journal of Laboratory and Clinical Medicine, v. 146, n. 3, p. 160-173, 2005.

LIM. T.K.Y.; SHI. X, Q.; JOHNSON, J. M.; RONE, M. B.; ANTEL, J. P.; DAVID, S.; ZHANG, J. Peripheral nerve injury induces persistent vascular dysfunction and endoneurial hypoxia, contributing to the genesis of neuropathic pain. Journal of Neuroscience, v.35, n. 8, p. 3346-3359, 2015. 
LIMA, N. T. M. S.; FAZAN, V. P. S.; COLAFÊMINA, J. F.; BARREIRA, A. A. Recurrente laryngeal nerve post-natal development in rats. Journal of Neuroscience Methods, v. 165, n. 1 , p. $18-24,2007$

LIN, Y. Y.; CHENG, Y. J.; HU, J. H.; CHU, L. X.; SHYU, W. C.; KAO, C. L.; LIN, T. B.; KUO, C, H.; YANG, A. L.; LEE. S. D. The coexistence of hypertension and ovariectomy additively increases cardiac apoptosis. International Journal of Molecular Science, v. 17, p. 20-36, 2016.

LIU, H.; MANTYH, P. W.; BASBAUM, A.I. NMDA-receptor regulation of substance P release from primary afferent nociceptors. Nature., v. 386, p. 721-724, 1997.

LIU, M.; KELLEY, M. H.; HERSON, P. S.; HURN, P. D. Neuroprotection of sex steroids. Minerva Endocrinologica, v. 35, n. 2, p. 127-143, 2010.

LLEWELLYN-SMITH, I. J.; FURNESS, J. B.; COSTA, M. Ultrastructural analysis of substance $\mathrm{p}$-immunoreactive nerve fibers in myenteric ganglia of guinea pig small intestine. Journal of Neuroscience, v. 9, p. 174-187, 1989.

LOCATELLI, J.; PAIVA, N. C. N.; CARVALHO, S. H. R.; LAVORATOM V. N.; GOMES, L. H. .L .S. CASTRO, Q. J. T.; GUIMARÃES-GRABE, A.; CARNEIRO, C. M.; NATALIN A. J.; ISOLDI, M. C. Swim training attenuates the adverse remodeling of LV structural and mechanical properties in the early compensated phase of hypertension. Life Sciences, v. 187, p. 42-49, 2017. 
LOUIS, W. J.; TABEI, R.; SPECTOR, S. Effects of sodium intake on inherited hypertension in the rat. Lancet, v. 2, p. 1283-1296, 1971.

MAAN, A. A.; EALES, J.; AKBAROV, A.; RPWLAND, J.; XU, X.; JOBLING, M. A.; CHARCHAR, F. J.; TOMASZEWSKI, M. The Y chromosome: a blueprint for men's health? European Journal of Human Genetics, v. 25, p. 1182-1188, 2017.

MAENO, H.; KIYAMA, H.; TOHYAMA, M. Distribution of the substance $\mathrm{P}$ receptor (NK-1 receptor) in the central nervous system. Brain Research. Molecular Brain Research, v. 18, n. 1-2, p. 43-58, 1993.

MAGGI, C. A. The mammalian tachykinin receptors. General Pharmacological, v. 26, n. 5, p. 911-944, 1995.

MAJEED, S. K. Survey on spontaneous peripheral neuropathy in aging rats. Arzneimittel Forschung - Drug Research, v. 42, p. 986-90, 1992.

MARIC-BILKAN, C.; GILBERT, E. L.; RYAN, M. J. Impact of ovarian function on cardiovascular health in women: focus on hypertension. International Journal of Women's Health, v. 6, p. 131-139, 2014.

MARIS, M. E.; MELCHERT, R. B.; JOSEPH, J.; KENNEDY, R. H. Gender differences in blood pressure and heart rate in spontaneously hypertensive and wistar-kyoto rats. Clinical and Experimental Pharmacology and Physiology, v. 32, p. 35-39, 2005. 
MARTINS, S. R.; SIQUEIRA, G. M.; TEDESCO-MARCHESE, A. J. Neuroma sintomático do nervo sural uma complicação rara após a retirada do nervo: relato de caso. Arquivos de Neuro-Psiquiatria, v. 60, n. 3, p. 866-868, 2002.

MIWA, I.; KANBARA, M.; WAKAZONO, H.; OKUDA, J. Analysis of sorbitol, galactitol, and myo-inositol in lens and sciatic nerve by high-performance liquid chromatography. Analytical Bioschemistry, v. 15, n. 173, p. 39-44, 1988.

MORIYAMAA, H.; HAYASHIB. S.; INOUEA, Y.; ITOHB, M.; OTSUKA, N. Sex differences in morphometric aspects of the peripheral nerves and related diseases. NeuroRehabilitation, v. 39, p. 413-422, 2016.

MULLINS, M. M.; BANKS, R. O. Age-related changes in $\mathrm{Na}+$ excretion in saline-loaded spontaneously hypertensive rats. American Journal of Physiology, v. 231:13641370, 1976.

MUÑOZ, M.; ROSSO, M.; AGUILAR, F. J.; GONZÁLEZ-MOLES, M.A.; ESTEBAN, F. NK-1 receptor antagonists induce apoptosis and counteract substance P-related mitogenesis in human laryngeal cancer cell line Hep-2. Invest New Drugs, v. 26, p. 111-118, 2008.

NABIKA, T. From animal models to humans. Clincal and Experimental Pharmacology and Physiology, v. 26, p. 541- 543, 1999. 
NAKANISHI, T.; NORRIS, F. H. JR. Motor fibers in rat sural nerve. Experimental Neurology., v. 26 (2), p. $433-435,1970$.

NASCIMENTO-NETO, R. M.; PEREIRA, A. C.; COELHO, G. L.; KRIEGER, J. E. Atlas corações do Brasil. Rio de Janeiro, 2006. p. 44. Disponível em: <https://www.prefeitura.sp.gov.br/cidade/secretarias/upload/saude/arquivos/program as/Atlas_CoracoesBrasil.pdf>. Acesso em: 19 nov. 2019.

NELSON, D. K.; COULSON, R. L.; MEYERS, J. H.; BROWNING, R. A. Neuroanatomical differentiation in the brain of the spontaneously hypertensive rat (shr). i. volumetric comparisons with wky control. Clinical and Experimental Hypertension, v. 15, n. 5, p. 867-894, 2009.

NELSON, J.; ADNAN, S.; AJAMI, N.; PETROSINO, J.; BRYAN, R.; DURGAN, D. Alterations in the gut microbiota can elicit hypertension in rats. The Faseb Journal_ supplement, v. 31, n. 1, p. 1012,13-1012.13, 2017.

NERI, L. O.; DE AMORIM, M. M.; CAMPOS, S. A. R.; SANADA, L. S.; FAZAN, V. P. S. Hind limb sensory innervation in rats: comparison between sural and saphenous nerve morphometry. International Journal of Morphology, v. 33, n. 2, p. 743-750, 2015.

NETTER, F. H. Netter atlas de anatomia humana. 7. ed. São Paulo: Elsevier, 2018. 
KING, R.; GINSBERG, L. Handbook of Clinical Neurology. 3. ed. Londres: Elsevier, 2013.

NIIGAKI, S. T.; PERES, F. F.; FERREIRA, L.; LIBANIO, T.; GOUVEA, D. A.; LEVIN, R.; ALMEIDA, V.; SILVA, N. D.; DIANA, M. C.; SUIAMA, M. A.; CALZAVARA, M. B.; ABILIO, V. C. Young spontaneously hypertensive rats (SHRs) display prodromal schizophrenia-like behavioral abnormalities. Progress in NeuroPsychopharmacology and Byological Psychiatry, v. 90, p. 169-176, 2019.

NUKADA, H.; BABA, M.; OGASAWARA, S.; McMORRAN, D.; YAGILHASHI, S. Neuropathy in the spontaneously hypertensive rat: An electrophysiological histological study. Muscle \& Nerve, v. 54, n. 4, p. 756-762, 2016.

O’BRIEN, P. D.; HUR, J.; ROBELL, N. J.; HAYES, J. M.; SAKOWSKI, S. A.; FELDMAN, E. L. Gender-especific differences in diabetic neuropathy in BTBR ob/ob mice. Journal of Diabetics and its Complications, v. 30, n. 1, p. 30-37, 2016.

OKAMOTO, K.; AOKY, K. Development of a strain os spontaneously hypertensive rats. Japanese Circulation Journal, v. 27, p. 282-293, 1963.

PAGE, I. H. The production of persistent arterial hypertension by cellophane perinephritis. JAMA, v. 113, n. 23, p.2046- 2048,1939.

PAGE, N. M.; BELL, N. J.; GARDINER, S. M.; MANYONDA, I. T.; BRAYLEY, K. J.; STRANGE, P. G.; LOWRY, P. J. Characterization of the endokinins: human 
tachykinins withcardiovascular activity. Proceedings of the National Academy of Sciences of the United States of America, v. 100, n. 10, p. 6245-6250, 2003.

PARRY, G. J.; BROWN, M. J. Selective fiber vulnerabdity in acute ischemic neuropathy. Annals of Neurology, v. 11, p. 147-154, 1982.

PEREIRA, J. R. et al. Análise das demanda judiciais para o fornecimento de medicamentos pela Secretaria de Estado da Saúde de Santa Catarina nos anos de 2003 e 2004. Ciência e Saúde Coletiva, v. 15, p. 3551-3560, 2010.

PENNEFATHER, J. N.; LECCI, A.; CANDENAS, M. L.; PATAK.; E.; PINTO, F. M.; MAGGI, C. A. Tachykinins and tachykinin receptors: a growing family. Life Sciences, v. 74, n. 12, p. 1445-1463, 2004.

PICON, R. V.; FUCHS, F. D.; MOREIRA, L. B.; FUCHS, S. C.Prevalence of hypertentions among elderly persons in urban Brazil: a systematic review with metaanalysis. American Journal of Hypertentions, v. 26, n. 4, p. 541-548, 2013.

PONS-VÁZQUEZ, S.; GALLEGO-PINARO, R.; GALBIS-ESTRADA, C.; ZANONMORANO, V.; GARCIA-MEDINA, J. J.; VILA-BOU, V.; SANZ-SOLANA, P.; PINAZODURÁN, M. D. Combined pre- and posnatal ethanol exposure in rats disturbs the myelination of optic axons. Alcohol and Alcoholism, v. 46, n. 5, p. 514-522, 2011. 
POTTS, J. T.; MCKEOWN, K. P.; SHOUKAS, A. A. Reduction in arterial compliance alters carotid baroreflex control of cardiac output in a model of hypertension. American Journal of Physiology, v. 43, p. H1121-H1131, 1998.

POVLSEN, B.; HILDEBRAND, C.; WIESENFELD-HALLIN, Z.; STANCOVIC, N. Functional projection of regenerated rat sural nerve axons to the hind paw skin after sciatic nerve lesion. Experimental Neurology., v. 119 (1), p. 99 - 106, 1993.

PUIGDELLÍVOL-SNACHEZ, A.; FORCADA-CALVET, P.; PRATS-GALINO, A.; MOLANDER, C. Contribuition of femoral and proximal sciatic nerve branches to the sensory innervation of hindlimb digits in the rat. The Anatomical Records., v. 260, p. $180-188,2000$.

QUARTARA, L.; MAGGI, C. A. The tachykinin NK1 receptor. Part II: distribution and pathophysiological roles. Neuropeptides, v. 32, n. 1, p. 1-49, 1998.

RAMOS-VARA, J. A. Technical aspects of immunohistochemistry. Veterinary Patholology, v. 42, n. 4, p. 405-426, 2005.

REGOLI, D.; BOUDON, A.; FAUCHÉRE, J. L. Receptors and antagonists for substance $\mathrm{P}$ and related peptides. Pharmacological Reviews, v. 46, n. 4, p. 551599, 1994. 
REN, J. Influence of gender on oxidative stress, lipid peroxidation, protein damage and apoptosis in hearts and brains from spontaneously hypertensive rats. Clinical and Experimental Pharmacology and Physiology, v. 34, p. 432-438, 2007.

RIBEIRO, M. O.; ANTUNES, E.; DE-NUCCI, G.; LOVISOLO, S. M.; ZATZ, R. Chronic inhibition of nitric oxide synthesis: a new model of arterial hypertension. Hypertension, v. 20 , p. $298-303,1992$.

RIMOLDI, S. F.; SCHERRER, U.; MESSERLI, F. H. Secondary arterial hypertension: when, who, and how to screen? European Heart Journal, v. 35, p.1245-1254, 2014.

ROBERTSON, K. R.; KAPOOR, C.; ROBERTSON, W. T.; FISCUS, S.; FORD, S.; HALL, C. D. No gender differences in the progression of nervous system disease in HIV infection. Journal of Acquired Immune Deficiency Syndromes, v. 36, n. 3, p. 817-822, 2004

RODRIGUES, A. R.; FERREIRA, R. S.; SALGADO, H. C.; FAZAN, V. P. S. Morphometric analysis of the phrenic nerve in male and female Wistar-Kyoto and spontaneously hypertensive rats (SHR). Brazilian Journal of Medical and Biological Research, v. 44, p. 583-591, 2011.

RUSSI, S.; SANSONNO, D.; MONACO, S.; MARIOTTO, S.; FERRARI, S.; PAVONE, F.; LAULETTA, G.; DAMMACCO, F. HCV RNA Genomic sequences and HCV-E2 glycoprotein in sural nerve biopsies from HCV-infected patients with peripheral 
neuropathy. Neuropathology and Applied Neurobiology, v. 44, n. 4, p. 427-438, 2018.

RUSSO, E.; LEO, A.; SCICCHITANO, F.; DONATO, A.; FERLAZZO, E.; GASPARINI, S.; CIANCI, V.; MIGNOGNA, C.; DONATO, G.; CITRARO, R.; AGUGLIA, U.; DE SARRRO, G. Cerebral small vessel disease predisposes to temporal lobe epilepsy in spontaneously hypertensive rats. Brain Research Bulletin, v. 120, p. 245-250, 2017.

SABBATINI, M.; VEGA, J. A.; AMENTA, F. Peripheral nerve vascular changes in spontaneously hypertensive rats. Neuroscience Letters, v. 217, p. 85-88, 1996.

SABBATINI, M.; BELLAGAMBA, G.; VEGA, J. A.; AMENTA, F. Effect of anthypertensive treatment on peripheral nerve vascuatre in spontaneously hypertensive rats. Clinical and Experimental Hypertension, v. 23, p. 157-166, 2001.

SALGADO, H.C.; FAZAN-JR, R.; SALGADO, M.C.O. Vasopressor mechanisms in acute aortic coarctation hypertension. Brazilian Journal of Medical and Biological Research, v. 30, p. 447-452, 1997.

SANADA, L. S.; TAVARES, M. R.; NEUBERN, M. C. M.; SALGADO, H. C.; FAZAN, V.P. S. Can Wistar rats be used as the normotensive controls for nerve morphometry investigations in spontaneously hypertensive rats (SHR)? Acta Cirúrgica Brasileira, v. 26, n. 6, p. 514-520, 2011. 
SANADA, L. S.; KALIL, A. L. R.; TAVARES, M. R.; NEUBEM, M. C. M.; SALGADO, H. C.; FAZAN, V. P. S. Sural nerve involvement in experimental hypertension morphology and morphometry in male and female normotensive Wistar-Kyoto (WKY) and Spontaneously Hypertensive Rats (SHR). BMC Neuroscience, v. 13, n. 24, p. 2-11, 2012.

SANADA, L. S.; TAVARES, R. M.; SATO, L. K.; FERREIRA, S, R.; NEUBERN, M. C. M.; CASTANIA, A. J.; SALGADO, C. H.; FAZAN, V.P.S. Association of chronic diabetes and hypertension in sural nerve morphometry: an experimental study. $\boldsymbol{B M C}$ Diabetology and Metabolic Syndrome, v. 7, n. 9, p. 1-9, 2015.

SCALA, L.C.; MAGALHÃES, L. B.; MACHADO, A. Epidemiologia da hipertensão arterial sistêmica. In: Livro texto da Sociedade Brasileira de Cardiologia. 2a . ed. São Paulo: Manole, p. 780- 785, 2015.

SCHIAVONNI, M. C. L.; FAZAN, V. P. S. There is no relation between the fascicular and the endoneural blood vessel areas on the cervical vagus nerve of normotensive rats. Journal of Neuroscience Methods, v. 158, p. 171-178, 2006.

SCHMALBRUCH, H. Fiber composition of the rat sciatic nerve. The Anatomical Record., v. 215, p. $71-81,1986$.

SCRIDON, A.; PUERTAS, R. D.; MANATI, W.; FOUILLOUX-MEUGNIER, E.; LOIZON, E.; ORÉA, B.; CHAPUIS, B.; JULIEN, C.; BARRÈS, C.; TABIB, A.; CHEVALIERA, P. Age-dependent ventricular arrhythmias risk, structural and molecular remodeling in 
systemic arterial hypertension. Mechanisms of Age and Development, v. 166, p. 48$54,2017$.

SEGURA, B.; MELO, A. I.; FlEMING, A. S.; MENDOZA-GARRIDO, M. A.; DEL PLIEGO, M. G.; AGUIRRE-BENITEZ, E. L.; ANDEZ-FALCON, J. H.; JIMENEZESTRADA, I. Early social isolation provokes electrophysiological and structural changes in cutaneous sensory nerves of adult male rats. Developmental Neurobiology, v. 74, n. 12, p. 1184-1193, 2014.

SELYE, H.; STONE, H. Pathogenesis of the cardiovascular and renal changes which usually accompany malignant hypertension. The Journal of Urology, v. 56, p. 399419, 1946.

SHENGFENG, L.; XIN, C.; OHARA, H.; NAKAMURA, Y.; IZUMI-NAKASEKO, H.; ANDOM K.; WANXIN, L.; SUGIYAMA, A.; BINGMEI, Z. Common parameters of acupuncture for the treatment of hypertension used in animal models. Journal of traditional Chinese Medicine, v. 35, n. 3, p. 343-348, 2015.

SIDDIQUI, A. N.; SIDDIQUI, N.; KHAN, R. A.; KALAM, A.; JABIR, N. R.; MOHAMMAD, A. K.; FIROZ, C. K.; TABREZ, S. Neuroprotective role of steroidal sex hormones: An overview. CNS Neuroscience \& Therapeutics, v. 22, p. 342-350, 2016

SIMÕES, A. L. B.; SILVA, G. A. R.; GIORGETTO, C.; DO CARMO-CAMPOS, E. C.; DIAS, F. J.; FAZAN, V. P. S. Substance P in dorsal root ganglionneurons in young and 
adult rats, afternociceptive stimulation during the neonatal period. The Anatomical Record, v. 301, n. 5, p. 849-861, 2018.

SINAIKO, A. R.; MIRKIN, B. L. Isoproterenol-evoked renin release from the in situ perfused kidney. Dose-response characteristics in spontaneously hypertensive and normotensive Wistar rats. Circulation Research, v. 42, p. 381-385, 1978.

SMIRK, F. H.; HALL, W. H. Inherited hypertension in rats. Nature, v.182, p. 727-728, 1958.

SMITH, S.; ROSSIGNOLM P.; WILLIS, S.; ZANNAD, F.; MENTZ, R.; POCOCK, S.; BISOGNANO, J.; NADIM, Y.; GELLER, Y.; RUBLE, S.; LINDE, C. Neural modulation for hypertension and heart failure. International Journal of Cardiology, v. 214, p. 320-330, 2016.

SOCIEDADE BRASILEIRA DE CARDIOLOGIA. Departamento de hipertensão arterial. VII Diretrizes brasileiras de hipertensão. Arquivos Brasileiros de Cardiologia, v. 107, (supl. 3), p. 1-83, 2016.

SOMMER, C. Nerve and skin biopsy in neuropathies. Current Opinion in Neurology, v. 31, n. 5, p. 534-540, 2018.

STENBERG, L.; DAHLIN, L. B. Gender differences in nerve regeneration after sciatic nerve injury and repair in healthy and in type 2 diabetic Goto-Kakizaki rats. $\mathbf{B C M}$ Neuroscience, v. 15, n. 107, p. 2-10, 2014. 
STENBERG, L. Peripheral Nerve Regeneration after Injury, Repair and Reconstruction in Experimental Diabetes. 2019. 84f. Tese (Doutorado)- Lund University, Lund. 2019.

STEWART, D. C.; RUBIANO, A.; SANTISTEBAN, M. M. SHENOY, V.; QI, Y.; PEPINE, C. J.; RAIZADA, M. K.; SIMMONS, C. S. Hypertension-linked mechanical changes of rat gut. Acta Biomaterialia, v. 45, p.296-302, 2016.

SUN, Z.; ZHANG, Z. Historic perspectives and recent advances in major animal models of hypertension. Acta Pharmacologica Sinica, v. 26, n. 3, p. 295-301, 2005.

SUNDKVIST, G.; DAHLIN, L. B.; NILSSON, H.; ERIKSSON, K. F.; LINDGÄRDE, F.; ROSÉN, I.; LATTIMER, S. A.; SIMA, A. A.; SULLIVAN, K.; GREENE, D. A. Sorbitol and myo-inositol levels and morphology of sural nerve in relation to peripheral nerve function and clinical neuropathy in men with diabetic, impaired, and normal glucose tolerance. Diabetic Medicine, v. 17, n. 4, p. 259-268, 2000.

SWETT, J. E.; WOOLF, C. J. The somatotopic organization of primary afferent terminals in the superficial laminae of the dorsal horn of the rat spinal cord. Journal of Comparative Neurology, v. 231, n. 1, p. $66-77,1985$.

TEUNISSEN, L. L.; FRANSSEN, H.; WOKKE, J. H. J.; VAN DER GRAAF, Y.; LINSSEN, W. H. J. P.; BANGA, J. D., LAMAN, D.M.; NOTERMANS, N. C. Is cardiovascular disease a risk factor in the development of axonal polyneuropathy? Journal of Neurology Neurosurgery and Psychiatry, v. 72, p. 590-595, 2002. 
THOMAS, P. K.; KING, R. H.; SHARMA, A. K. Changes with age in the peripheral nerves of the rat. Acta Neuropathologica, v. 52, p. 1-6, 1980.

THOMAS, C. J.; RANKIN, A. J.; HEAD, G. A.; WOODS, R. L. ANP enhances bradycardic reflexes in normotensive but not spontaneously hypertensive rats. Hypertension, v. 5, p. 1126-1132, 1997.

TOBLLI, J. E.; STELLA, I.; INSERRA, F.; FERDER, L.; ZELLER, F.; MAZZA, O. N. Morphological changes in cavernous tissue in spontaneously hypertensive rats. American Journal of Hypertension, v. 13, n. 6, p. 686-692, 2000.

TOMASSONI, D.; TRAINI, E.; VITAIOLI, L.; AMENTA, F. Morphological and conduction changes in the sciatic nerve of spontaneously hypertensive rats. Neuroscience Letters, v. 362, p. 131-135, 2004.

TORRES, M. F. Análise do potencial citotóxico agudo da bupivacaína e levobupivacaína (s75-r25) incorporadas a microesferas sobre o nervo ciático de ratos. 2010. 68f. Tese (Doutorado) - Universidade Federal do Paraná, Curitiba. 2010.

UGRENOVIĆ, S.; JOVANOVIĆ, I.; VASOVIĆ, L.; KUNDALIC', B.; CUKURANOVIC', R.; STEFANOVIC', V. Morphometric analysis of the diameter and $g$-ratio of the myelinated nerve fibers of the human sciatic nerve during the aging process. Anatomic Science International, v. 91, n. 3, p. 238-245, 2016. 
ULCAY, T.; UZUN, A. Anatomical variations of the formation of human sural nerve in stillborns. Journal of Anatomical Society of India, v. 67, n. 1, p. 50-54, 2018.

ULIN, G.; GUSTAVII, K.; PERSSON, B. A. Bioanalysis of picomole amounts of acetylcholine by ion-pair partition chromatography applied to rat sciatic nerve. Journal of Pharmacy and Pharmacology, v. 28, n. 9, p. 672-675, 1976.

VEJSADA, R.; PALECEK, J.; HNÍK, P. Permanent alterations of spinal cord reflexes following nerve lesion in newborn rats. Physiological Research, v. 48, n. 6, p. 483489, 1999.

VEITCH, N. C. Horseradish peroxidase: a modern view of a classic enzyme. Phytochemistry, v. 65, n. 3, p. 249-259, 2004.

VON EULER, U. S.; GADDUM, J. H. An unidentified depressor substance in certain tissue extracts. The Journal of Physiology, v. 72, n. 1, p. 74-87, 1931

ZIAGO, E. K. M.; FAZAN, V. P. S.; IYOMASA, M. M.; SOUSA, L. G.; YAMAUCHI, P. Y.; DA SILVA, E. A.; BORIE, E.; FUENTES, R.; 3 \& DIAS, F. J. Analysis of the variation in low-level laser energy density on the crushed sciatic nerves of rats: a morphological, quantitative, and morphometric study. Laser in Medical Science, v. 32, n. 2, p. 369$378,2017$. 
ZHAO, D.; QI, Y.; ZHENG, Z.; WANG. Y.; ZHANG, X. Y.; LI, H. J.; LIU, H. H.; ZHANG, X. T.; DU, J.; LIU J. Dietary factors associated with hypertention. Nature Reviews, v. 8, n. 8, p. 456-465, 2011.

WALSH, D.T.; WEG, V. B.; WILLIAMS, T. J.; NOURSHARGH, S. Substance Pinduced inflammatory responses in guinea-pig skin: The effet of specific receptor antagonists and the role of endogenous mediators. British Journal of Pharmacology, v. 114, p. 1343-1350, 1995.

WANG. K.; XU. Y.; YANG. W.; ZHANG. Y. Insufficient hypothalamic angiotensin converting enzyme 2 is associated with hypertension in SHR rats. Oncotarget, v. 8, n. 12, p. 20244-20251, 2017.

WEBER, M. A.; SCHIFFRIN, E. L.; MANN, S.; LINDHOLM, L. H.; KENERSON, J. G.; FALCK, J. M.; CARTER, B. L.; MATERSON, B. J.; RAM, C. V.; COHEN, D. L.; CADET, J. C.; JEAN-CHARLES, R. R.; TALER, S.; KOUNTZ, D.; TOWNSEND, R. R.; CHALMERS, J.; RAMIREZ, A. J.; BAKRIS, G. L.; WANG, J, SCHUTTE, A. E.; BISOGNANO, J. D.; TOUYZ, R. M.; SICA, D.; HARRAP, S. B. Clinical practice guidelines for the management of hypertension in the community: a statement by the American Society of Hypertension and the International Society of Hypertension. Journal of Clinical Hypertention, v. 16, n. 1, p. 14-26, 2013.

WEYER, G. W.; DUNLAP, B.; SHAH, S. D. Hypertension in women: Evaluation and management. Obstetrics and Gynecology Clinics of North America, v. 43, n. 2, p. 287-306, 2016. 
WIDIMSKÝ, J. The role of arterial hypertension in the primary prevention of stroke. Cor et Vasa, v. 58, n. 2, p. e279-e286, 2015.

WILSON, C.; BYRON, F. B. The vicious circle in chronic Bright's disease: experimental evidence from the hypertensive rat. Quarterly Journal of Medicine, v. 10, n. 2, p. 6593, 1941.

WORLD HEALTH ORGANIZATION. A global brief on hypertension. In: .Hypertension: the basic facts. Suiça, 2013. p.17. Disponível em: <http://apps.who.int/iris/bitstream/10665/79059/1/WHO_DCO_WHD_2013.2_eng.pdf ?ua=1>. Acesso em: 19 nov. 2019.

YAMAGUCHI,T.; SASASE, T.; MERA, Y.; TOMIMOTO, D.; TADAKI, H.; KEMMOCHI, Y.; OHTA, T.; SATO, E.; MATSUSHITA, M. Diabetic peripheral neuropathy in spontaneously diabetic torii-leprfa (SDT Fatty) rats. Journal of Veterinary Meducal Science, v. 74, n. 12, p. 1669-1673, 2012.

YAMORI, Y.; MATSUMOTO, M.; YAMABE, H.; OKAMOTO, K. Augmentation of spontaneou hypertension by chronic stress in rats. Japanese Circulation Journal, v. 33, p. 399-409, 1969. 


\subsection{COMISSÃO DE ÉTICA NO USO DE ANIMAIS}

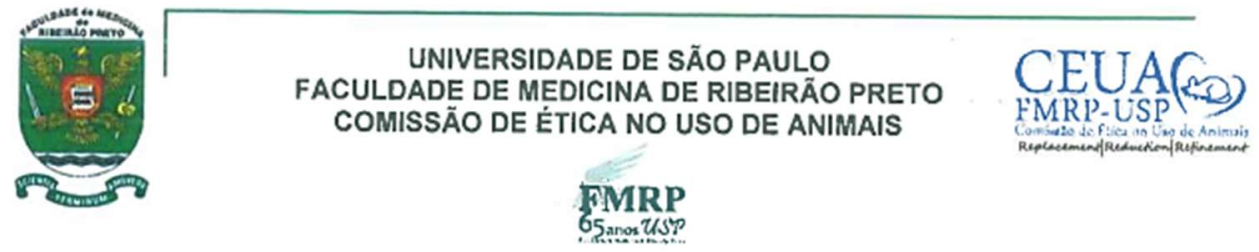

\section{CER TIFICADO}

Certificamos que o Protocolo intitulado "Quantificação de fibras positivas para Substância $P$ em nervo sural de ratos espontaneamente hipertenso", registrado com o número 153/2017, sob a responsabilidade da Profa. Dra. Valeria Paula Sassoli Fazan, envolvendo a produção, manutenção ou utilização de animais pertencentes ao filo Chordata, subfilo Vertebrata (exceto humanos) para fins de pesquisa científica, encontra-se de acordo com os preceitos da Lei $n^{\circ} 11.794$ de 8 de outubro de 2008 , do Decreto $n^{\circ} 6.899$ de 15 de julho de 2009 e com as normas editadas pelo Conselho Nacional de Controle de Experimentação Animal (CONCEA), e foi APROVADO pela Comissão de Ética no Uso de Animais da Faculdade de Medicina de Ribeirão Preto da Universidade de São Paulo em reunião de 25 de setembro de 2017.

Este Protocolo prevê a utilização de 12 ratos WKY machos, pesando $240 \mathrm{~g}, 12$ ratos WKY fềmeas pesando $240 \mathrm{~g} ; 12$ ratos SHR machos pesando $240 \mathrm{~g}$ e 12 ratos SHR fêmeas pesando $240 \mathrm{~g}$ oriundos do Biotério do Laboratório de Neurologia Aplicada e Experimental. Vigência da autorização: 25/09/2017 a 02/03/2020.

We certify that the Protocol $n^{\circ} 153 / 2017$, entitled "Substance $P$ quantification in the sural nerves of hypertensive rats", is in accordance with the Ethical Principles in Animal Research adopted by the National Council for the Control of Animal Experimentation (CONCEA) and was approved by the Local Animal Ethical Committee from Ribeirão Preto Medical School of the University of São Paulo in 09/25/2017. This protocol involves the production, maintenance or use of animals from phylum Chordata, subphylum Vertebrata (except humans) for research purposes, and includes the use of 12 male WKY rats weighing $240 \mathrm{~g} ; 12$ female WKY rats weighing $240 \mathrm{~g} ; 12$ male SHR rats weighing $240 \mathrm{~g}$ and 12 female SHR rats weighing $240 \mathrm{~g}$ from Animal House of the Laboratory of Applied and Experimental Neurology of Ribcirao Preto Medical School, University of São Paulo. This certificate is valid until 03/02/2020.

Ribeirão Preto, 25 de setembro de 2017

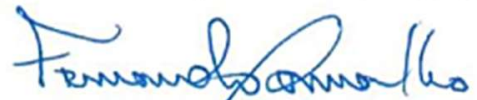

Prof. Dr. Fernando Silva Ramalho

Presidente da CEUA-FMRP - USP 


\subsection{ARTIGO SUBMETIDO PARA PERIÓDICO}

The Anatomical Record

The Anatomical Record

WILEY

Nerve fiber immunostaining as an alternative analysis tool for embedding in resin and transmission electron microscopy

\begin{tabular}{|c|c|}
\hline Journal: & Anatomical Record \\
\hline Manuscript ID & AR-19-0384 \\
\hline Wiley - Manuscript type: & Full Length Article \\
\hline $\begin{array}{l}\text { Date Submitted by the } \\
\text { Author: }\end{array}$ & 22-Dec-2019 \\
\hline Complete List of Authors: & $\begin{array}{l}\text { Giorgetto, Carolina; Universidade de Sao Paulo Faculdade de Medicina de } \\
\text { Ribeirao Preto } \\
\text { Simoes, Ana Leda; Universidade de Sao Paulo Faculdade de Medicina de } \\
\text { Ribeirao Preto, } \\
\text { Zanon, Renata; Federal University of Uberlandia (UFU), Department of } \\
\text { Morphology } \\
\text { Fazan, Valéria Paula; School of Medicine of Ribeirão Preto, Department } \\
\text { of Surgery and Anatomy }\end{array}$ \\
\hline Keywords: & $\begin{array}{l}\text { nerve, immunohistochemistry, immunofluorescence, embedding in epoxy } \\
\text { resin, substance-p }\end{array}$ \\
\hline
\end{tabular}

SCHOLARONE

Manuscripts 


\title{
8.3. TRABALHOS PUBLICADOS EM ANAIS DE CONGRESSOS
}

\section{Identification of the Neurotransmitter Substance P in Sural Nerve of Rats: An Immunohistochemistry Approach}

Carolina Giorgetto, Ana Leda Bertoncini Simoes, and Valeria Paula Sassoli Fazan

Published Online: 1 Apr 2017 Abstract Number: 748.7

A About

\begin{abstract}
The sural nerve in rats is mainly sensory, providing innervation for the lateral side of the hind paws [1]. The substance $P(S P)$ is a neurotensmitter known to be present in small myelinated and unmyelinated fibers, being closely related to pain tranmission to the central nervous system [2]. Thus, the presence of $\mathrm{SP}$ is expected in small fibers of the sural nerves. Nevertheless, morphological demonstration of the presence of SP in sural nerves of rats were not yet performed by immunohistochemestry (IHC). We developed an IHC protocol to identify the SP in sural nerve of male and female Wistar-Kyoto rats. The animals were anesthetized and had the sural and phrenic nerves (positive control) surgically removed, immersed in Karnovsky solution (4\% paraformaldehyde, $2 \%$ glutaraldehyde) and cryoprotected in solutions of sucrose with increasing concentrations. Transversal cryosections $(18 \mu \mathrm{m})$ of the nerves were incubated in rabbit polyclonal antibody anti-substance $P(1: 10.000,24 \mathrm{~h})$, followed by biotinylated antirabbit IgG (1:500; 24h) and finally Extravidin-HRP (1:1500, 24h). A reaction with diaminobenzidine intensified with nickel revealed immunoreactivity by light microscopy, confirming the effectiveness and viability of the IHC technique proposed by our protocol for identification of the SP in sural nerve. These results indicate the possibility of investigating neurotransmitter contents in different fiber pupulations in normal nerves and their correlation with peripheral neuropathies such as diabetes and hypertension.
\end{abstract}

Support or Funding Information

FAPESP, CNPq, CAPES and FAEPA 


\title{
FASEB ounut
}

\begin{abstract}
Peripheral nerve biopsy is an invaluable aid to diagnosis carefully selected patients. The nerves histological evaluation gives clues for investigating diseases mechanisms and causes, as well as guides the therapeutic planning of inflammatory, infectious, demyelinating or degenerative lesions [1]. Nerves histological processing method that provides the best image quality is the epoxy resin embedding. Thus, nerve sections can be observed by light and/or transmission electron microscopy (TEM) and classes of nerve fibers can be morphometrically identified and studied. Epoxy resin embedding and TEM is considered the gold standard method for unmyelinated fibers identification and quantification. More recently, the immunohistochemistry technique $(\mathrm{IHC})$ is being added to the inflammatory neuropathy investigation and the most important of the panel of antibodies employed are those needed to differentiate lymphocytes into T (CD3pve) and B cells (CD20pve). In addition, antibodies against macrophages, myelin basic protein, neurofilaments, and epithelial membrane antigen (EMA) (for perineurial cells) are included [1]. Neurotransmitters and their fiber "carrier" are much less explored. We suggest that it would be possible to use the IHC to identify nerve fiber classes as an alternative to TEM and morphometry, with the gain on functional information. To investigate this hypothesis we used IHQ and immunofluorescence (IF) to immunolabel small myelinated and unmyelinated fibers in sural nerves of rats. The nerves were surgically removed, immersed in paraformaldehyde $4 \%$ for 18 hours, and cryoprotected in increasing concentrations of sucrose solutions, before transversal cryosectioning $(12 \mu \mathrm{m})$. For IHC, sections were incubated in rabbit polyclonal antibody anti-substance $\mathrm{P}(1: 5.000,18 \mathrm{~h})$ followed by anti-rabbit IgG $(1: 500 ; 2 \mathrm{~h})$ and Extravidin-HRP $(1: 1500,2 \mathrm{~h})$. A reaction with diaminobenzidine intensified with nickel revealed immunoreactivity, observed by light microscopy. For IF, sections were incubated in rabbit polyclonal antibody anti-substance $P(1: 1.000,18 \mathrm{~h}$ ) followed by anti-rabbit IgG (Alexa Fluor@ 594) (1:200,2h). The immunoreactivity was observed by fluorescence microscopy. Both protocols worked on transverse sections to identify substance $P$ immunolabeled small myelinated and unmyelinated fibers. Results were compared with transverse sections prepared for TEM and the IHC results showed labeled small myelinated and unmyelinated axons intermingled with large unlabeled myelinated axons, with preservation of their myelin sheath. The IHC transverse sections were comparable to the epoxy resin embedded for small fiber localization in the endoneural space. Further studies on quantification of these fibers will be performed comparing both methods (IHC and IF) with the TEM images in order to show that IHC might also be a reliable method for quantifying axons.
\end{abstract}

\section{Support or Funding Information}

